MAESTRÍA EN DIRECCIÓN DE EMPRESAS

FACULTAD DE CIENCIAS ECONÓMICAS

UNIVERSIDAD NACIONAL DE LA PLATA

Trabajo de tesis para optar al título de Magister

Tema:

\title{
LA CALIDAD PROFESIONAL EN LAS ORGANIZACIONES DE SALUD. UN ESTUDIO SOBRE LOS GRADUADOS EN ENFERMERÍA
}




\section{SOBRE LA MAESTRÍA EN DIRECCIÓN DE EMPRESAS}

La Maestría en Dirección de Empresas de la Facultad de Ciencias Económicas de la Universidad Nacional de La Plata se encuentra acreditada y categorizada por la Comisión Nacional de Evaluación y Acreditación Universitaria (Res. 207/10). A diciembre de 2015 lleva completadas 17 ediciones, con más de quinientos profesionales que ya pasaron por sus aulas. Se trata de un programa de dos años que se completa con la aprobación de dieciséis materias, dos seminarios, un taller de metodología y la realización de una tesis. Su cursada es de modalidad presencial, en actividades que se desarrollan en su sede de calle $3 n^{\circ} 590$ en la ciudad de La Plata, Buenos Aires, Argentina.

\section{SOBRE EL AUTOR}

Fernando Muñoz nació en Adolfo Gonzales Chaves, provincia de Buenos Aires. Es Contador Público Nacional, graduado en la Facultad de Ciencias Económicas de la Universidad Nacional de La Plata. Ha trabajado en diversos estudios profesionales especializándose en consultoría de procesos e impositiva. Tiene antecedentes gestionando organizaciones de salud en la región de La Plata, Berisso y Ensenada. En la actualidad, es socio en PM2 Consultora, firma en la que tiene a cargo las líneas de negocio Herramientas de crédito y Subsidios para el desarrollo de PyMES. Es parte de la $13^{\circ}$ promoción del programa MBA (FCE-UNLP). 


\section{Indice temático}

1.- Planteo del problema 1

2.- Objetivos de la investigación 3

3.- Evaluación del problema 3

4.- Alcance de la investigación 5

5.- Marco teórico de referencia 6

5.1.- Algunos trabajos relevantes como antecedentes de la investigación 6

5.2.- Los fundamentos teóricos en la metodología de investigación $\quad 10$

6.- Metodología de la investigación 21

6.1.- Universo y muestra $\quad 21$

6.2.- Tipo de investigación 23

6.3.- Técnicas de relevamiento de datos 23

6.4.- Técnicas de análisis 25

7.- Resultados de la investigación 31

7.1.- Análisis descriptivo de la muestra 32

7.2.- Atributos del graduado. Sus conocimientos, habilidades y actitudes 32

7.3.- Desempeño en el trabajo por parte del graduado 98

7.4.- Satisfacción de los empleadores sobre el trabajo de los graduados $\quad 100$

$\begin{array}{ll}\text { 8.- Conclusiones } & 101\end{array}$

9.- Bibliografía consultada 106

10 - Referencias y anexos 108 


\section{Planteo del problema}

Las universidades, institutos terciarios y demás instituciones relacionadas con la educación superior suelen disponer de distintas herramientas para, periódicamente, realizar un control sobre la calidad del trabajo que realizan en proveer a la sociedad de profesionales en las distintas ciencias y disciplinas. Ese control provee la información necesaria para justificar la existencia de esas instituciones y evaluar la vigencia de las carreras y los planes de estudio que componen sus ofertas educativas.

No obstante, los esfuerzos para evaluar la calidad educativa se concentran, en general, en la figura del educando y futuro profesional, en la de sus distintos educadores a lo largo de la carrera y en la de los procesos administrativos puestos en práctica por las instituciones para asegurar su producto, los graduados.

La relación de las instituciones educativas con los organismos del Estado que gestionan las políticas de educación (ministerios de Educación, direcciones de Educación Superior o como se denominen en los distintos niveles del sector público) enriquecen el proceso de generación de información sobre calidad educativa, aunque manteniendo el foco en el profesional y en la institución que lo forma, resultando entonces el análisis, cuanto menos, parcial.

Son pocas las veces en que un análisis de calidad profesional de los egresados de las distintas ciencias y disciplinas de la oferta educativa considera la visión de la "demanda" de esa oferta; esto es, la visión de quienes demandan de esos egresados para incorporarlos a un puesto de trabajo en particular. En otras palabras, no es habitual que las instituciones del sistema educativo busquen en el mercado de trabajo información que les sirva para evaluar la calidad de sus procesos educativos, lo que no hace más que desaprovechar la oportunidad de contar con una perspectiva de análisis alternativa, enriquecedora y más completa.

En concreto, las instituciones educativas, como cualquier organización, necesitan conocer el grado de aceptación de sus productos, pudiendo valerse a 
tal efecto de la información que pueden aportarles los reales y eventuales demandantes.

\section{Justificación de la elección del tema de tesis}

Como se dijo precedentemente, existe la necesidad de contar con información sobre la calidad profesional de graduados desde la perspectiva de sus empleadores, y además, ese tipo de información es requerida por la Maestría en Dirección de Empresas para muchos tipos de carreras, en virtud de ser utilizada como insumo para investigaciones que allí se llevan a cabo sobre competitividad económica regional (siendo la calidad de graduados terciarios y universitarios uno de los determinantes de la competitividad económica). Considerando asimismo que existen en la región que se planteó como objeto de estudio (La Plata, Berisso y Ensenada) numerosos establecimientos de salud públicos y privados para el abordaje de la investigación, y tomando en cuenta por otra parte los antecedentes laborales del autor, quien tiene conocimiento de las realidades del mercado laboral de los enfermeros profesionales, es que se eligió como carrera a analizar a la de Enfermería de la Facultad de Ciencias Médicas de la Universidad Nacional de La Plata.

Así elegida la carrera de Enfermería, encuentra justificación como trabajo de tesis el adentrarse en la dilucidación de si los graduados en ella alcanzan los valores de calidad requeridos por quienes son o serán sus empleadores, indagando para ello en la calidad esperada al momento de la contratación y percibida por quien contrata una vez que el profesional se encuentra en su puesto de trabajo.

En función de los objetivos planteados y los resultados obtenidos en la investigación que hace al presente trabajo, se podrá concluir si la calidad esperada por parte de los empleadores coincide o difiere con los niveles de calidad que en efecto perciben de los profesionales de la enfermería desarrollando su trabajo. En espera de llegar a esa instancia, puede estimarse a priori que el trabajo representa un aporte al análisis de calidad de la oferta 
educativa en el sector específico que se ha elegido como objeto de investigación.

Cabe una última mención como parte del planteo del problema, y es la referida a la consideración de quienes emplean y contratan a los profesionales de enfermería, en cuanto que clientes de este específico mercado laboral. La lógica que se plantea es entonces la de considerar a las instituciones educativas como las "productoras" de los profesionales que componen la oferta de trabajo, siendo los empleadores quienes demandan esta oferta. Estos últimos se convierten así en los verdaderos clientes de aquellas instituciones, y, como todo cliente, son los que detentan la mayor legitimidad para juzgar la calidad del "producto" que están contratando.

\section{Objetivos de la investigación}

Se plantean para el presente trabajo los siguientes objetivos:

- Identificar cuáles son, desde la perspectiva del empleador en cuanto cliente de la oferta educativa, los aspectos críticos a considerar en el desempeño profesional de un graduado en enfermería, relacionados con los conocimientos, habilidades y actitudes mostradas en el ejercicio de la profesión.

- Evaluar el nivel de expectativas de los empleadores respecto a cómo cumplen los graduados con tales aspectos críticos, determinando asimismo el grado de satisfacción general de las expectativas en función del desempeño efectivo de los graduados.

- Obtener una medición y un análisis puntual de la calidad profesional de los graduados en Enfermería que se hayan graduado en un momento específico (2007 a 2011), que hayan egresado de una determinada universidad (Facultad de Ciencias Médicas de la UNLP) y que trabajen en 
organizaciones de salud de una zona puntual (La Plata, Berisso y Ensenada).

\section{Evaluación del problema}

El identificar criterios que hacen al desempeño profesional de los graduados en Enfermería, evaluar cuáles son las expectativas respecto de esos criterios por parte de los empleadores y determinar el grado de cumplimiento de ellas, aporta un marco necesario para evaluar la calidad y las competencias de ese tipo de trabajadores. Este aporte es necesario en función de tres cuestiones:

- El tipo de profesional que es objeto de estudio de este trabajo es producto de la oferta académica de una institución educativa pública, lo que exige que siempre existan herramientas para poder medir la calidad de dicha oferta. En términos más generales, siempre deben existir herramientas para medir cuán productiva resulta la inversión, por parte del Estado, de recursos públicos destinados a una oferta académica.

- Los empleadores-clientes identificados en este trabajo son instituciones relacionadas con la salud de la población. La salud de la población es un tema que debe considerarse como de prioritario interés público. En consecuencia, todos los actores interesados en ella deben tener la posibilidad de disponer de elementos para poder medir y analizar la calidad de los profesionales involucrados en el sector.

- La propia institución educativa objeto de estudio, la Facultad de Ciencias Médicas de la Universidad Nacional de la Plata (UNLP), necesita contar con una evaluación de calidad de su oferta educativa desde la perspectiva de quienes demandan dicha oferta, única manera de contar con evaluaciones integrales de su desempeño como educadora. 
El medir calidad debe considerarse como una función ineludible de quienes tienen responsabilidades en el sector de la salud. Esto es así porque la medición de calidad no sólo es una forma de diagnosticar desvíos respecto de lo esperado de determinada competencia profesional, sino que también resulta ser un insumo muy valioso para plantear una mejora continua de los distintos procesos presentes en el sector.

En la actualidad, y en cada vez más disciplinas del ámbito académico y sectores de la economía, se encuentra presente la idea de profesionalización de la mayor cantidad posible de tipos de trabajadores y la de formación continua en las distintas profesiones. Esta necesidad de alcanzar un nivel profesional no puede satisfacerse sin el concurso de otra institución que no sea la universidad. Se insiste, la salud de la población es de tal interés público que toda la sociedad debe poder confiar en las instituciones encargadas de formar a los profesionales que deben atenderla y asegurar que alcance niveles de calidad aceptables. Esa confianza sólo puede darla la universidad, que, pública o privada, se encuentra sometida al cumplimiento de normas y obligaciones fiscalizadas por el propio Estado. En este marco, la medición de la calidad en todo el proceso que hace a la salud pública se convierte entonces en algo de extrema importancia, y pasa a ser un factor imprescindible a considerar.

\section{Alcance de la investigación}

El presente trabajo de tesis sobre calidad de profesionales desde la perspectiva de sus empleadores tiene como objeto de estudio los graduados de la carrera de Enfermería de la Facultad de Ciencias Médicas de la UNLP, sobre quienes se evalúa su calidad profesional tomando en cuenta para ello una muestra representativa de las organizaciones públicas o privadas que habitualmente cuentan en sus recursos humanos con profesionales de la Enfermería. 
Los resultados de la investigación fueron obtenidos en el marco de un trabajo de campo que excede a la carrera de Enfermería, y que comprendió la obtención de datos de fuente primaria para la totalidad de las carreras que componen la oferta educativa de nivel terciario y de grado universitario de la Facultad de Ciencias Médicas de la UNLP.

Dicho trabajo de campo tuvo por objetivo proveer información sobre calidad educativa y de formación de recursos humanos en la región de La Plata, Berisso y Ensenada. Esa información global fue por su parte uno de los insumos de un proyecto de investigación vigente en la Maestría en Dirección de Empresas de la Facultad de Ciencias Económicas (UNLP) sobre Competitividad Económica en dicha región. La porción de resultados correspondiente a los profesionales de la enfermería fue entonces el insumo puntual del presente trabajo de tesis.

\section{Marco teórico de referencia}

\section{1.- Algunos trabajos relevantes como antecedentes de la investigación}

\section{La satisfacción de las partes interesadas con los graduados de ingeniería civil (Curtin University, Australia)}

El primer antecedente a la investigación que debe mencionarse es el trabajo de tesis de Albani Musyafa para la obtención del grado de Doctor en Filosofía por la Curtin University of Technology de Bentley, Australia. Esta tesis doctoral (datada en marzo de 2009 y que lleva por título Stakeholders' Satisfaction with Civil Engeineering Graduates ${ }^{1}$ ) es una investigación sobre las competencias profesionales de ingenieros civiles graduados en algunas universidades de Australia durante un período de tiempo específico. El trabajo

\footnotetext{
${ }^{1}$ Musyafá, Albani (2009). Stakeholders' satisfaction with civil engineering graduates. Curtin University (http://bit.ly/1Q6dR2r)
} 
adopta -como el presente trabajo de tesis- la perspectiva de los actores interesados (stakeholders) en conocer las competencias profesionales de los graduados ingenieros civiles con los que, en condiciones de desempeño laboral, deberán interactuar. La investigación se ubica de ese modo en una posición alternativa a la de la visión tradicional de medir calidad de egresados desde el punto de vista de las instituciones educativas "que los producen". Si bien este antecedente tomado de Australia no es el único que aborda objeto de estudio y perspectiva similar al del presente trabajo, sí es relevante porque de él se toma buena parte de las herramientas de investigación y análisis utilizadas, como ser la encuesta a stakeholders para el relevamiento de datos de fuente primaria y las metodología para procesar, presentar e interpretar los mismos.

Los datos para la investigación en la Curtin University, incluyendo la competencia de los graduados, el desempeño de los egresados, la satisfacción de las partes interesadas, sus percepciones y sus expectativas, se obtuvieron mediante una encuesta elaborada sobre la base de variables e indicadores establecidos. Los encuestados fueron aquellos que monitoreaban a los egresados en los lugares de trabajo. Para la comparación también se recogieron los datos académicos y profesionales tanto de los graduados como de los encuestados.

Una vez obtenidos, los datos fueron analizados utilizando métodos estadísticos en los niveles de la muestra y de la población. Se clasificaron las variables relacionadas con las competencias de los graduados para que sus debilidades y fortalezas pudieran ser entendidas. También se clasificaron las variables relacionadas con las expectativas de las partes interesadas de manera que se identifiquen las competencias que deben ser priorizadas en la educación.

Más adelante en este mismo apartado y en el apartado 6-Metodología de la investigación se verá con detalle la relación con este antecedente a la investigación, junto a todas las cuestiones de metodología y de obtención y análisis de los datos. 
Los estudios de opinión de empleadores. Estrategia para elevar la calidad de la educación superior no universitaria

Otro antecedente que puede mencionarse es el de Simon, Pauda y Arellano Mont, publicado en 2010 en la Revista Iberoamericana sobre Calidad, Eficacia y Educación, y que tiene por título Los estudios de opinión de empleadores. Estrategia para elevar la calidad de la educación superior no universitaria ${ }^{2}$. Este trabajo si bien, como en su título se indica, tiene por objeto de estudio la educación sólo terciaria, resulta interesante por la forma en que toma la perspectiva de los empleadores al momento de evaluar la calidad profesional de determinado tipo de graduados con educación formal. Según los autores, al evaluar calidad de competencias profesionales es ineludible reparar en los perfiles laborales vigentes en el mercado de trabajo de las distintas disciplinas. Sin conocer estos perfiles y la dinámica de cómo evolucionan en el tiempo siempre será incompleta una evaluación que repare solamente en las aptitudes y actitudes con que las instituciones educativas intentar dotar a sus egresados. Lo efectivo resulta entonces mantener el foco en la relación entre ámbitos académico y laboral, ya que de las características de ese vínculo surgen los criterios de efectividad que deben aplicarse a las competencias profesionales de los graduados.

Investigación de mercado del programa Administración en Salud con énfasis Gestión de Servicios de Salud

Un tercer antecedente es el trabajo realizado en el ámbito de la Universidad de Antioquía, Colombia, de Morales, Ramírez y Pérez; publicado en 2004 en la Revista de la Facultad Nacional de Salud Pública, con título Investigación de mercado del programa Administración en Salud con énfasis

\footnotetext{
${ }^{2}$ Simon, Javier Damián; Montes Pauda, Eusebio y Arellano Monto, Lluvia Jazmín (2010). Los estudios de opinión de empleadores. Estrategia para elevar la calidad de la educación superior no universitaria. Revista Iberoamericana sobre Calidad, Eficacia y Cambio en Educación (2010. Volumen 8, Número 3).
} 
Gestión de Servicios de Salud ${ }^{3}$. El trabajo se concentra en un problema de baja inserción laboral de graduados de un programa específico de servicios de salud. Investiga las causas de esta problemática desde un análisis del cumplimiento real en el mercado laboral de las expectativas de los egresados y, lo más interesante, desde la perspectiva de las empresas u organizaciones de salud que debieran emplearlos. Analizan que los potenciales empleadores en buena medida no contratan a los graduados por desconocimiento de la compatibilidad entre los perfiles laborales demandados y las características de la oferta representada por aquellos. El estudio resulta ser otro ejemplo de que, tomando en cuenta la perspectiva de los empleadores, las instituciones educativas podrían ajustar la oferta educativa para satisfacer los criterios de calidad que en cuanto a competencias profesionales impone el mercado laboral, a fin de salvar las deficiencias de comunicación que parecen existir entre entidades educativas/formativas y demandantes de la oferta laboral que estas producen.

\section{El procedimiento de análisis de la inserción laboral de los graduados: una propuesta de modelo longitudinal}

Otro trabajo que puede sumarse como antecedente es el de Burriel y Beas, quienes en el ámbito de la Universidad Jaime I, de Castellón de la Plana, España, realizan el estudio El procedimiento de análisis de la inserción laboral de los graduados: una propuesta de modelo longitudinal ${ }^{4}$. El estudio tiene por uno de sus tópicos el realizar una vez cada seis años encuestas a empleadores de los que son los graduados de esa casa de estudios. El modelo de análisis que proponen los autores es integral, en cuanto a que toman en cuenta la opinión de todos los involucrados en la calidad profesional de los graduados, a saber: la institución educativa, los propios graduados y quienes serán o son sus empleadores. Lo que aquí nos interesa es la perspectiva partiendo de la visión

\footnotetext{
${ }^{3}$ Morales, Natalia; Ramírez, Carolina y Pérez, Pascual Hernando (2004). Investigación de mercado del programa Administración en Salud con énfasis Gestión de Servicios de Salud. Revista de la Facultad Nacional de Salud Pública (Volumen 23, № 2, jul-dic 2006).

${ }^{4}$ Burriel, Raúl y Beas, María Isabel (2007). El procedimiento de análisis de la inserción laboral de los graduados: una propuesta de modelo longitudinal. Observatorio ocupacional de la Universitat Jaume I (http://bit.ly/1GZjUDZ).
} 
de los empleadores, y cómo eso se integra con las demás perspectivas para llegar a un análisis de calidad que sirva como retroalimentación del proceso que diseña e implementa la oferta educativa. Como los mencionados antes, es de destacar en esta última investigación el objetivo de enriquecer el análisis de la calidad de capacidades profesionales tomando en cuenta expectativas y real cumplimiento de los requisitos que hacen a ella desde la perspectiva de la demanda, de aquellos que componen el grupo de quienes emplearán a los graduados.

\section{2- Los fundamentos teóricos en la metodología de investigación}

\subsection{1.- Definiciones conceptuales}

El relevamiento de información y la metodología de investigación utilizada descansan sobre una serie de fundamentos teóricos que permiten interpretar los resultados obtenidos en el estudio, cotejarlos con los objetivos que se han planteado y arribar a una serie de conclusiones sobre la problemática elegida. Los fundamentos suponen la necesidad de plantear una clara definición de los conceptos y variables presentes en la investigación, para acordar un único tipo de interpretación sobre la materia presente en objetivos, resultados y conclusiones. Por todo esto, es necesario exponer como parte del cuerpo teórico del trabajo de tesis las definiciones sobre qué se entiende respecto de cada una de las variables presentes en la investigación.

\section{Empleadores}

Es la figura de quien tiene a cargo tomar las principales decisiones que determinan y condicionan cuál y cómo será el tipo de trabajos y tareas que realizarán los graduados en Enfermería. El alcance de las decisiones obviamente variará en cada caso. Unos podrán tener a cargo todas las 
decisiones que involucran al graduado en situación laboral (reclutamiento, selección, inducción, asignación de tareas, negociación laboral, supervisión, flujos de información, evaluación de desempeño, reconocimiento, apercibimientos, sanciones, despidos, etc.) y otros en cambio sólo una parte de ellas. Además, algunos podrán ser jefes directos con plena autoridad, y otros supervisores del trabajo del graduado. No obstante, en todos los casos, la figura del empleador se define como la que más incidencia tiene en las condiciones en las que los graduados se desempeñan en sus cargos.

El empleador es también la figura más relevante de la investigación en el sentido de que, si bien no es el objeto principal de estudio (lo son los graduados), es su perspectiva la que se considera para llegar a las mediciones de calidad profesional que se formulan como objetivo.

\section{Graduados}

Los graduados de la carrera de Enfermería de la Facultad de Ciencias Médicas de la UNLP que hayan obtenidos sus títulos habilitantes en el período de tiempo considerado en la investigación son el principal objeto de estudio.

La calidad profesional que se está midiendo y estudiando se entiende que es la aportada por estos graduados en el ámbito del desempeño de los cargos o las tareas para los que fueran contratados por los empleadores. Sobre el desempeño de los graduados es donde se generan las expectativas y las percepciones de los graduados que son el centro neurálgico de la metodología de medición y análisis de la calidad profesional.

\section{Desempeño laboral del graduado. Expectativas y percepciones}

El graduado en su ámbito laboral desarrollando las tareas asignadas por el empleador es quien genera la información a utilizar en las mediciones de calidad. 
Por su parte, el empleador tiene formadas expectativas respecto a cuál debe ser el desempeño esperado por el graduado, expectativas que se ha formado desde el inicio ( $\mathrm{y}$ antes también) de la relación laboral, y que están obviamente influenciadas por la experiencia del empleador en el sector de la salud y en el trato con otros graduados.

Las expectativas son comparadas con las percepciones que surgen del desempeño efectivo del graduado, de lo concreto de los resultados que genera en oportunidad de realizar sus tareas. El cotejo entre expectativas y percepción, lógica que se da en la figura del empleador, es lo que genera la aparición de brechas de calidad, elemento clave en la medición y análisis de calidad profesional.

\section{Atributos del graduado. Conocimientos}

Los atributos del graduado referidos a sus conocimientos son una parte del conjunto de elementos que hacen a las expectativas de desempeño esperado y a las percepciones de desempeño real de los graduados por parte de los empleadores. Están referidos a las cuestiones inherentes a la formación profesional de los graduados, aquellas que los distinguen como especialistas de una determinada disciplina. Versan sobre los procedimientos elementales del trabajo de enfermería, sobre los marcos legales y regulatorios del ejercicio profesional, sobre el carácter económico y organizacional del rol de profesional enfermero dentro de una organización dedicada a la salud, sobre la comprensión del carácter básico de otras disciplinas relacionadas, sobre la identificación de problemas y la formulación e implementación de soluciones. Junto a las habilidades y las actitudes, los conocimientos conforman el perfil laboral del graduado en Enfermería.

\section{Atributos del graduado. Habilidades}

El segundo conjunto de atributos tienen que ver con las habilidades mostradas por el graduado en el desempeño de su puesto de trabajo. Sería 
algo así como la "puesta en acción" de los conocimientos aprehendidos en su etapa formativa. Las habilidades están referidas a la forma de aplicar a situaciones concretas de trabajo los conceptos teórico-prácticos obtenidos, al uso apropiado de tecnologías disponibles que hacen al desempeño en la disciplina, a la capacidad de acceder, evaluar y sintetizar información, a la efectiva capacidad para las comunicaciones interpersonales, al funcionar eficazmente en grupos de trabajo o las condiciones para asumir responsabilidades de liderazgo y/o conducción.

\section{Atributos del graduado. Actitudes}

Por último, el tercer grupo de atributos tiene que ver con las actitudes, entendidas como la predisposición o la capacidad de los graduados de, en situaciones laborales, pensar en forma crítica, creativa y reflexiva, en comprometerse con una lógica de aprendizaje permanente, en ser responsables ante la organización y la sociedad en el cumplimiento de su trabajo, en poder adaptar su actuación ante las variadas exigencias de los distintos grupos culturales con quienes les toca interrelacionarse. En definitiva, las actitudes tienen que ver con el conjunto de valores que funcionan como "filtros" entre los conocimientos y las habilidades de los graduados y forma de desempeñarse en concreto en sus ámbitos de trabajo.

\section{Medición y análisis de la calidad profesional}

Por medición y análisis de calidad se entiende la aplicación de la metodología específica de relevamiento de información de fuente primaria sobre los opinantes calificados representados en la figura de los empleadores. Esta es una metodología muy utilizada en mediciones y análisis de calidad y de competitividad, en el marco de lo que se conoce como método comparativo en ciencias sociales. Implica la medición sobre el objeto de estudio en particular para obtener un valor puntual que cobra significado al ser comparado con valores del mismo tipo obtenidos sobre el mismo objeto en otro tiempo y/o en 
otro espacio. En el presente trabajo, esto se aplica al medir: a) el mismo objeto de estudio (los graduados), b) en distintos tiempos (dados tanto por la duración del trabajo de campo como por los años de graduación de los profesionales), c) en distintos espacios (los distintos ámbitos y realidades inherentes a cada organización de salud donde trabajan los graduados) y d) desde la perspectiva de los empleadores (generadores del conjunto de expectativas y percepciones sobre las que se mide y analiza la calidad).

\subsection{2.- El modelo teórico subyacente en la metodología de investigación}

El modelo teórico que subyace en la metodología de investigación utilizada es la combinación entre la Escala Multidimensional Servqual (EMS) y el Modelo de las brechas sobre la calidad del servicio (BCS) ${ }^{5}$. EI EMS es una herramienta para medir y analizar calidad en los servicios que fuera desarrollada en 1988 por Zeithami, Parasuraman y Berry y que cuenta con una serie de mejoras y actualizaciones que se le han practicado a lo largo del tiempo. Como complemento, el BCS desarrollado por Zeithami y Bitner, propone como idea central que los prestadores de servicios que logran construir en el tiempo relaciones sólidas con sus clientes en el marco de una efectiva prestación de servicios, son los que pueden explotar la oportunidad que supone la existencia de brechas positivas y la capacidad de cerrar las que se presentan como negativas.

El EMS es el modelo que planteó por primera vez que la calidad debía medirse y analizarse a partir de las brechas, positivas o negativas, originadas en las diferencias entre expectativas de clientes ante el desempeño de un servicio que están contratando y las percepciones concretas sobre desempeño real del mismo.

Para el EMS, la percepción del cliente se refiere a como éste estima que el prestador del servicio (una empresa, una persona que presta servicios profesionales, un trabajador contratado, etc.) está cumpliendo con lo pautado o

\footnotetext{
${ }^{5}$ Castillo Morales, Eduardo (2005). Escala Multidimensional SERVQUAL. Revista de la Facultad de Ciencias Empresariales de la Universidad del Bío-Bío, Chile.
} 
acordado -en forma explícita o implícita- al momento de la contratación del mismo. En toda relación entre dos partes que suponga la prestación de un servicio determinado, siempre existirá, con mayor o menor grado de determinación, una serie de condiciones o pautas a cumplir por parte del prestador y que están determinadas por lo que espera el cliente. El cumplimiento real de esas condiciones o pautas en el momento de la prestación concreta del servicio es lo que genera la percepción que el cliente se forma sobre el servicio que está recibiendo y su prestador.

Por otra parte, las expectativas del cliente son lo que definen qué es lo que él espera de la prestación que contrata. La motivación que el cliente manifiesta al decidir la contratación o compra de un servicio está generada en las expectativas que haya llegado a formarse. Y a su vez, estas expectativas se forman, entre otras cosas, por sus experiencias pasadas en el consumo de servicios iguales o parecidos, en sus necesidades conscientes, en la información que posea sobre los detalles del servicio, etc.

Al momento de la prestación efectiva del servicio, las expectativas y las percepciones son cotejadas "en la mente del cliente" y de ese proceso surgen las brechas positivas o negativas entre ambas dimensiones. La determinación del tamaño de esas brechas supone una medición de la calidad del servicio, mientras que la evaluación de las causas por las cuáles se han generado representa su análisis.

EI EMS considera además la necesidad de evaluar las distintas ponderaciones que el cliente otorga a los elementos que componen una oferta de servicios. Según el EMS, de la serie de elementos sobre los que el cliente se forma una expectativa y luego construye su percepción, no tienen todos igual importancia o trascendencia para él. En virtud de cuales sean sus características como cliente, otorgará mayor o menor valor a uno u otro elemento, ponderándolo en consecuencia y "pesando" distinto al momento de comparar expectativas y percepciones para medir la calidad recibida y evaluar su grado de conformidad. 


\subsection{3.- Una adaptación del modelo EMS al vínculo empleadores y graduados en Enfermería}

En una adaptación del modelo EMS al objeto de investigación específico del presente trabajo de tesis, puede plantearse que existen dos ámbitos dentro del modelo: el del empleador que de una u otra forma pertenece a una organización de salud y el del graduado en Enfermería. El núcleo del modelo es el cotejo entre las expectativas sobre el servicio esperado por parte del empleador y la percepción que éste tiene realmente sobre el servicio que efectivamente recibe. Pero a ese núcleo se llega por una serie de causas y efectos que son presentados en el siguiente esquema gráfico y desarrollados a continuación:

(en página siguiente: Esquema de medición de calidad profesional de graduados en Enfermería) 


\section{Esquema de medición de calidad profesional de graduados en Enfermería}

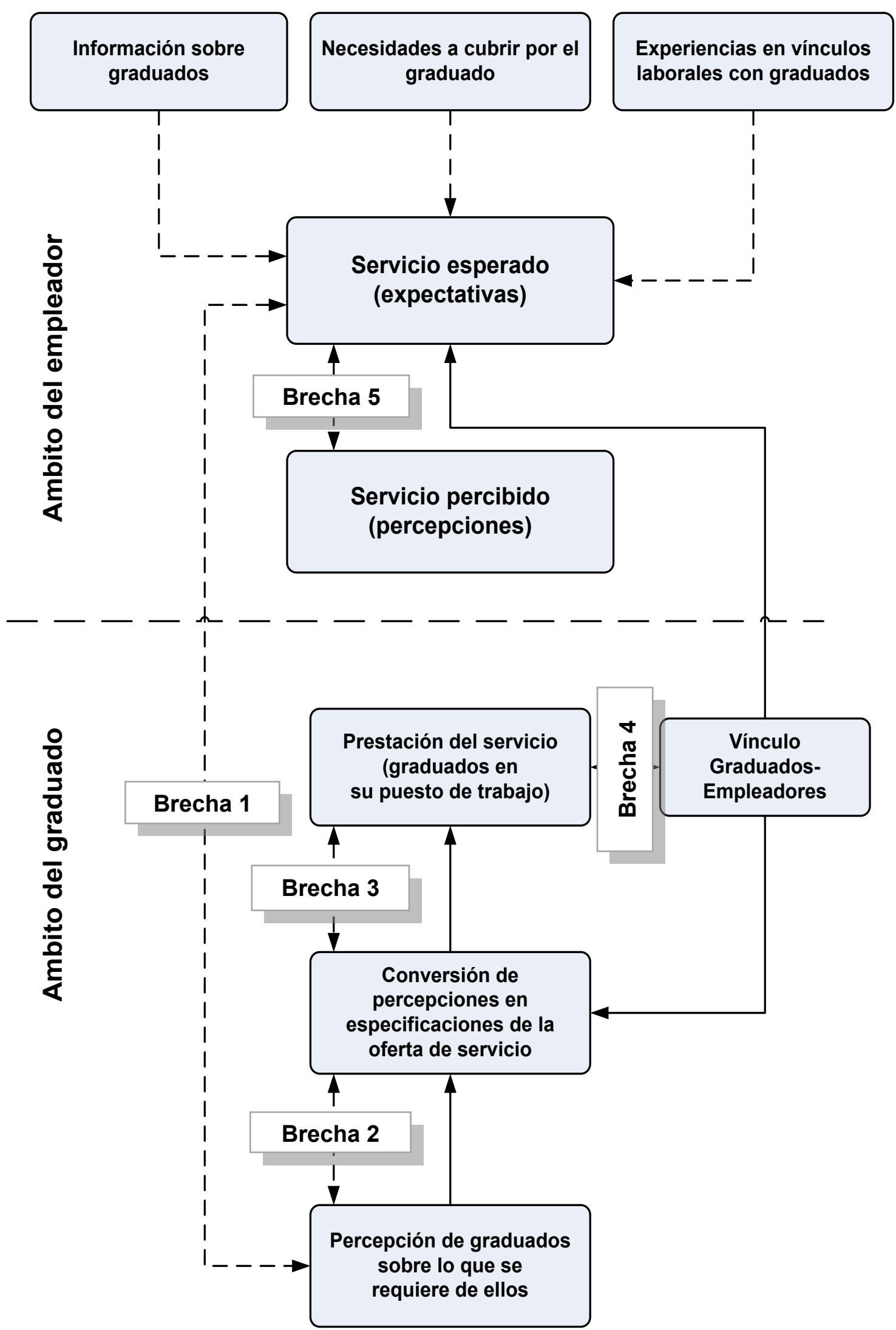

Fuente: Elaboración propia (adaptado del modelo EMS de Zeithami, Parasuraman y Berry) 


\section{Formación de expectativas sobre el servicio esperado}

Como puede verse en el esquema gráfico, las expectativas sobre el servicio esperado se forman con la información previa que el empleador pueda tener sobre los perfiles o las características del tipo de graduado que debe analizar, con la naturaleza de las necesidades que a su entender debe cubrir el graduado y con la experiencia que haya podido acumular en vínculos laborales previos con otros graduados del mismo tipo.

\section{Cotejo entre expectativas y percepciones (Brecha 5)}

Las expectativas cotejadas con las percepciones que se forma el empleador cuando recibe en forma efectiva el servicio profesional brindado por los graduados es, como se dijo, el núcleo del modelo. De este cotejo surgen las brechas que al empleador le servirán para medir la calidad y, en función de las ponderaciones otorgadas a cada elemento del servicio, valorar los beneficios o perjuicios de lo positivo o negativo que puedan resultar tales brechas.

El modelo EMS identifica como Brecha 5 las diferencias (brechas) que surgen del cotejo entre expectativas y percepciones. Esta brecha, por su parte, se explica -y es la resultante- de la existencia de cuatro brechas previas que también presenta el modelo, y que suponen una lógica de formación de las expectativas y percepciones por etapas, combinando distintos elementos tanto del ámbito del graduado como del empleador.

\section{Expectativas del empleador y percepción de los graduados (Brecha 1)}

Esto se refiere a la percepción de los graduados, no la del empleador que es parte del núcleo del modelo. Este otro tipo de percepción tiene que ver entonces con la capacidad de los graduados para interpretar cuáles son las expectativas de los empleadores sobre el servicio esperado, a fin de poder adaptar así la forma en que ofrecerán sus cualidades profesionales para ocupar un puesto de trabajo. 
Cuanto menor sea el grado de coincidencia entre las expectativas del empleador y la lectura e interpretación que los graduados hagan de ella, mayor será el tamaño de la brecha 1.

\section{Especificación de la oferta de servicio en base a percepción de los graduados (Brecha 2)}

Según el modelo, los graduados "diseñan" el servicio profesional que ofrecen en función de la percepción que tengan sobre qué es lo que realmente esperan los empleadores que los contratarán. Esto es, los graduados tienen una percepción sobre cuáles son las expectativas de los empleadores, y la utilizan para acondicionar en consecuencia las características del tipo de servicio a ofrecer. Cuanto mejor sea la lectura que hagan sobre las expectativas del empleador, mayor será la capacidad de "diseñar" y ofrecer un servicio de calidad.

\section{Prestación del servicio especificado (Brecha 3)}

Una vez que los graduados especificaron el servicio que ofrecen en función de la percepción que tuvieron sobre las expectativas de los empleadores, están en condiciones de prestar en concreto el servicio; esto es, de desempeñar su tareas en el lugar de trabajo. Cuanto menor sea esta nueva brecha, menos condicionada terminará estando la "brecha núcleo", la brecha 5.

Así, va tomando forma lo que será el cotejo final en brecha 5 entre expectativas y percepciones del empleador, porque a esta altura los graduados ya hicieron una interpretación sobre qué esperan los empleadores (brecha 1), acondicionaron la oferta de servicio en base a eso (brecha 2) y prestaron sus servicios en consecuencia (brecha 3). 


\section{Vínculo graduados-empleadores (Brecha 4)}

La forma en la que realmente los graduados presten sus servicios terminará dependiendo del tipo de vínculo que tengan con los empleadores en el ámbito de la relación laboral, en la situación específica del graduado desempeñando sus tareas en el puesto de trabajo. Cuando "menor ruido" exista en este vínculo (brecha 4), menor será la incidencia sobre la magnitud de las brechas anteriores y de la posterior, la central, la brecha 5.

\section{La Brecha 5, el núcleo del modelo}

Se cierra entonces el circuito que plantea el modelo con la brecha 5, determinada por la serie de causas y efectos generados por las brechas anteriormente descriptas. La magnitud que tome cada una de las primeras cuatro brechas contribuirá a generar la magnitud total a tomar por la brecha 5; esto es, la magnitud total en la que se basa el modelo para medir calidad por medio del cotejo entre expectativas y percepciones del empleador. 


\section{Metodología de la investigación}

\subsection{Universo y Muestra}

\subsubsection{Universo}

La investigación de la presente tesis es parte de una de mayor alcance que comprende a los graduados de todas las carreras de la Facultad de Ciencias Médicas de la UNLP. Esta investigación más amplia tiene, por su parte, el objetivo de ser insumo de estudios a cargo de la Maestría en Dirección de Empresas de la Facultad de Ciencias Económicas (UNLP) destinados a evaluar la calidad educativa de los graduados de distintas facultades con influencia en la región de La Plata, Berisso y Ensenada. Ampliando aún más el foco, los estudios sobre calidad educativa en graduados universitarios y terciarios de distintas facultades son insumo a su vez de investigaciones sobre competitividad económica en la región, siendo como es el de la educación superior uno de los pilares de la competitividad.

El universo de toda la investigación sobre calidad educativa en graduados de la Facultad de Ciencias Médicas se definió entonces como el integrado por los graduados durante el período 2007-2011 de las carreras de Medicina, Enfermería, Licenciatura en Enfermería, Licenciatura en Obstetricia y Licenciatura en Fonoaudiología. La porción de todo el universo correspondiente a la carrera de Enfermería es el objeto de estudio de la presente tesis.

\subsubsection{Muestra}

La población bajo estudio para esta investigación está constituida por todos los egresados de la Facultad de Ciencias Médicas de UNLP. De la misma se considera extraer una muestra aleatoria cuyo tamaño $\mathrm{n}$ se calcula mediante la expresión: 


$$
n=\frac{Z_{\alpha}^{2} \cdot N \cdot p \cdot q}{e^{2} \cdot(N-1)+Z_{\alpha}^{2} \cdot p \cdot q}
$$

La misma corresponde al cálculo del tamaño muestral cuando se desea estimar la proporción de éxitos $p$, con universo conocido.

Donde:

$$
\begin{aligned}
N= & 5.065 \text { egresados (tamaño de la población) } \\
p= & \text { prevalencia esperada del parámetro a evaluar, que en caso } \\
& \text { de desconocerse, se aplica la opción más desfavorable } \\
& (p=0,5), \text { que hace mayor el tamaño muestral } \\
q= & \text { complemento de la prevalencia esperada del parámetro a } \\
& \text { evaluar, es decir } 1-p=0,5 \\
Z= & 1,95996 \text { para } \alpha=5 \%, \text { o sea un nivel de confianza del } 95 \% \\
e= & 8 \% \text { error de muestreo } \\
N= & 150 \text { personas a encuestar (tamaño de la muestra) }
\end{aligned}
$$

Dado que se trata de cinco áreas a estudiar si se considera la investigación más amplia de toda la oferta de la Facultad de Ciencias Médicas, se ha distribuido la cantidad de encuestas a realizar de acuerdo al porcentaje de participación de cada especialidad en el total de graduados. Lo cual implica la siguiente distribución para cada una de las especialidades (y resaltado en negrita, lo correspondiente al objeto de estudio de la presente tesis):

\begin{tabular}{lrr} 
Especialidad & $\begin{array}{l}\text { Porcentaje } \\
\text { participación }\end{array}$ & Encuestas \\
\hline Enfermería & $\mathbf{1 3 \%}$ & $\mathbf{1 9}$ \\
\hline Licenciatura en Enfermería & $39 \%$ & 58 \\
\hline Licenciatura en Fonoaudiología & $4 \%$ & 6 \\
\hline Licenciatura en Obstetricia & $6 \%$ & 9 \\
\hline Medicina & $38 \%$ & 57 \\
\hline Total & $\mathbf{1 0 0 \%}$ & $\mathbf{1 5 0}$
\end{tabular}




\subsection{Tipo de Investigación}

La investigación que se realizó para el trabajo de tesis es de tipo exploratoria, por tratarse de un objeto de investigación poco conocido y poco estudiado (los egresados, en un período concreto de años, de la carrera de Enfermería de la Facultad de Ciencias Médicas de la UNLP, y ejerciendo sus labores en el ámbito específico de la región de La Plata, Berisso y Ensenada). Por tanto, los resultados conseguidos en la investigación son una visión aproximada al objeto de estudio, sin poder alcanzar un conocimiento profundo del mismo ni poder establecer con certeza relaciones causa y efecto.

No obstante carecer en relación al objeto de estudio de información suficiente y conocimientos previos a la investigación, ésta sí permitió formular el problema en forma más definida, representando un buen antecedente y punto de partida para investigaciones futuras que deseen realizarse sobre el mismo objeto. La investigación permitió obtener datos y elementos que pueden conducir a formular con mayor precisión preguntas y objetivos de investigación para estudios posteriores y de mayor entidad que los de un trabajo de tesis como el presente.

\subsection{Técnicas de relevamiento de datos}

Los datos de fuente primaria necesarios para la investigación fueron obtenidos de la muestra seleccionada al efecto. Esto tanto para la investigación más amplia de toda la oferta educativa de la Facultad de Ciencias Médicas de la UNLP como para la correspondiente a este trabajo de tesis referida a la carrera de Enfermería.

Las encuestas fueron realizadas bajo la modalidad presencial, en encuentros coordinados con responsables de las organizaciones empleadoras de egresados en Enfermería que conformaron la muestra. 
Como fuera adelantado en el apartado sobre antecedentes de la investigación, la encuesta utilizada (traducida el español) es la de la tesis doctoral Stakeholders' Satisfaction wiht Civil Engeineering Graduates, de Albani Musyafa para la Curtin University of Technology de Bentley, Australia.

La realización de encuestas a la muestra seleccionada permitió obtener información sobre graduados de la carrera de Enfermería durante el período 2007-2011, en preguntas del tipo "cerradas" referidas a la calidad profesional percibida. El relevamiento de información a empleadores encuestados respetó la siguiente lógica (ver apartado 10. Referencias y anexos):

1. Información relacionada con el encuestado. Se refiere al empleador o referente de la organización que emplea al profesional en enfermería. De él se relevaron los datos personales (edad, sexo, antigüedad en el trabajo) y los referidos al lugar de trabajo tanto del empleador como del graduado.

2. Información relacionada con el graduado. En forma similar para el graduado, se relevaron sus datos personales y algunos de detalle referidos a su graduación (año de obtención del título, capacitación adicional al título, años de experiencia en el puesto de trabajo).

3. Información referida al puesto de trabajo. Con detalle de cuál es la naturaleza del trabajo que desempeña el graduado, y cuáles son algunas de las aptitudes y actitudes que al graduado le requiere.

4. Atributos del graduado. Información ya más relevante de cara al análisis y extracción de conclusiones. El encuestado responde evaluando los conocimientos, las habilidades y las actitudes del graduado, en un formato de responder a distintos ítems propuestos graduando con escala de 1 a 5 entre Totalmente en desacuerdo y Muy de acuerdo.

5. Desempeño en el trabajo. Con formato similar de respuesta a ítems que hay que graduar entre 1 y 5 , el encuestado responde 
sobre cómo evalúa al graduado en el desempeño de su puesto de trabajo, calificando en un rango entre Mucho más que lo planificado y Mucho menos que lo planificado.

6. Satisfacción. En forma muy concreta, se pregunta al encuestado cuán satisfecho está con la obtención de resultados por parte del graduado, en un solo ítem de la misma escala de 1 a 5 pero respondiendo a un solo ítem entre Muy insatisfecho y Muy satisfecho.

7. Expectativa. Aquí se cambia la escala, para pasar de 1 a 9 , teniendo que puntuar en ese rango sobre distintos ítems de lo que se espera del graduado en su puesto de trabajo.

8. Comentarios. La encuesta cierra con una opción voluntaria para el encuestado de realizar los comentarios que desee sobre lo que se le ha preguntado, siendo útil información de tipo cualitativa para dar contexto a los datos relevados.

\subsection{Técnicas de Análisis}

El necesario análisis de los datos obtenidos para generar resultados de la investigación y luego proponer conclusiones ha seguido la siguiente lógica:

1. Se confeccionó una base de datos con diseños de registro que respetaron el tipo de datos a relevar.

2. Los datos relevados en las encuestas a empleadores fueron cargados en una matriz, en la cada campo registrado representó cada una de las preguntas de la encuesta.

3. A fin de facilitar el proceso de carga de datos, las respuestas fueron codificadas con un número específico para cada una de ellas.

4. Además, se practicó un análisis univariado sobre la totalidad de los datos obtenidos. 
5. Luego se calculó el Saldo de respuesta ${ }^{6}$ de cada pregunta realizada, en función de la fórmula siguiente:

Saldode Re spuesta $=\frac{\sum_{i=1}^{n} F_{i} \cdot i}{\sum_{i=1}^{n} F_{i}}$

Donde:

$\mathrm{Fi}=$ Es la cantidad de respuestas (frecuencias) de cada ítem para cada valor de las opciones de respuesta

$\mathrm{i}=$ Es el valor de cada uno de las opciones de respuesta

El cálculo consiste en multiplicar los componentes de las cantidades de respuestas (frecuencias) por el tipo de respuesta dado y luego sumar esos productos. Posteriormente, a ese número se lo divide por la sumatoria de la cantidad de respuestas.

6. Como ya se mencionó, a fin de relevar los datos necesarios para la investigación se utilizó, traducida al español, la misma encuesta que la utilizada en la investigación Stakeholders' satisfaction with Civil Engineering Graduates. Cómo ésta no incluía la determinación de la brecha entre la expectativa y la percepción de calidad del graduado fue necesario realizar dos transformaciones matemáticas.

La primera transformación tuvo que ver con que la percepción respecto de la calidad ofrecida por el graduado calificaba el peor

\footnotetext{
${ }^{6}$ El cálculo de ese promedio sigue idéntica metodología que la del Global Competitiveness Index del World Economic Forum para el procesamiento de la Executive Opinion Survey en que se pregunta sobre una serie de cuestiones y se solicita que se califique en un rango que va de 1 a 7 en que 1 es lo peor y 7 lo mejor y que luego se sintetiza a través de un promedio. Xavier Sala-i-Martin (Cabrera de Mar, Barcelona, España, 1963), es un economista de origen español y de nacionalidad estadounidense, articulista, catedrático de economía en la Universidad de Columbia y Asesor Jefe ("Chief Advisor") del World Economic Forum donde, además, es coautor del Global Competitiveness Report y el padre intelectual del Global Competitiveness Index que ordena a más de 140 países del mundo según su competitividad.
} 
resultado con el valor de 1 , y el mejor con 5; mientras que para las expectativas del empleador sobre los aspectos del graduado se calificaba con 1 lo mejor y con 9 lo peor. Debido a eso se invirtió la escala para las percepciones.

Se utilizó la determinación de la ecuación de la recta de transformación en función de los ejes cartesianos de los extremos.

\begin{tabular}{|l|c|c|}
\hline Percepción & $\begin{array}{l}\text { Calificación } \\
\text { original }\end{array}$ & $\begin{array}{l}\text { Nueva } \\
\text { calificación }\end{array}$ \\
\hline Lo peor & 1 & 5 \\
\hline Lo mejor & 5 & 1 \\
\hline
\end{tabular}

Los extremos conforman los pares siguientes:

$$
\begin{aligned}
& \left(x_{0} ; y_{0}\right)=(1 ; 5) \\
& \left(x_{1} ; y_{1}\right)=(5 ; 1)
\end{aligned}
$$

De tal modo, la pendiente de la recta de transformación "m" es:

$$
m=\frac{\left(y_{1}-y_{0}\right)}{\left(x_{1}-x_{0}\right)}=\frac{(1-5)}{(5-1)}=-1
$$

Y la ordenada al origen "b" es:

$$
b=-m \cdot x_{0}+y_{0}=-(-1) \cdot 1+5=6
$$

Y la ecuación de la recta de transformación es:

$$
y=m \cdot x+b=-1 \cdot x+6
$$


La segunda transformación refiere a que las expectativas iban en un rango de 1 a 9 , por lo que resultó necesario llevarlo a uno que comprendiera valores de 1 a 5 .

Determinación de la ecuación de la recta de transformación en función de los ejes cartesianos de los extremos.

\begin{tabular}{|l|c|c|}
\hline Expectativa & $\begin{array}{l}\text { Calificación } \\
\text { original }\end{array}$ & $\begin{array}{l}\text { Nueva } \\
\text { calificación }\end{array}$ \\
\hline Lo peor & 9 & 5 \\
\hline Lo mejor & 1 & 1 \\
\hline
\end{tabular}

Los extremos conforman los pares siguientes:

$$
\begin{aligned}
& \left(x_{0} ; y_{0}\right)=(1 ; 1) \\
& \left(x_{1} ; y_{1}\right)=(9 ; 5)
\end{aligned}
$$

De tal modo, la pendiente de la recta de transformación "m" es:

$$
m=\frac{\left(y_{1}-y_{0}\right)}{\left(x_{1}-x_{0}\right)}=\frac{(5-1)}{(9-1)}=0,5
$$

Y la ordenada al origen "b" es:

$$
b=-m \cdot x_{0}+y_{0}=-0,5 \cdot 1+1=0,5
$$

Y la ecuación de la recta de transformación es:

$$
y=m \cdot x+b=0,5 \cdot x+0,5=0,5 \cdot(x+1)
$$

Luego se calculó la frecuencia de la brecha de satisfacción de la calidad del graduado, como la diferencia entre las percepciones y las expectativas que tienen los empleadores. 
La brecha de satisfacción de los empleadores es la resultante de la resta entre la calificación otorgada a la expectativa que un empleador tiene sobre un aspecto del graduado y la percepción respecto de la calidad ofrecida por éste último. El "árbol de posibilidades" queda conformado según la siguiente tabla (que comienza en ésta página, se interrumpe al pie y continúa en la siguiente):

\begin{tabular}{|c|c|c|}
\hline Expectativa & Percepción & Brecha \\
\hline 1,0 & 5,0 & $-4,0$ \\
\hline 1,0 & 4,0 & $-3,0$ \\
\hline 1,0 & 3,0 & $-2,0$ \\
\hline 1,0 & 2,0 & $-1,0$ \\
\hline 1,0 & 1,0 & 0,0 \\
\hline 1,5 & 5,0 & $-3,5$ \\
\hline 1,5 & 4,0 & $-2,5$ \\
\hline 1,5 & 3,0 & $-1,5$ \\
\hline 1,5 & 2,0 & $-0,5$ \\
\hline 1,5 & 1,0 & 0,5 \\
\hline 2,0 & 5,0 & $-3,0$ \\
\hline 2,0 & 4,0 & $-2,0$ \\
\hline 2,0 & 3,0 & $-1,0$ \\
\hline 2,0 & 2,0 & 0,0 \\
\hline 2,0 & 1,0 & 1,0 \\
\hline 2,5 & 5,0 & $-2,5$ \\
\hline 2,5 & 4,0 & $-1,5$ \\
\hline 2,5 & 3,0 & $-0,5$ \\
\hline 2,5 & 2,0 & 0,5 \\
\hline 2,5 & 1,0 & 1,5 \\
\hline 3,0 & 5,0 & $-2,0$ \\
\hline 3,0 & 4,0 & $-1,0$ \\
\hline 3,0 & 3,0 & 0,0 \\
\hline 3,0 & 2,0 & 1,0 \\
\hline 3,0 & 1,0 & 2,0 \\
\hline 3,5 & 5,0 & $-1,5$ \\
\hline 3,5 & 4,0 & $-0,5$ \\
\hline 3,5 & 3,0 & 0,5 \\
\hline 3,5 & 2,0 & 1,5 \\
\hline 3,5 & 1,0 & 2,5 \\
\hline 4,0 & 5,0 & $-1,0$ \\
\hline 4,0 & 4,0 & 0,0 \\
\hline 4,0 & 3,0 & 1,0 \\
\hline 4,0 & 2,0 & 2,0 \\
\hline 4,0 & 1,0 & 3,0 \\
\hline 4,5 & 5,0 & $-0,5$ \\
\hline
\end{tabular}




\begin{tabular}{|c|c|c|}
4,5 & 4,0 & 0,5 \\
\hline 4,5 & 3,0 & 1,5 \\
\hline 4,5 & 2,0 & 2,5 \\
\hline 4,5 & 1,0 & 3,5 \\
\hline 5,0 & 5,0 & 0,0 \\
\hline 5,0 & 4,0 & 1,0 \\
\hline 5,0 & 3,0 & 2,0 \\
\hline 5,0 & 2,0 & 3,0 \\
\hline 5,0 & 1,0 & 4,0 \\
\hline \multicolumn{2}{|c|}{ Fuente: Elaboración propia }
\end{tabular}

Y resumiendo sólo los casos únicos, la tabla queda así:

\begin{tabular}{|c|l|}
\hline Brechas & Estados posibles de satisfacción \\
\hline$-4,0$ & Insatisfacción total \\
\hline$-3,5$ & Muy insatisfecho \\
$-3,0$ & \\
\hline$-2,5$ & Bastante insatisfecho \\
$-2,0$ & \\
\hline$-1,5$ & Algo insatisfecho \\
$-1,0$ & \\
\hline$-0,5$ & \\
0,0 & Satisfecho \\
0,5 & \\
\hline 1,0 & Algo más que satisfecho \\
1,5 & \\
\hline 2,0 & Bastante más que satisfecho \\
2,5 & \\
\hline 3,0 & Mucho más que satisfecho \\
\hline 3,5 & \\
\hline 4,0 & Satisfacción total \\
\hline
\end{tabular}

Fuente: Elaboración propia 


\section{Resultados de la investigación}

Habiendo planteado y evaluado el problema de investigación, definido los objetivos y el alcance de la misma, utilizada una metodología aplicada a una muestra específica del objeto de estudio, realizado el trabajo de campo sobre esa muestra para relevar datos de fuente primaria, y procesado y analizado todo lo relevado, se está en condiciones de presentar los resultados de la investigación, presentes en este apartado y paso previo para concluir la presente tesis con la expresión de conclusiones sobre lo que se ha decidido investigar.

Los resultados se presentarán siguiendo la lógica planteada para el relevo de la información de la que se extraen. Esto es, se presentarán los resultados respetando la siguiente secuencia en sub-apartados:

7.1. Análisis descriptivo de la muestra. Se refiere a los resultados obtenidos por toda la información que se relevó sobre la figura del empleador como encuestado, y todo lo aportado por éste último sobre características personales del graduado que hacen a su trabajo e información de algún detalle sobre el puesto y la situación laboral.

7.2. Atributos del graduado. Sus conocimientos, habilidades y actitudes en el puesto de trabajo. Se refiere a los resultados sobre la información relevada a propósito del análisis por parte de los empleadores de los conocimientos, las habilidades y las actitudes requeridas por el puesto de trabajo para obtener en el mismo un desempeño aceptable. Este sub-apartado supone ser la parte central de la evaluación de resultados, a partir del hecho de que en él está presente todo el análisis sobre las brechas registradas entre expectativas y percepciones de los empleadores respecto del desempeño laboral de los graduados, punto neurálgico de la metodología de investigación y análisis utilizada. 
7.3. Desempeño en el trabajo por parte del graduado. Referido a la duración de los trabajos de los graduados en base a la planificación previa o estándares de tiempo sobre los mismos, y a la calidad registrada de las tareas una vez realizadas respecto de los niveles esperados.

\subsection{Satisfacción de los empleadores respecto del trabajo de} los graduados. Sobre las apreciaciones y los niveles de satisfacción por parte de los empleadores respecto del desempeño del trabajo llevado a cabo por los graduados.

Cumplida la presentación de resultados, en el próximo apartado se concluirá sobre los mismos a modo de cierre del presente trabajo de tesis.

\subsection{Análisis descriptivo de la muestra}

\subsubsection{Información personal de los encuestados}

La estructura de relevamiento de datos de la investigación tiene su parte inicial en una serie de cuestiones relacionadas con datos formales de la figura de los empleadores, entendiéndose por estos -como ya se expresó en 5.2.1.Definiciones conceptuales- a quienes tienen autoridad formal 0 son supervisores del trabajo de los graduados en las organizaciones y/o empresas en que ambos desempeñan su labor. Los datos relevados sobre quiénes son los encuestados aporta la información sobre sus perfiles formales según la muestra de encuestados que se ha tomado. Esta información es la que se presenta en este apartado, reservando el siguiente para información de similar tipo pero -también generada por empleadores encuestados- reservada a los graduados. 


\section{Género de los encuestados}

Del total de los encuestados que componen la muestra de la investigación, el $58 \%$ son mujeres y el $42 \%$ hombres.

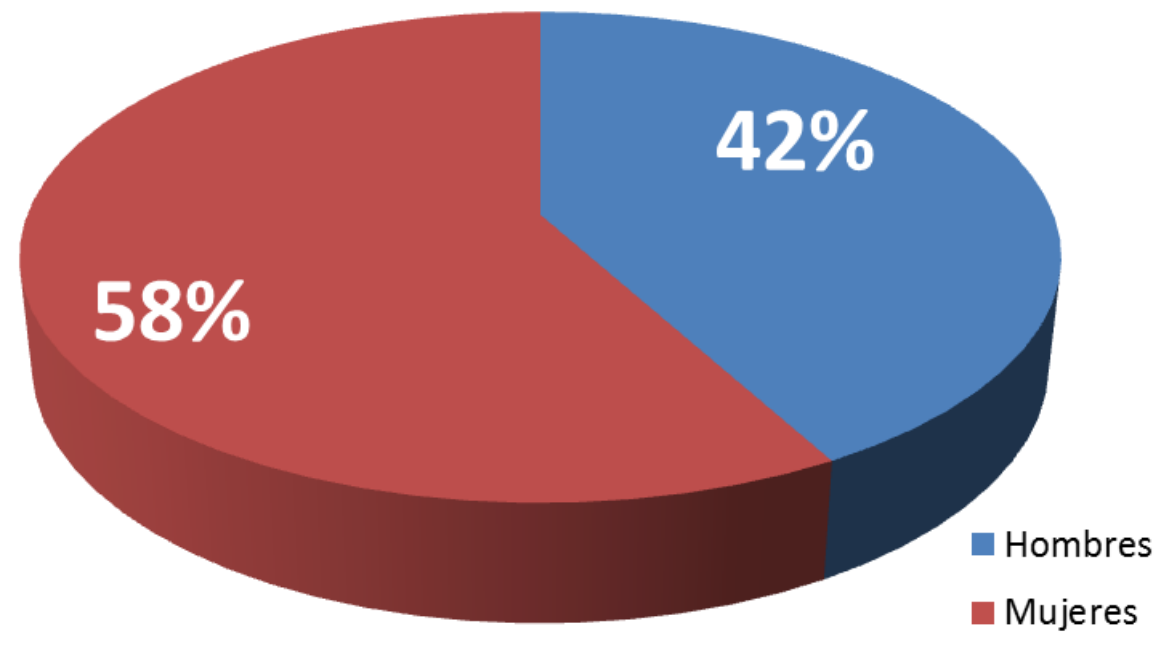

Fuente: Elaboración propia

\section{Ciudad en la que desempeñan sus actividades}

El $65 \%$ de los encuestados trabaja en La Plata, mientras que un $26 \%$ lo hace en Berisso y, como la menor cantidad de las tres ciudades que componen la región, sólo un 9\% trabaja en Ensenada.

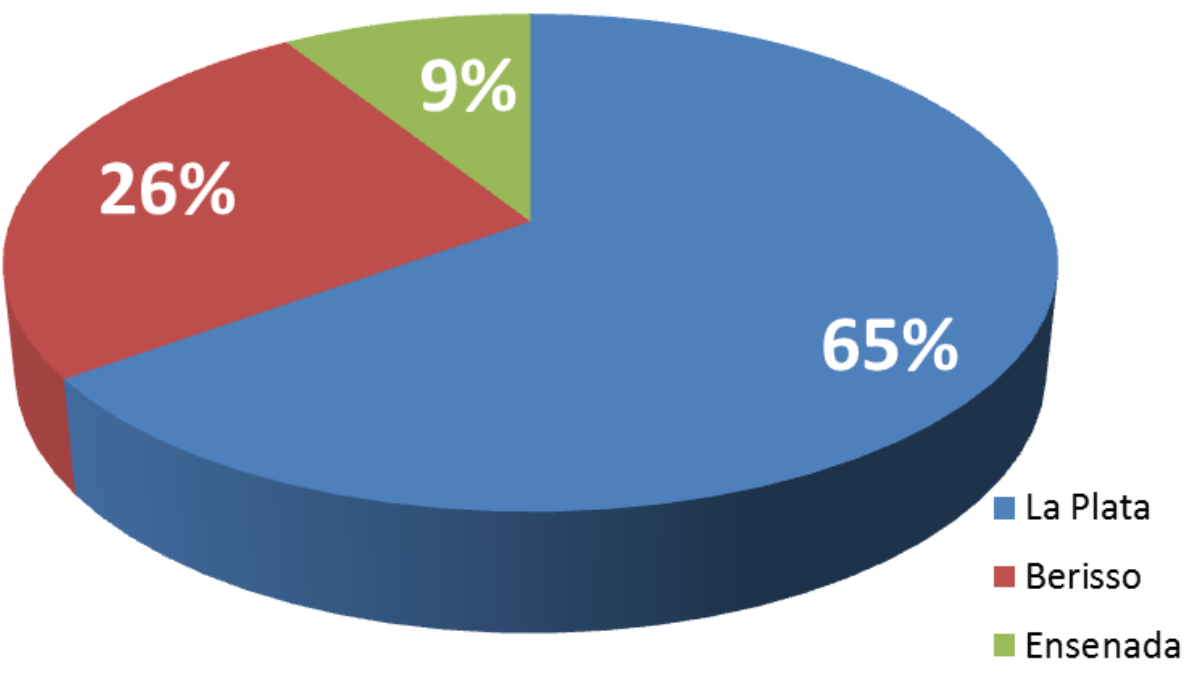

Fuente: Elaboración propia 


\section{Relación del encuestado en cuanto "empleador" con el graduado}

Si bien para la investigación se ha definido con la figura de "empleador" al encuestado, que es quien en definitiva califica el desempeño en los puestos de trabajo por parte de los graduados, sólo un $37 \%$ de a quienes se encuestó resultaron ser estrictamente empleadores; esto es, quienes poseen algún emprendimiento u empresa en marcha que emplea al tipo de graduados objeto de estudio. Los restantes $63 \%$ de encuestados son en realidad quienes ejercen sobre los graduados algún tipo de relación de jefatura o supervisión. A los fines de la investigación de evaluar calidad profesional ambos grupos son considerados bajo la figura de "empleador".

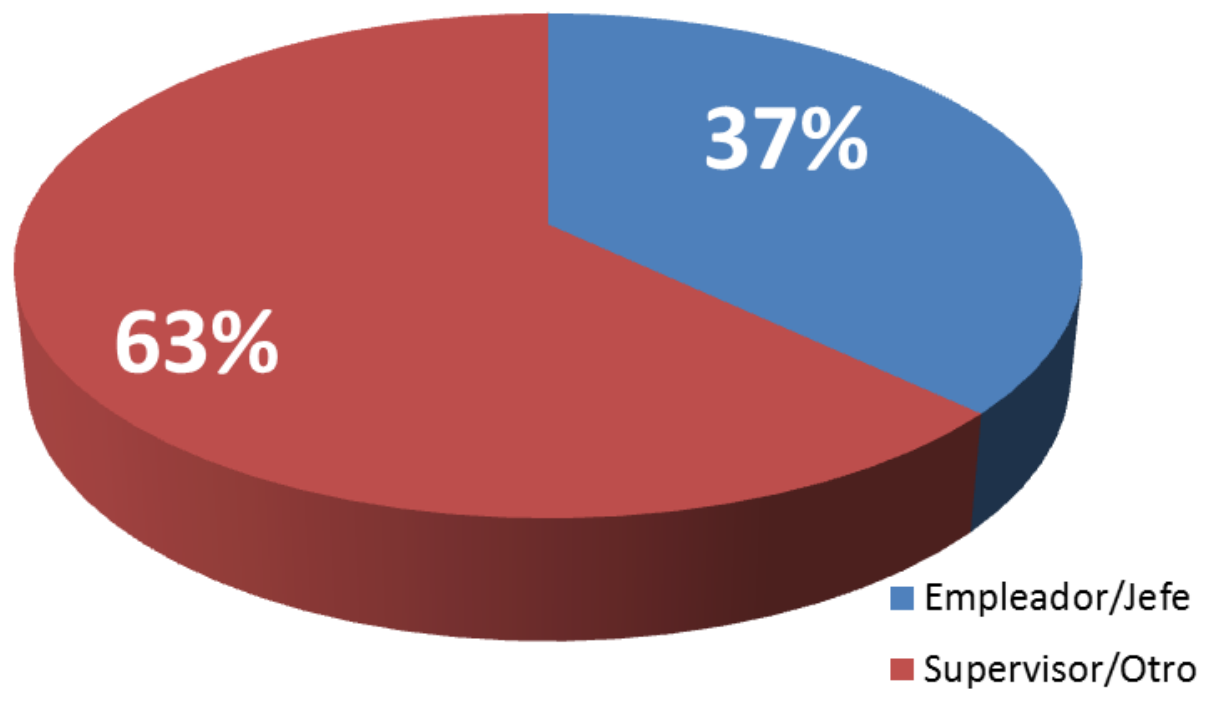

Fuente: Elaboración propia

\section{Antigüedad del encuestado en su propio puesto de trabajo}

El $47 \%$ de los encuestados lleva más de tres años de permanencia en su puesto de trabajo. El 32\% tiene una antigüedad en su puesto de entre dos y tres años, y el $21 \%$ restante entre uno y dos años. De los empleadores que fueron parte de la muestra, ninguno de ellos registró antigüedad menor a un año.

(gráfico en la página siguiente) 


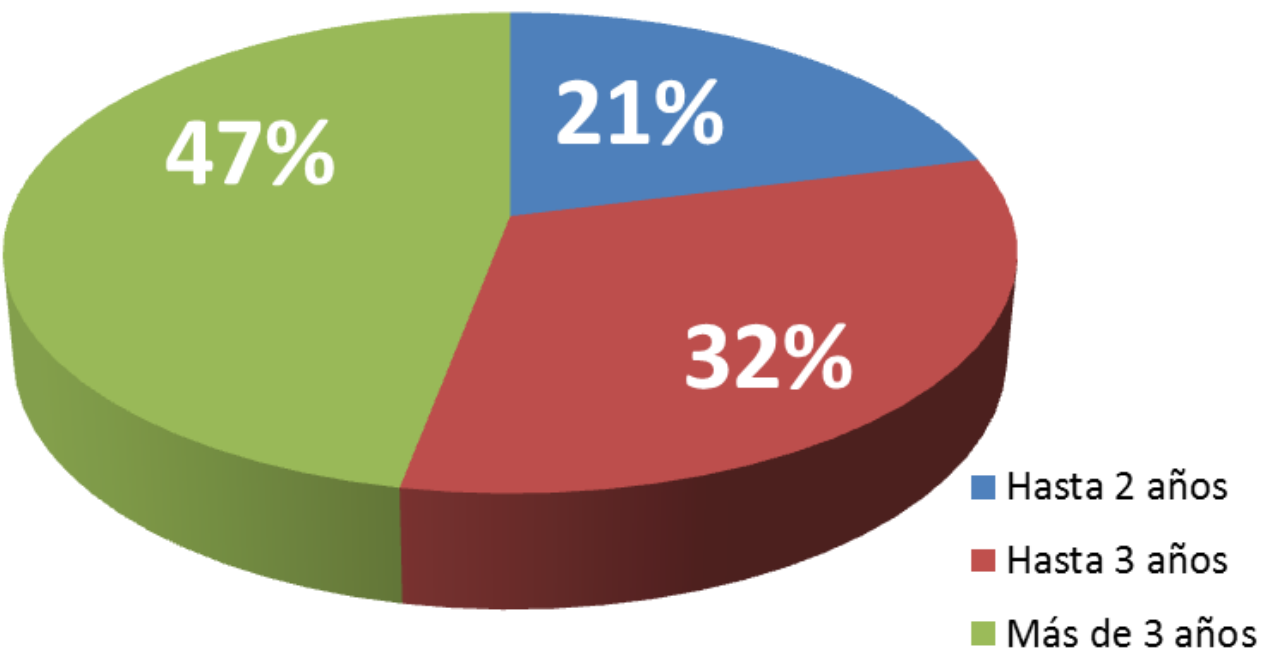

Fuente: Elaboración propia

\subsubsection{Información sobre los graduados}

Como se adelantó, la estructura de relevamiento de datos de la investigación comprende también una serie de cuestiones que responden a determinar también el perfil formal de los graduados.

\section{Género de los graduados}

Entre los graduados que en forma de jefatura directa o supervisión se encuentran a cargo de los empleadores, existe una alta proporción de mujeres, con $84 \%$ respecto del $16 \%$ correspondiente a hombres.

(gráfico en la página siguiente) 


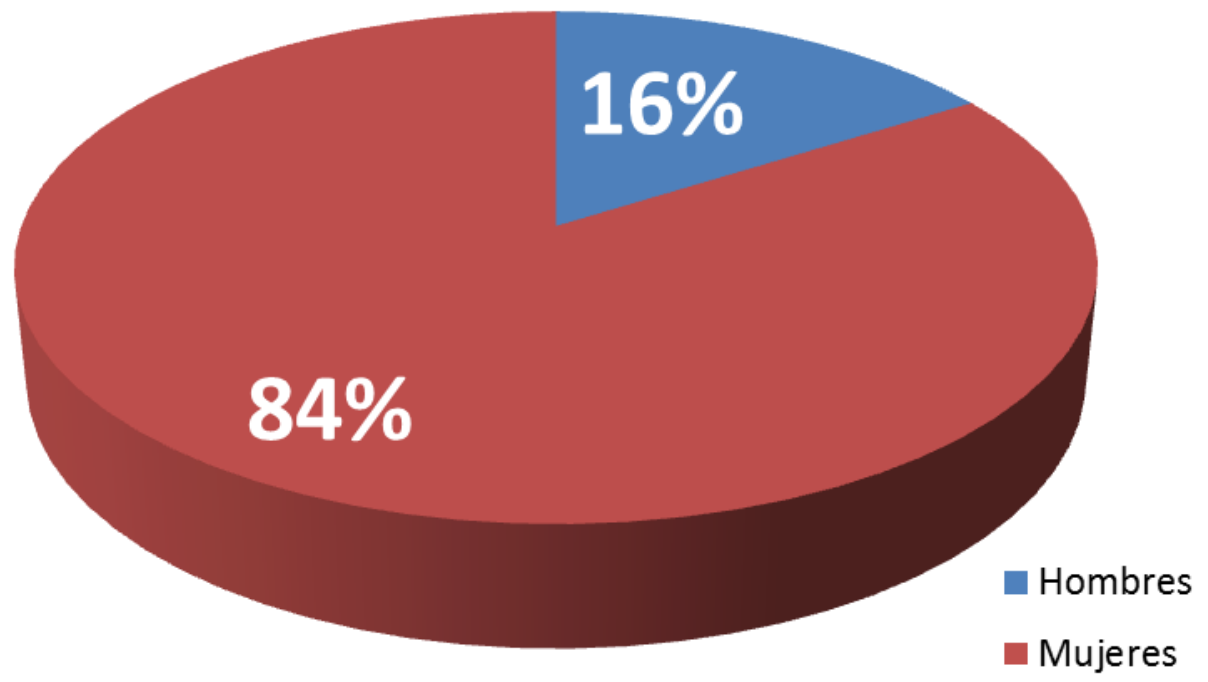

Fuente: Elaboración propia

\section{Año de obtención del título profesional por parte de los graduados}

Cómo puede verse en el gráfico que comprende todos los años del período de tiempo definido por la investigación, los años 2008 y 2009 son los de mayor cantidad de graduados de entre los que componen la muestra. Luego se ubica el año 2011, el 2007 y por último el 2010. Los porcentajes que se aprecian en ordenadas son los correspondientes a los graduados por año del total de los cinco años que componen el rango de tiempo definido en la investigación, y ninguna relación tienen a priori con porcentajes similares que pueda registrar el tiempo de vigencia total de la carrera como oferta académica.

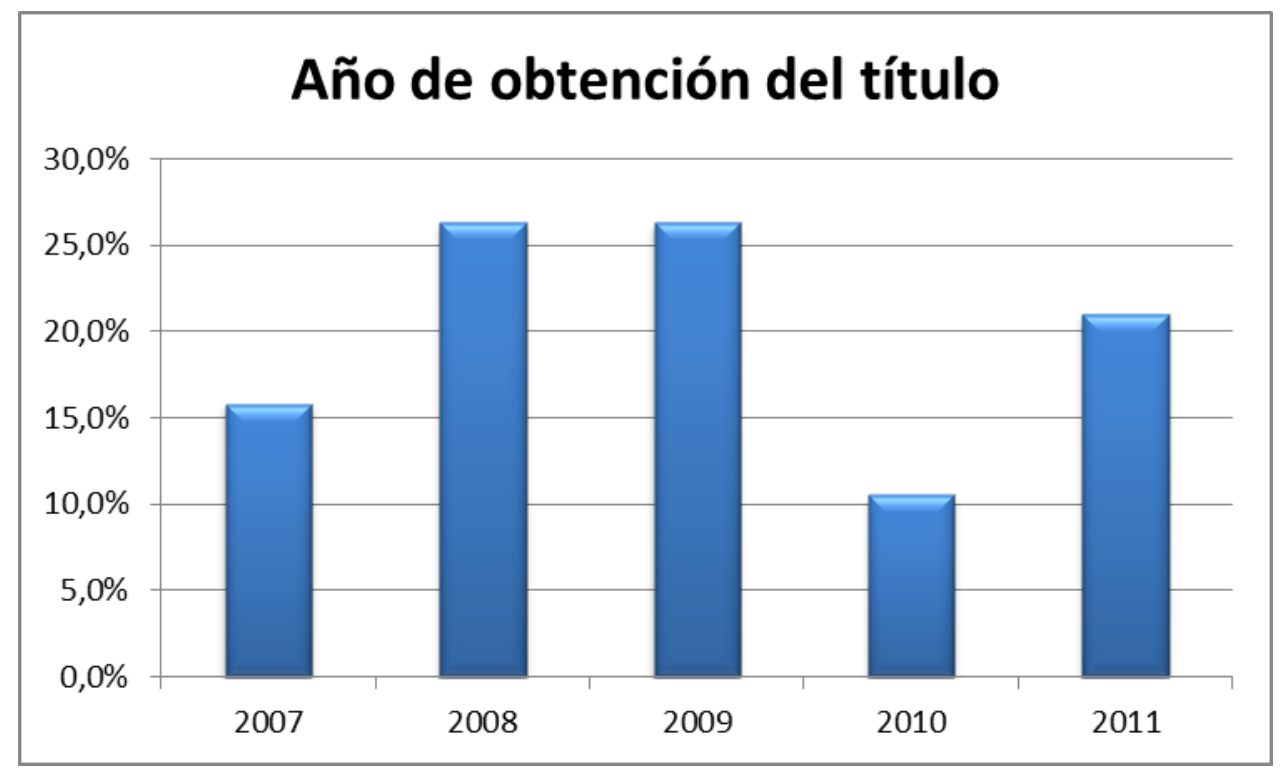

Fuente: Elaboración propia 
Formación continua. Perfeccionamiento y desarrollo profesional

Del total de graduados que componen la muestra un $63 \%$ ha realizado experiencias académicas de perfeccionamiento profesional. De ese segmento de $63 \%$, el $67 \%$ se decidió por la Licenciatura en Enfermería y el 33\% restante por la disciplina de Vacunación.

\section{Perfeccionamiento profesional}

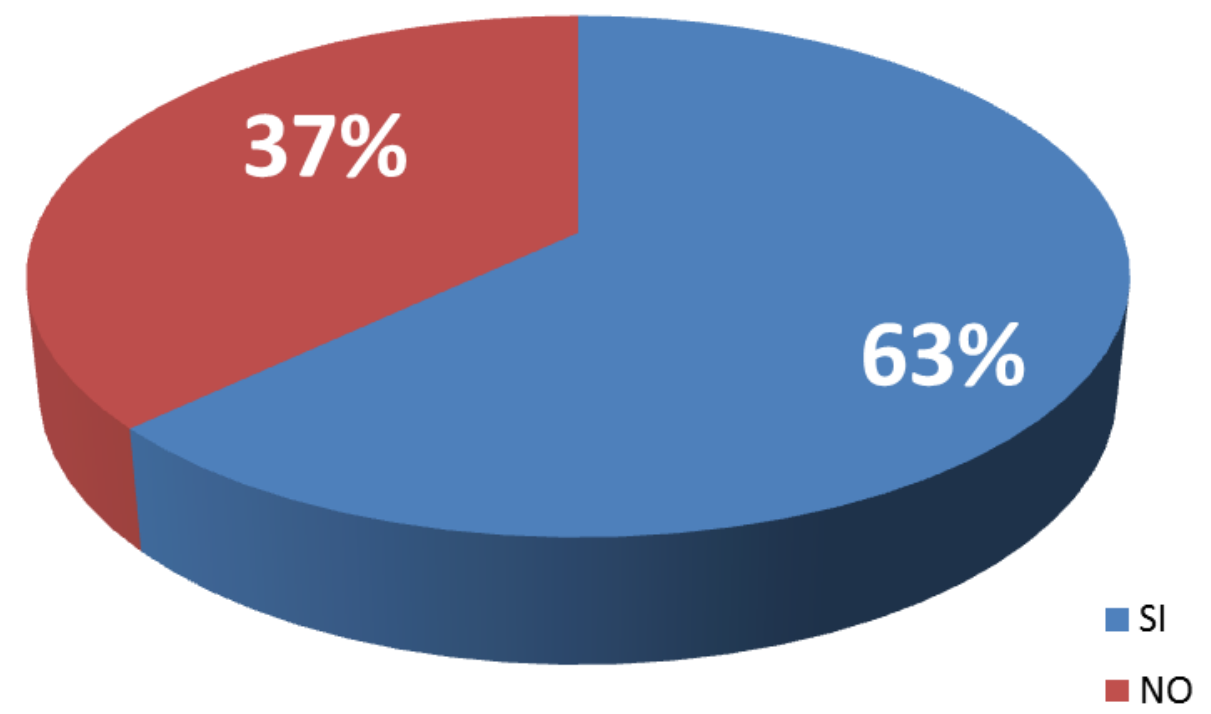

Fuente: Elaboración propia

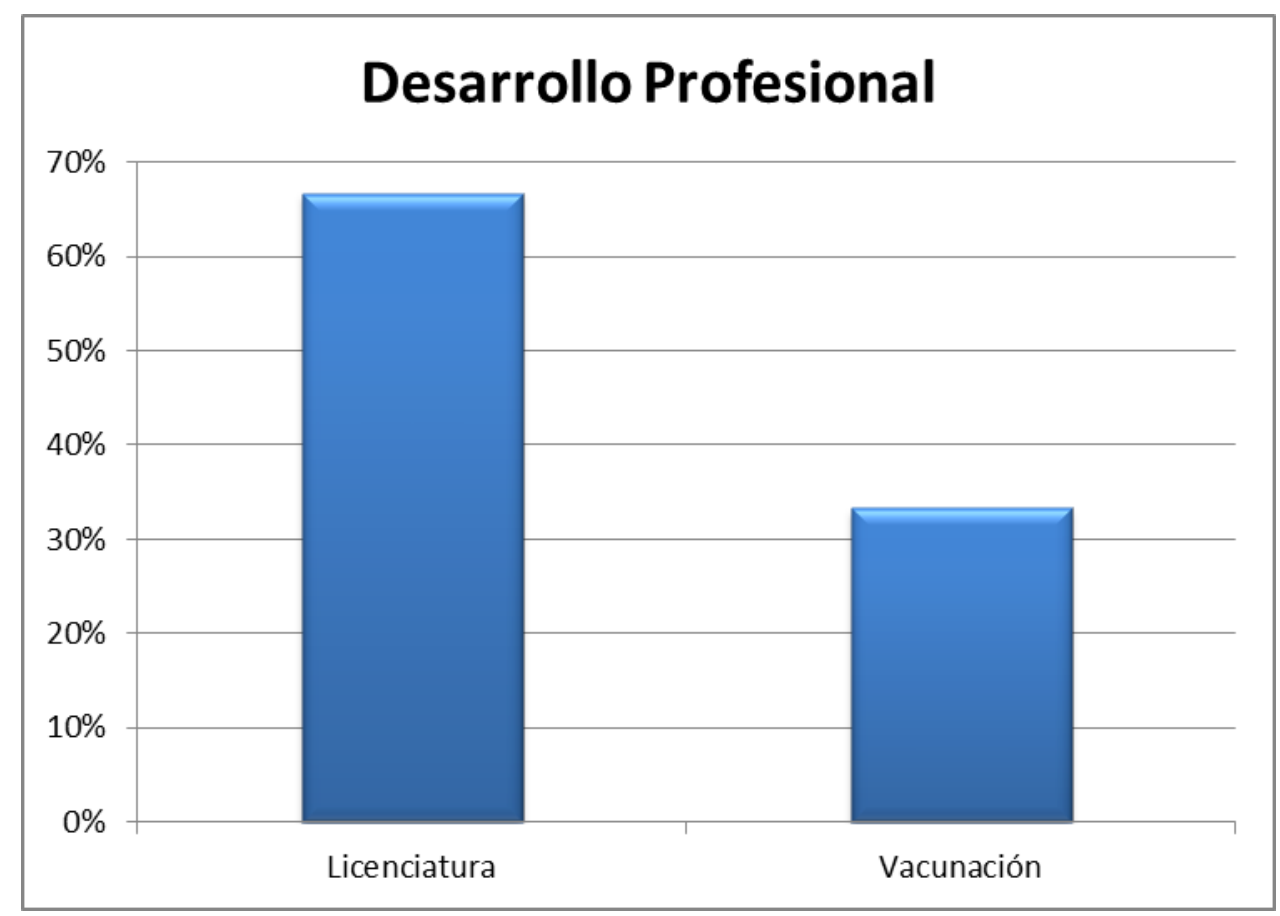

Fuente: Elaboración propia 


\section{Antigüedad en el puesto de trabajo}

Nuevamente presentando los resultados como porcentajes del total de la muestra leído en ordenadas, se puede apreciar que casi la mitad de los graduados tienen cinco o más años en sus puestos de trabajo; un poco más de un cuarto tiene entre dos y tres, y luego complementan la muestra quienes tienen entre tres y cuatro y entre cuatro y cinco años, no existiendo ningún caso para los que registran un año de permanencia en su puesto.

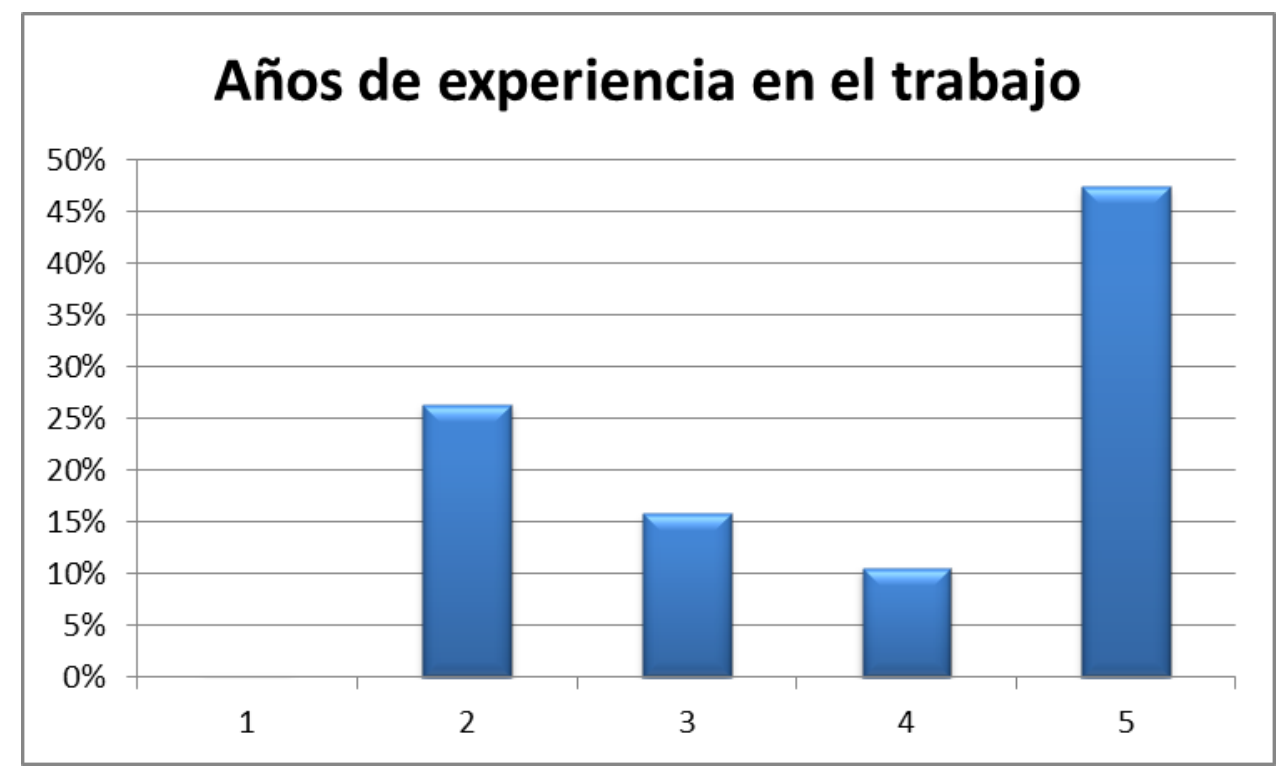

Fuente: Elaboración propia

\section{Capacitación de los graduados}

El $68 \%$ de los graduados que componen la muestra recibió algún tipo de capacitación destinados a perfeccionar o enriquecer sus capacidades profesionales. La capacitación fue casi en su totalidad "breve" en cuanto al tiempo insumido, ya que $84 \%$ de quienes recibieron alguna lo hicieron en experiencias que demandaron menos de 2 meses (46\%) o incluso menos de 24 hs. (38\%). La capacitaciones más prolongadas afectaron sólo al $16 \%$ del total de quienes recibieron capacitación, en experiencias de $8 \%$ cada una para las de entre 2 y 4 meses y más de 4 meses de duración. (gráfico en la página siguiente) 


\section{Son capacitados en el lugar de trabajo}

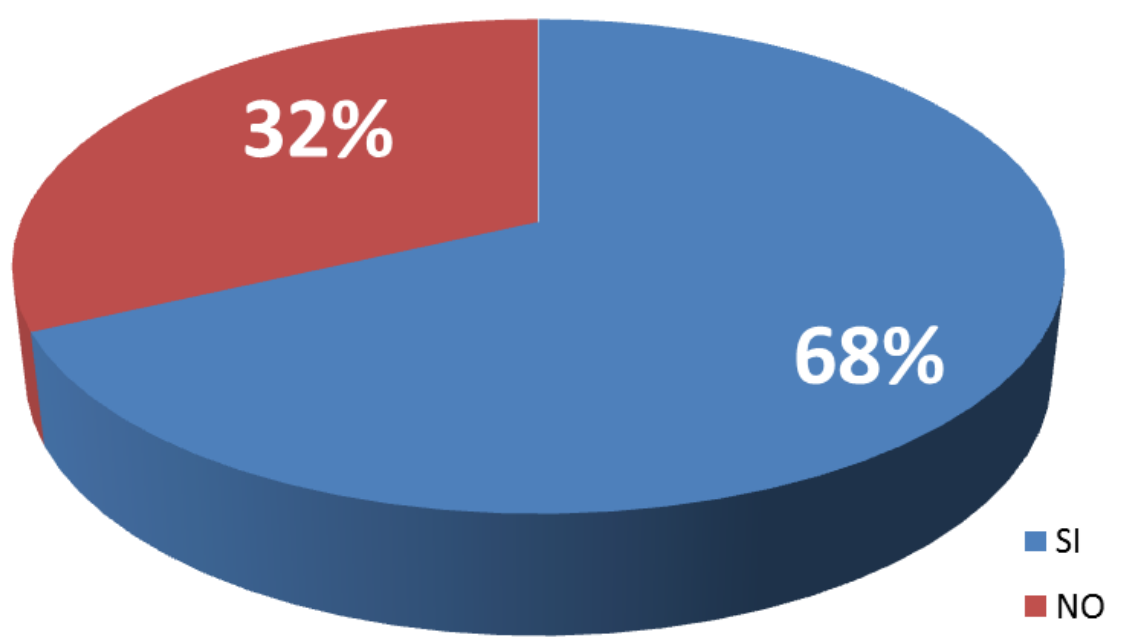

Fuente: Elaboración propia

\section{¿Cuánto duró la capacitación?}

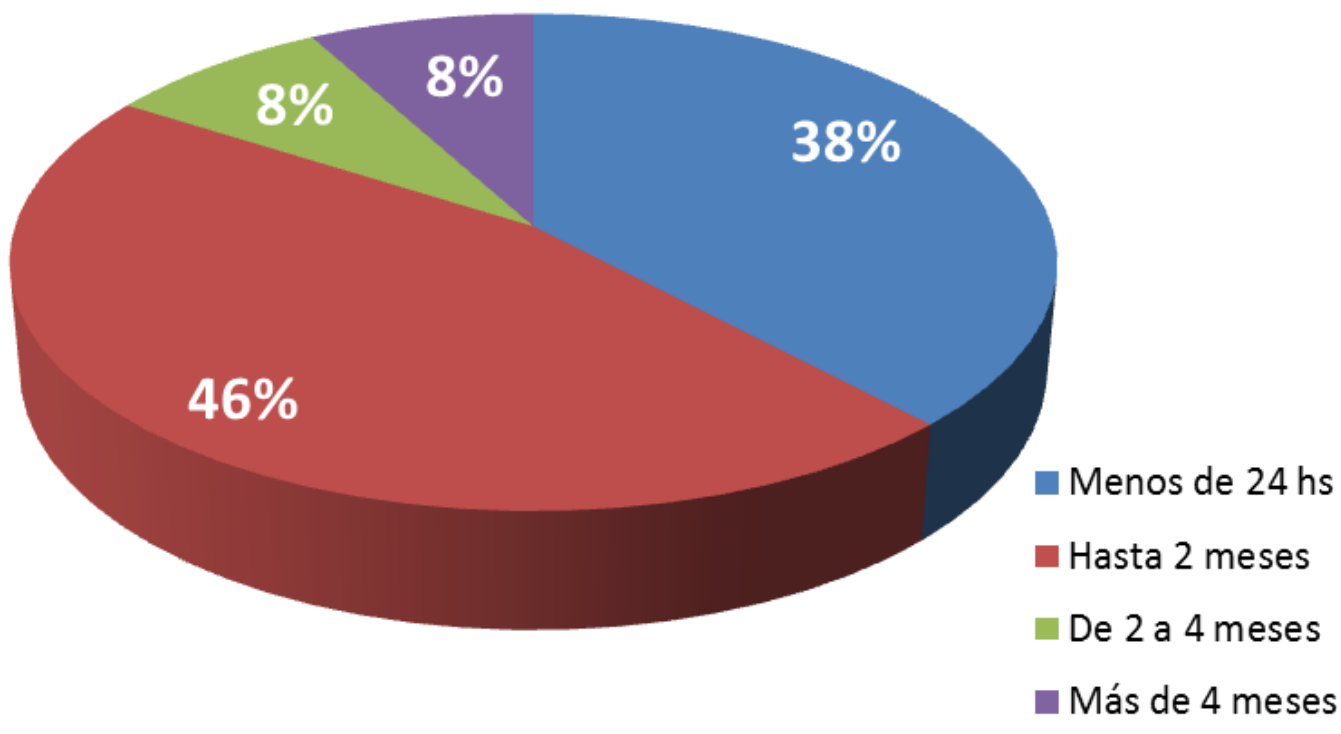

Fuente: Elaboración propia

\subsubsection{Detalle del trabajo del graduado}

El tercer gran agrupado de los datos que fueron relevados por medio de las encuestas brinda información sobre el detalle o la naturaleza del trabajo de 
los graduados, siempre obviamente desde la perspectiva de los empleadores encuestados como parte de la muestra.

\section{Naturaleza del tipo de trabajo del graduado}

En el relevamiento de información se planteaban las opciones de que el tipo de trabajo podía ser de gestión, técnico o de otro tipo, en cuyo caso, éste último, debía especificarse de cuál. Pues bien, los empleadores respondieron en su totalidad que el tipo de trabajo desempeñado por los graduados que tenían a su cargo era exclusivamente de tipo técnico.

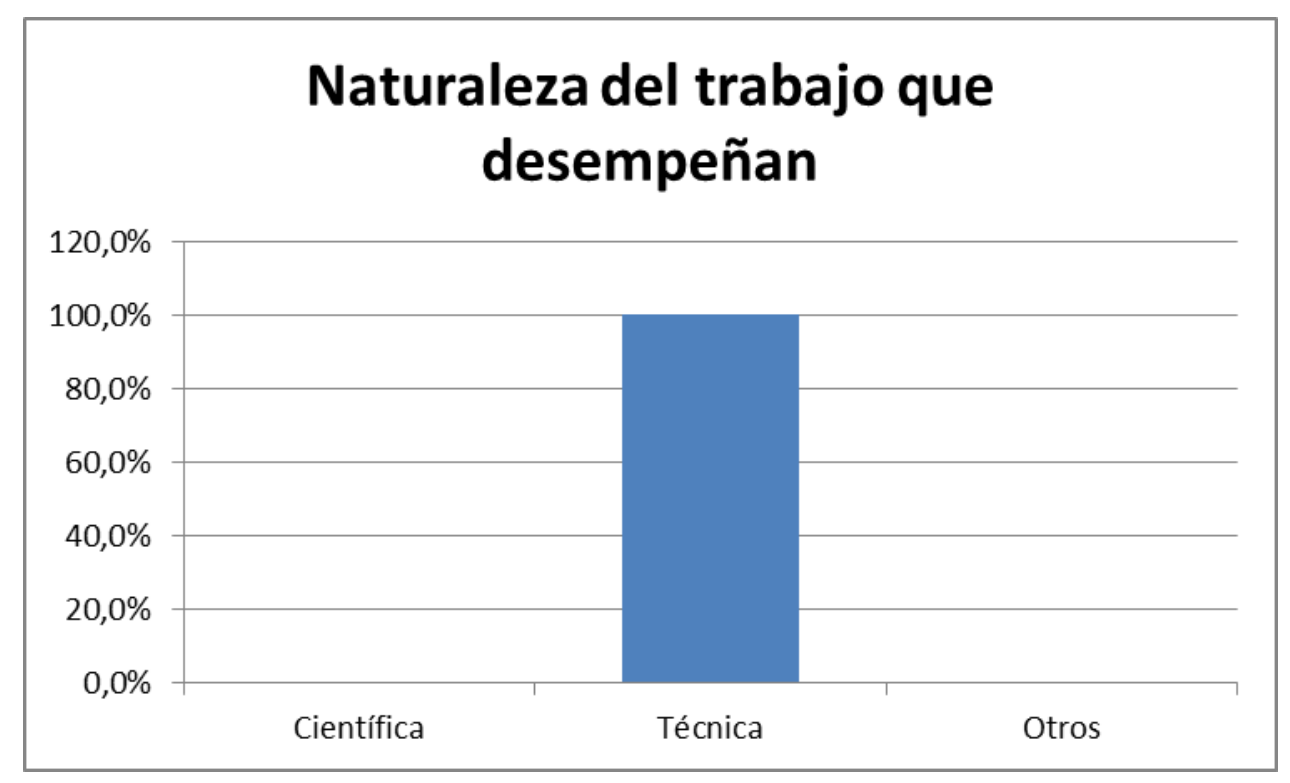

Fuente: Elaboración propia

\section{Tipo de comunicación interna más necesaria en el puesto de trabajo}

También como detalle del trabajo del graduado, se relevó entre los empleadores el tipo de comunicación predominante en la relación jefe/supervisor y empleado. El 79\% manifestó que predomina la comunicación oral, y el porcentaje restante se distribuye en partes iguales entre la comunicación escrita y la más formal de realización de informes, gráficos, etc. (gráfico en la página siguiente) 


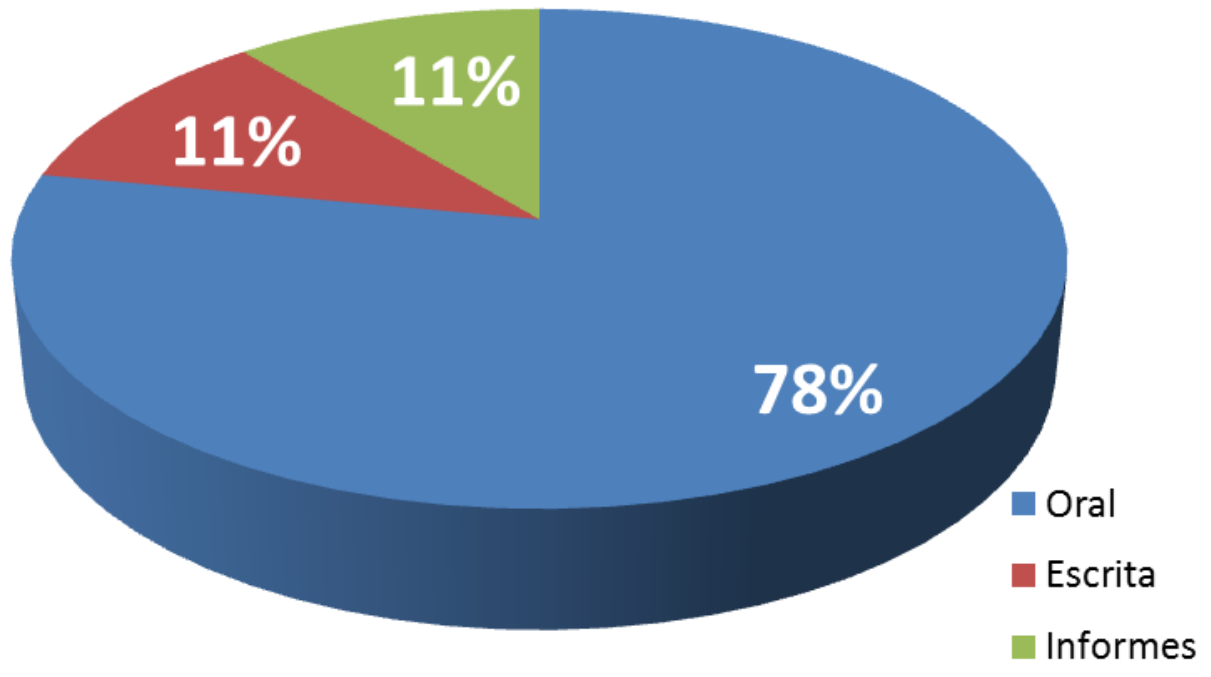

Fuente: Elaboración propia

\subsection{Atributos del graduado. Sus conocimientos, habilidades y actitudes en el puesto de trabajo}

En la evaluación de los atributos del graduado se combina la percepción sobre el desempeño de los mismos en los puestos de trabajo por parte de los empleadores con la expectativa de éstos últimos sobre tal desempeño, respondiendo a la lógica de evaluación de los graduados en Enfermería desde la perspectiva de quienes son sus empleadores.

Para cada uno de los atributos de los egresados se releva la información en los empleadores solicitándoles que evalúen la percepción que tienen sobre el desempeño de aquellos en base a las siguientes opciones; es decir, en base a su percepción de desempeño respondiendo si están:

$\begin{array}{ll}\checkmark & \text { Muy de acuerdo } \\ \checkmark & \text { De acuerdo } \\ \checkmark & \text { No está seguro } \\ \checkmark & \text { En desacuerdo } \\ \checkmark & \text { Totalmente en desacuerdo }\end{array}$


Obtenidos los valores correspondientes a la percepción de desempeño de los graduados en Enfermería, se obtienen las mediciones sobre las expectativas de los empleadores respecto de cada uno de los atributos. Esto es, los empleadores determinan el grado de significancia que les otorgan a los distintos atributos, en base a juzgarlos más o menos significativos de acuerdo a la siguiente escala:

$\begin{array}{ll}\checkmark & \text { Altamente significativo } \\ \checkmark & \text { Bastante más que significativo } \\ \checkmark & \text { Significativo } \\ \checkmark & \text { Muy poco significativo } \\ \checkmark & \text { Insignificante. }\end{array}$

En pocas palabras, se mide tanto la percepción de los empleadores sobre el desempeño de los graduados en cada uno de los atributos medidos, como la ponderación o significancia que aquellos le otorgan a cada atributo. Pueden darse entonces combinaciones de percepción de alto o bajo desempeño sobre atributos muy o poco calificados como relevantes. Las combinaciones posibles entre percepción de desempeño y expectativas de significancia es los que determina las coincidencias o la generación de brechas entre ambas dimensiones en que sustenta la medición.

A modo de ejemplo, un empleador puede sentirse en desacuerdo el evaluar el desempeño respecto de algún atributo en particular, pero la consecuencia no será relevante en la medida en que sobre ese atributo la expectativa sea de baja ponderación. Por el contrario, la consecuencia puede ser mayor si el desempeño es un poco mejor pero aún insuficiente, y se registra sobre un atributo altamente significativo. Sobre combinaciones como estas ejemplificadas se sustenta el análisis de detalle que se presenta a continuación.

Antes de eso, una breve digresión sobre la forma en que se presentan y deben interpretarse los resultados: Para facilitar la lectura de los gráficos, se decidió unificar las escalas de percepción y expectativa, quedando la escala del 
eje de las abscisas con los siguientes puntos discretos (el primero mencionado, el más cercano al origen del plano):

$\checkmark \quad$ Muy de acuerdo - Altamente significativo

$\checkmark \quad$ De acuerdo - Bastante más que significativo.

$\checkmark \quad$ No está seguro - Significativo

$\checkmark \quad$ En desacuerdo - Muy poco significativo

$\checkmark \quad$ Totalmente en desacuerdo - Insignificante

Esta combinación entre valores posibles que pueden tomar las dimensiones percepción y expectativa presentan los resultados respecto de los atributos en forma unificada y más simple de cara a extraer conclusiones de los mismos. Surgen entonces la posibilidad de observar en un mismo plano los puntos de coincidencia o la generación de brechas entre las dos dimensiones para cada uno de los atributos.

\subsubsection{Evaluación de conocimientos}

Dentro de Evaluación de conocimientos se evalúan ocho cuestiones relacionadas con el aprendizaje conceptual recibido por los graduados en su formación terciaria y cómo es que lo expresan en las situaciones concretas que les exige en el desempeño de sus puestos de trabajo. Se refiere a cuestiones conceptuales como principios básicos de la carrera, sus fundamentos, sus procedimientos técnicos, identificación de problemas, comprensión de leyes y reglamentaciones que hacen a su regulación, de los principios de gestión del negocio de las ciencias médicas, entendimiento de disciplinas relacionadas y comprensión de las implicancias y consecuencias económicas asociadas a las actividades inherentes al desempeño de la enfermería.

Tanto para la evaluación de conocimientos como para los restantes atributos (habilidades y actitudes), los resultados se presentan con el detalle de la medición de expectativas y percepción y determinación de brechas de cada cuestión analizada, con un resultado "resumen" para cada una de ellas describiendo los saldos de respuesta. 


\subsubsection{Principios básicos y conceptos relacionados con la carrera de} Enfermería

\section{Expectativas y percepción}

Se les preguntó a los encuestados acerca de la percepción que tienen sobre los graduados en lo que refiere al entendimiento de los principios básicos y conceptos relacionados con la carrera de Enfermería, y cuan significante es este tema para ellos.

El $100 \%$ de los encuestados cree que es bastante más que significativo o altamente significativo, y el $95 \%$ está de acuerdo y muy de acuerdo con que el graduado comprende esos principios. Sólo el 5\% no está seguro de que así sea.

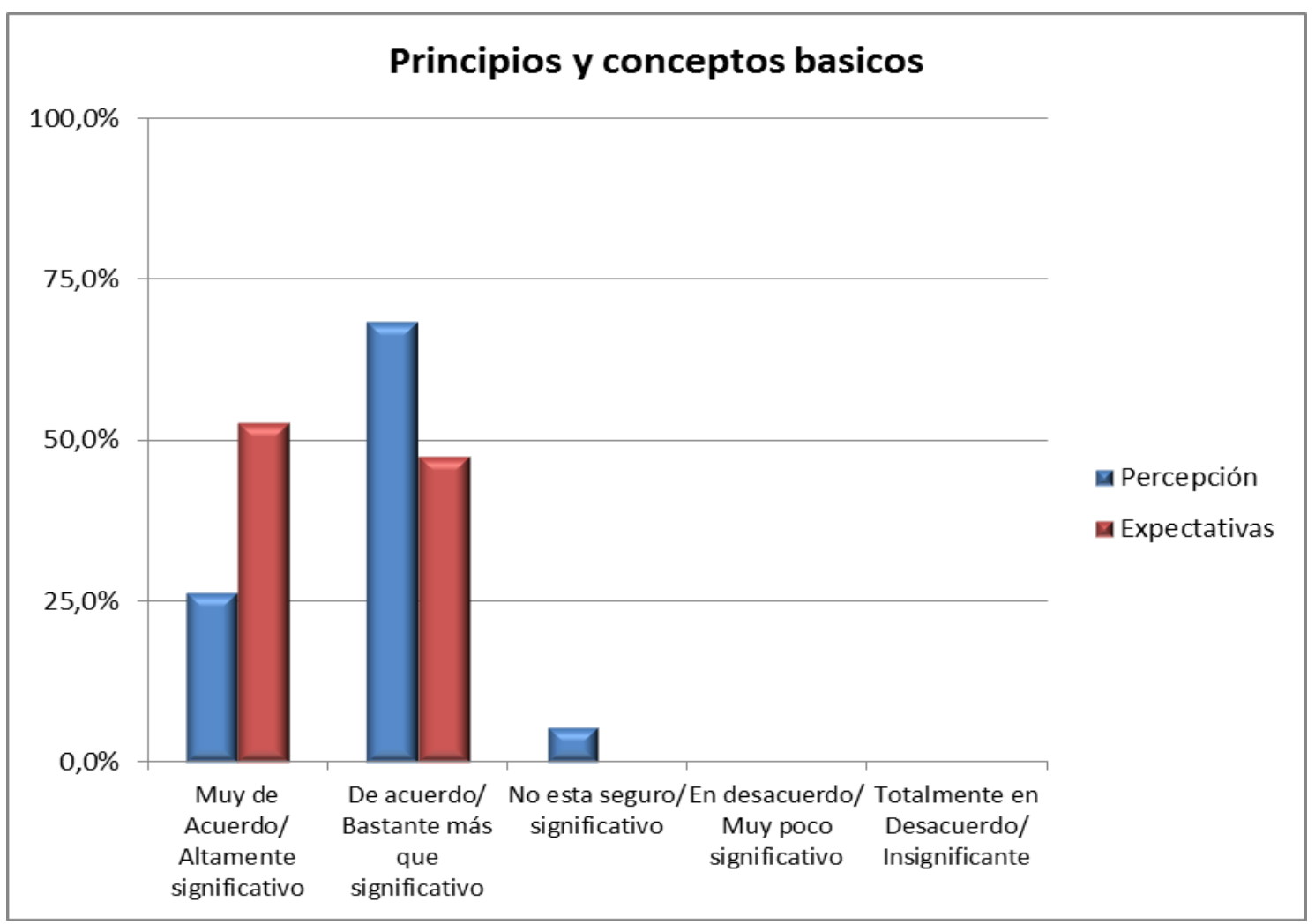

Teniendo en cuenta el orden de las alternativa: Fuente: Elaboración propia. opción muy de acuerdo la primera alternativa (1) y totalmente en desacuerdo la quinta (5), los encuestados están de acuerdo a muy de acuerdo sobre el 
entendimiento de los graduados sobre esta temática, ubicando su percepción según el saldo de respuesta en 1,79.

Del mismo modo y siendo la opción altamente significativo la primera alternativa (1) e insignificante la quinta (5), el saldo de respuesta, 1,53, sobre la expectativa, indica que los encuestados creen que es muy significativo que el graduado comprenda esto.

\section{Brechas}

En el siguiente gráfico se puede apreciar la expectativa versus la percepción de los encuestados.

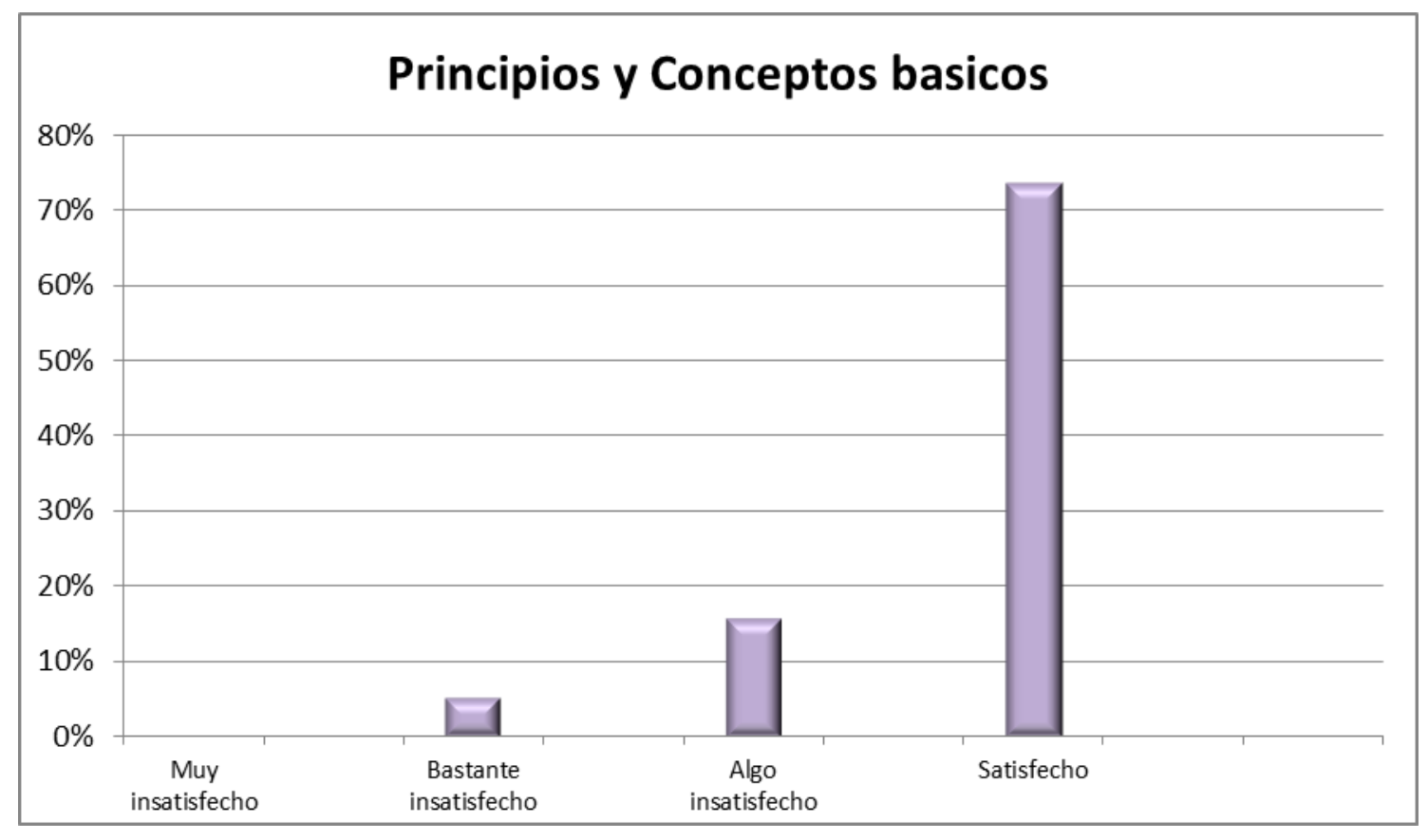

Fuente: Elaboración propia.

Como se ve casi el $75 \%$ de los encuestados está satisfecho, un $16 \%$ algo insatisfecho y sólo un 5\% bastante insatisfecho.

En la escala en que -4 es insatisfacción total y 4 satisfacción total, se obtiene un saldo de respuesta de $-0,26$, lo que representa satisfacción por parte de los encuestados. 
7.2.1.2 Fundamentos económicos relacionados con la carrera de Enfermería

\section{Expectativas y percepción}

El $100 \%$ de los encuestados cree que es bastante más significativo y altamente significativo que el graduado comprenda los fundamentos económicos relacionados con su carrera. Por otro lado, la mitad de ellos no están seguros que los graduados lo comprendan.

El saldo de respuesta sobre la expectativa, 1.53, indica que los encuestados creen que es totalmente significativo conocer los fundamentos económicos. Y el saldo de respuesta de su percepción, 2.26, refleja que están de acuerdo pero no tan seguros que los graduados lo comprendan.

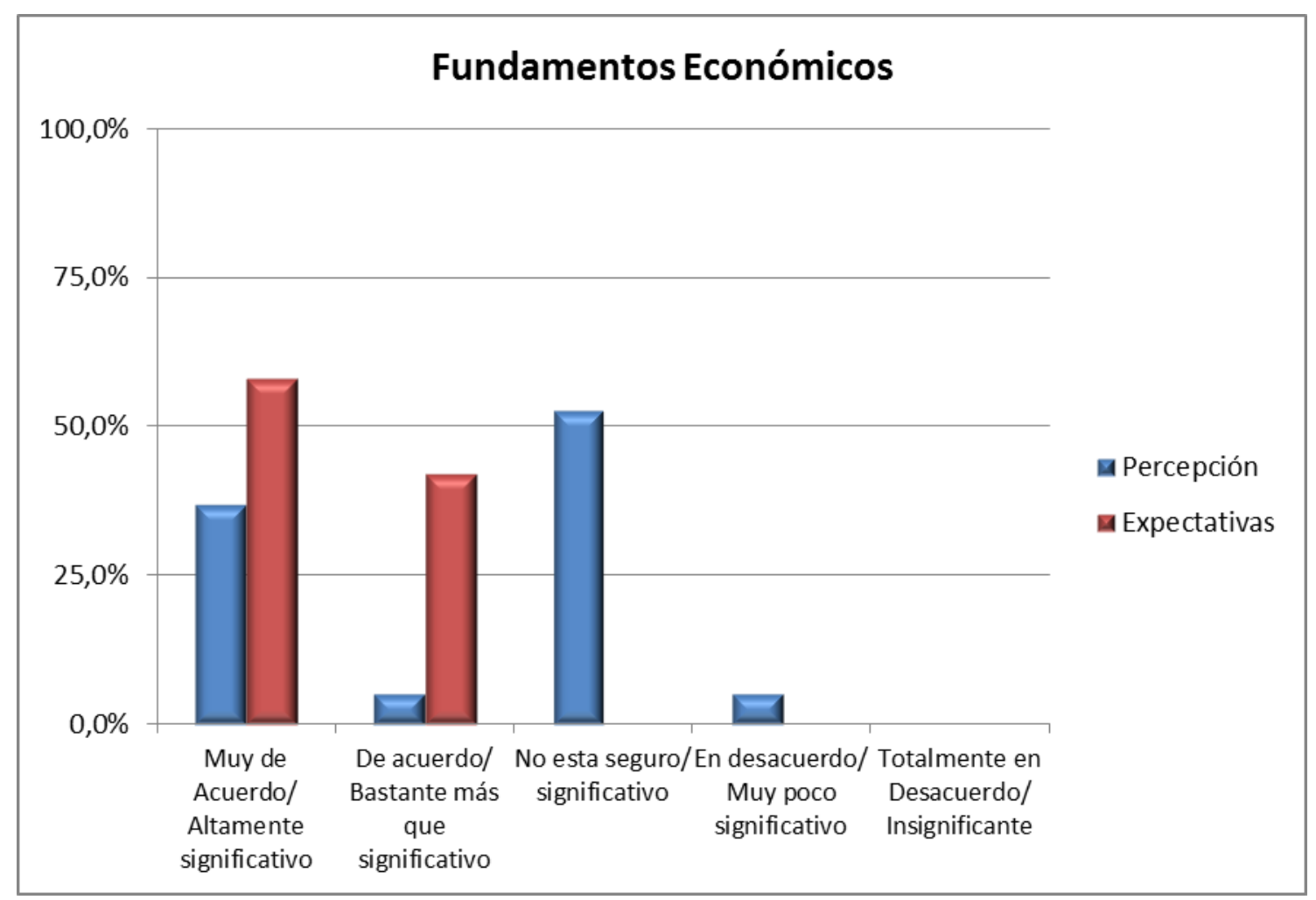

Fuente: Elaboración propia. 


\section{Brechas}

Poco más del $40 \%$ de los encuestados está satisfecho y el $53 \%$ algo insatisfecho, mientras que sólo el $5 \%$ se siente bastante insatisfecho sobre el entendimiento de los fundamentos económicos del graduado en Enfermería.

El saldo de respuesta de $-0,74$ representa la satisfacción de los encuestados, pero con un acercamiento a estar algo insatisfechos.

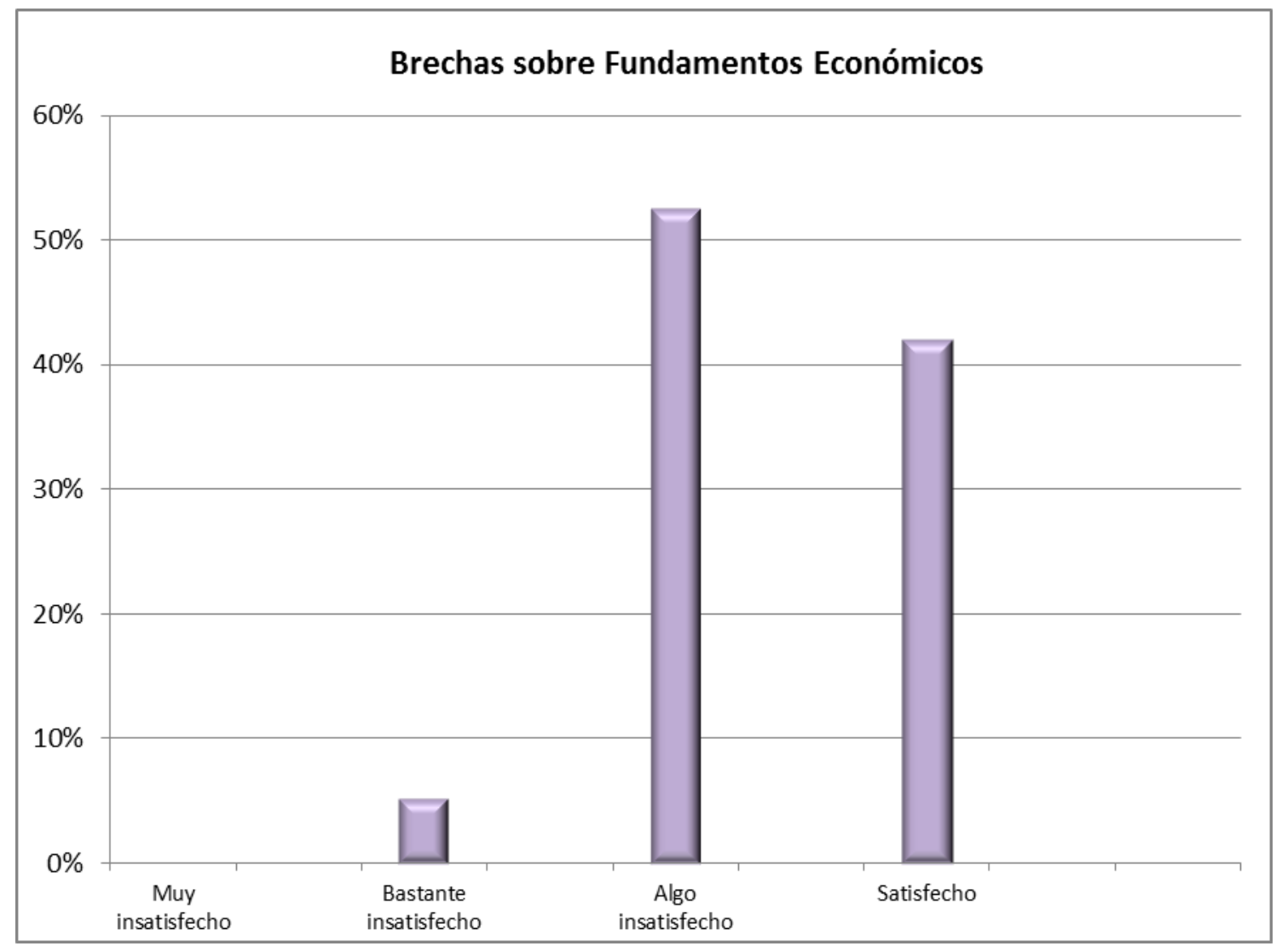

Fuente: Elaboración propia.

\subsubsection{Profundidad en los conocimientos técnicos relacionados con}

\section{Enfermería}

Expectativas y percepción

El $95 \%$ de los encuestados cree que es altamente significativo que el graduado entienda con profundidad los procedimientos técnicos relacionados con enfermería, y sólo el $5 \%$ lo ve más que significativo. 
A su vez, el $79 \%$ está de acuerdo con que el graduado comprende esos principios mientras que el restante $21 \%$ no está seguro que así sea.

El saldo de respuesta sobre la expectativa, 1,39, indica que los encuestados consideran totalmente significativo entender en profundidad los procedimientos técnicos de enfermería. Y el saldo de respuesta de su percepción, 1,84, refleja que están de acuerdo con que los graduados lo comprenden.

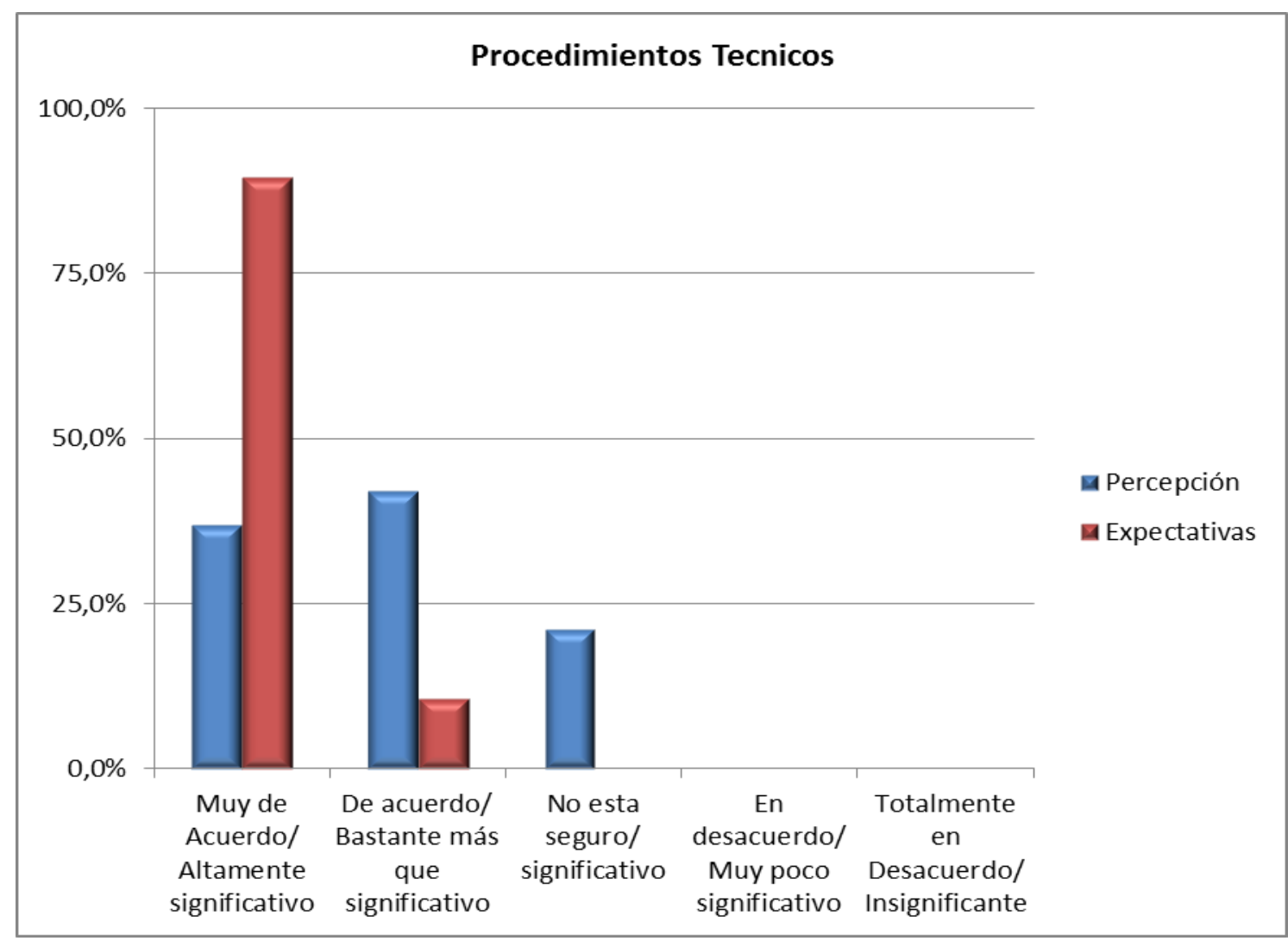

Brechas

Fuente: Elaboración propia.

Casi el $75 \%$ de los encuestados está satisfecho y el restante $26 \%$ algo insatisfecho con la relación de la importancia que le dan a los procedimientos técnicos y la comprensión que tienen los graduados del tema.

El saldo de respuesta de $-0,45$ demuestra la satisfacción de los encuestados.

(gráfico en la página siguiente) 


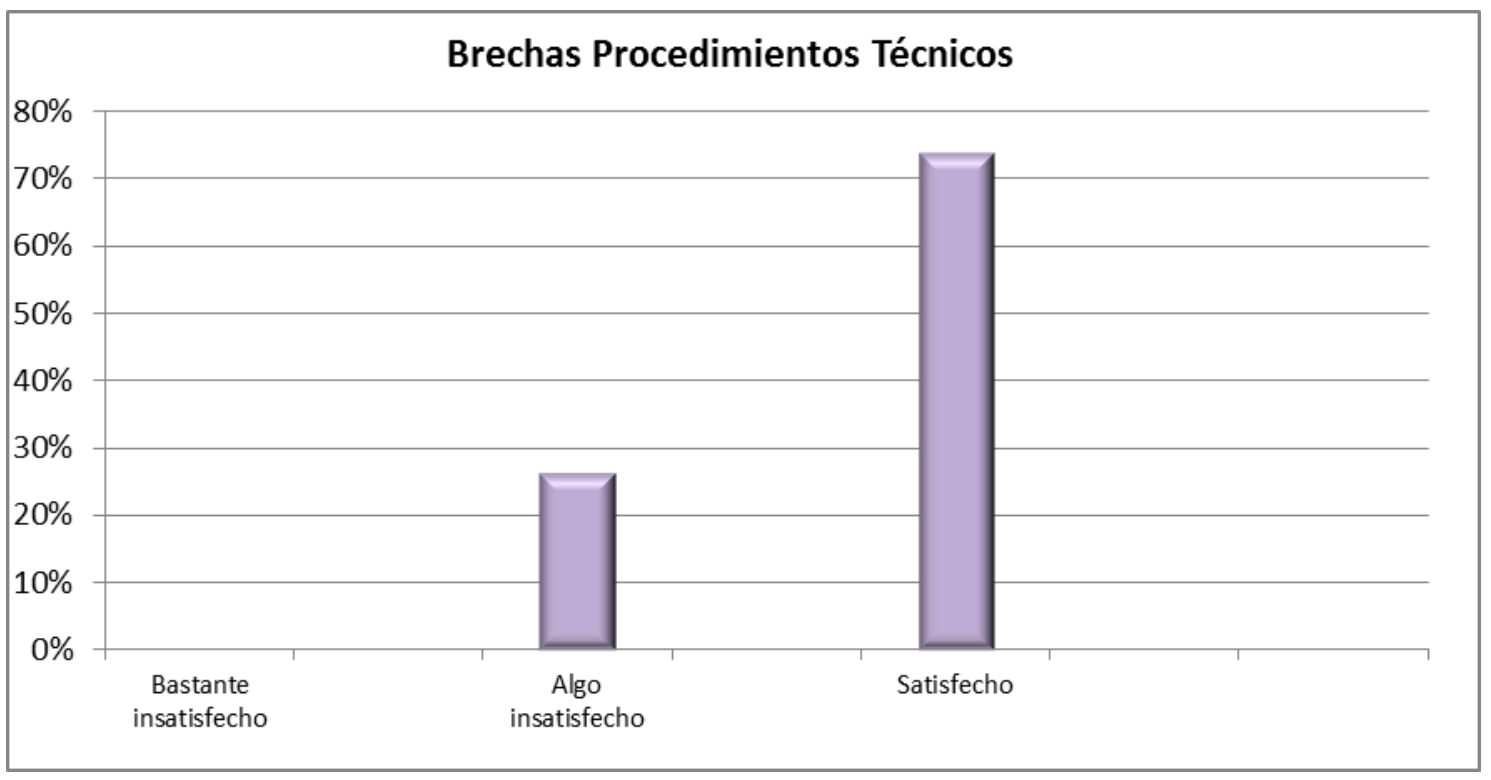

Fuente: Elaboración propia.

7.2.1.4 Identificación de problemas, formulación y desarrollo de soluciones asociadas a la carrera de Enfermería

Expectativas y percepción

El $100 \%$ de los encuestados cree que es entre bastante más significativo $\mathrm{y}$ altamente significativo que el graduado identifique problemas y formule $\mathrm{y}$ desarrolle las soluciones asociadas a su carrera. A su vez, el $84 \%$ de ellos lo comprende y sólo el $16 \%$ restante no está seguro que así sea.

El saldo de respuesta sobre la expectativa, 1,42, indica que los encuestados creen que es totalmente significativo que el graduado identifique problemas y formule y desarrolle las soluciones. Y el saldo de respuesta de su percepción, 1,84 , refleja que están de acuerdo con una leve acercamiento a no estar seguros que los graduados lo comprendan.

(gráfico en la página siguiente) 


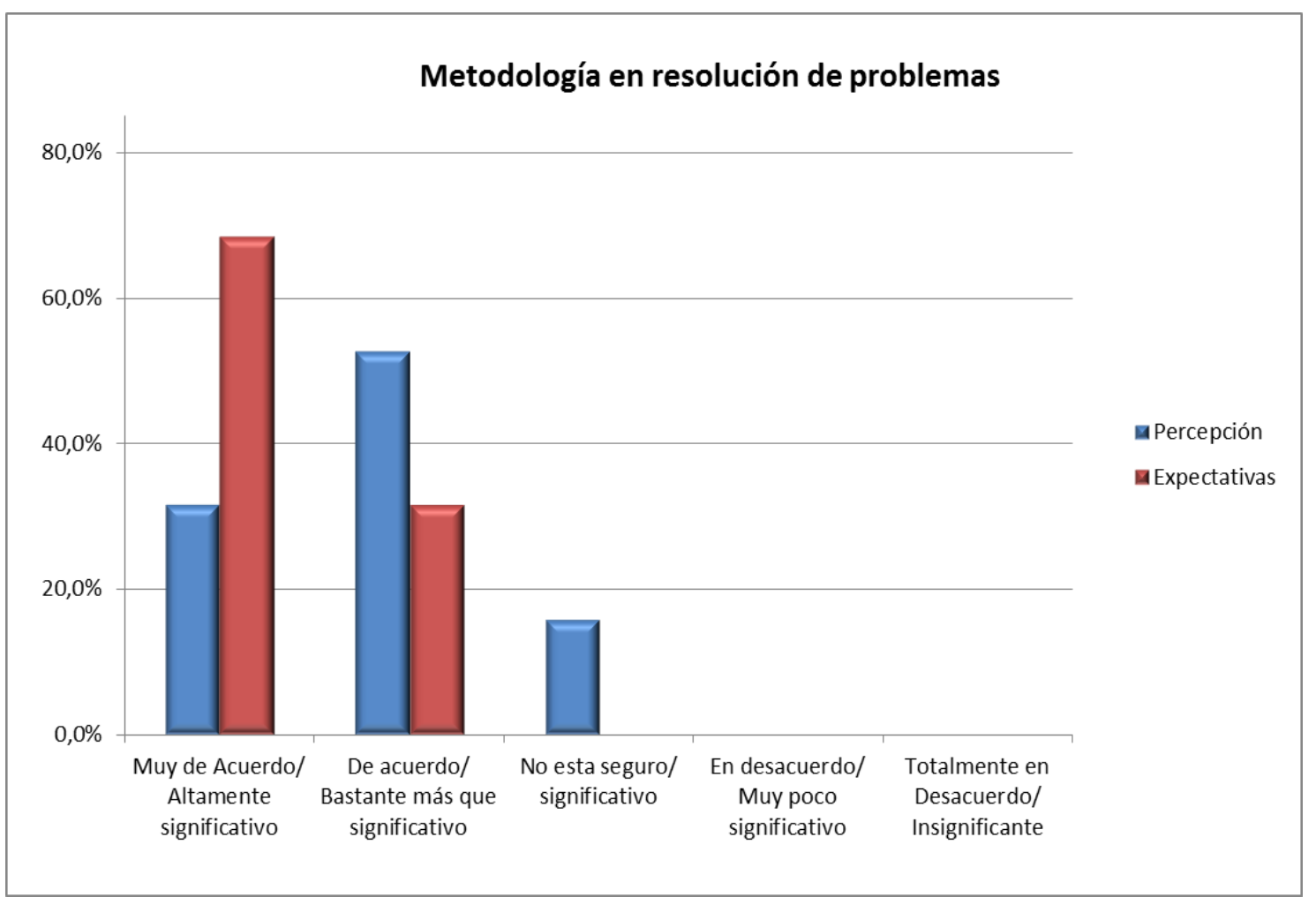

Fuente: Elaboración propia.

\section{Brechas}

El 95\% de los encuestados está entre satisfecho y algo insatisfecho con esta relación, mientras que sólo el $5 \%$ está algo más que satisfecho.

El saldo de respuesta de $-0,42$ demuestra la satisfacción de los encuestados.

(gráfico en la página siguiente) 


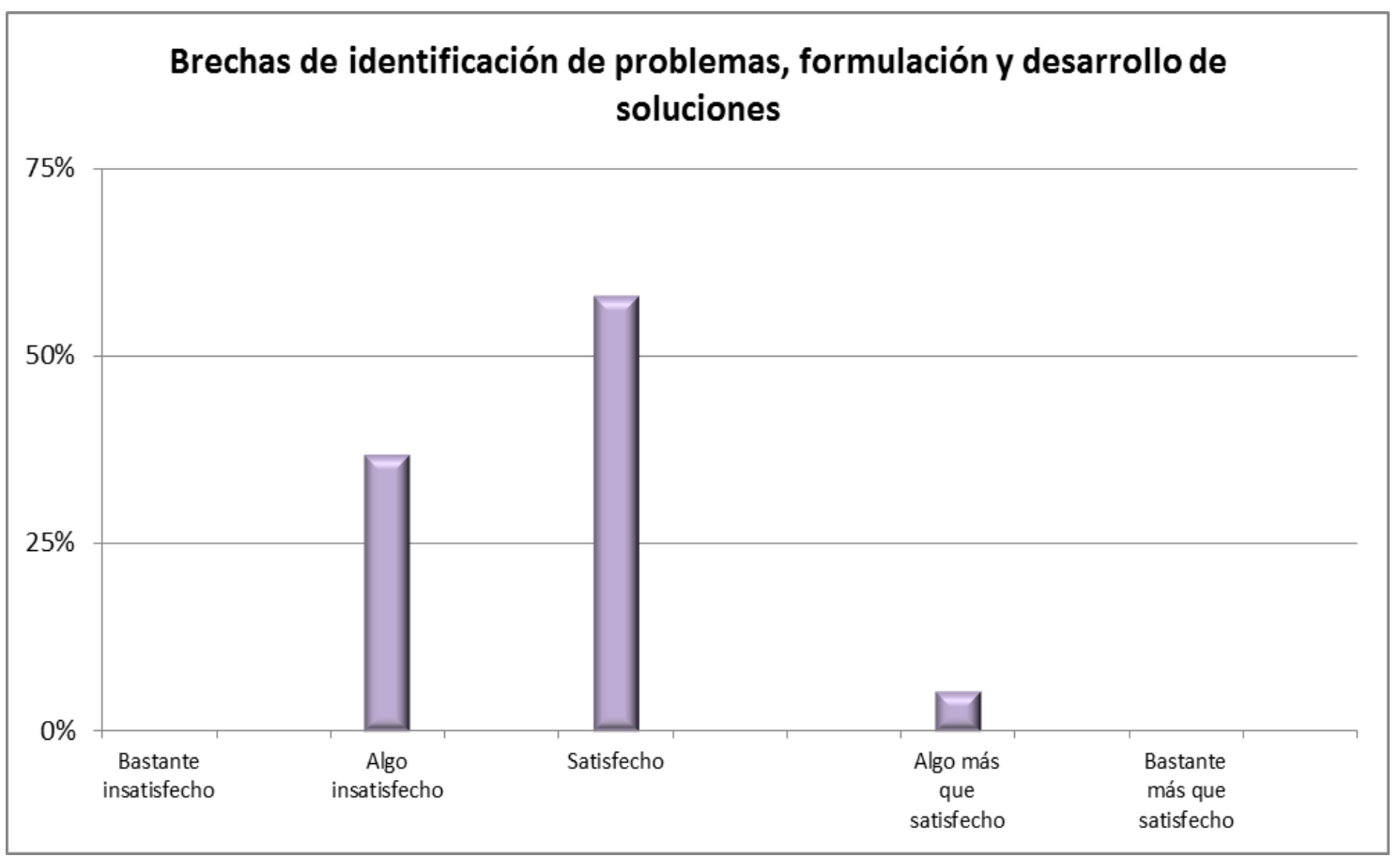

Fuente: Elaboración propia.

\subsubsection{Leyes, reglamentos y normas relacionadas a la carrera de Enfermería}

\section{Expectativas y percepción}

Para el $85 \%$ de los encuestados es altamente significativo que el graduado comprenda las leyes, reglamentos y normas asociadas a la carrera de Enfermería, y el $15 \%$ restante lo ve bastante más que significativo. A su vez, el $63 \%$ está entre muy de acuerdo y de acuerdo en que esto suceda, el $31 \%$ no está seguro y poco más del $5 \%$ está en desacuerdo con que los graduados lo comprenden

El saldo de respuesta sobre la expectativa, 1,39, indica que los encuestados creen que es totalmente significativo que el graduado comprenda estas leyes, reglamentos y normas. Y el saldo de respuesta de su percepción, 2,05 , denota que están de acuerdo con un leve acercamiento a no estar seguros que los graduados lo comprendan.

(gráfico en la página siguiente) 


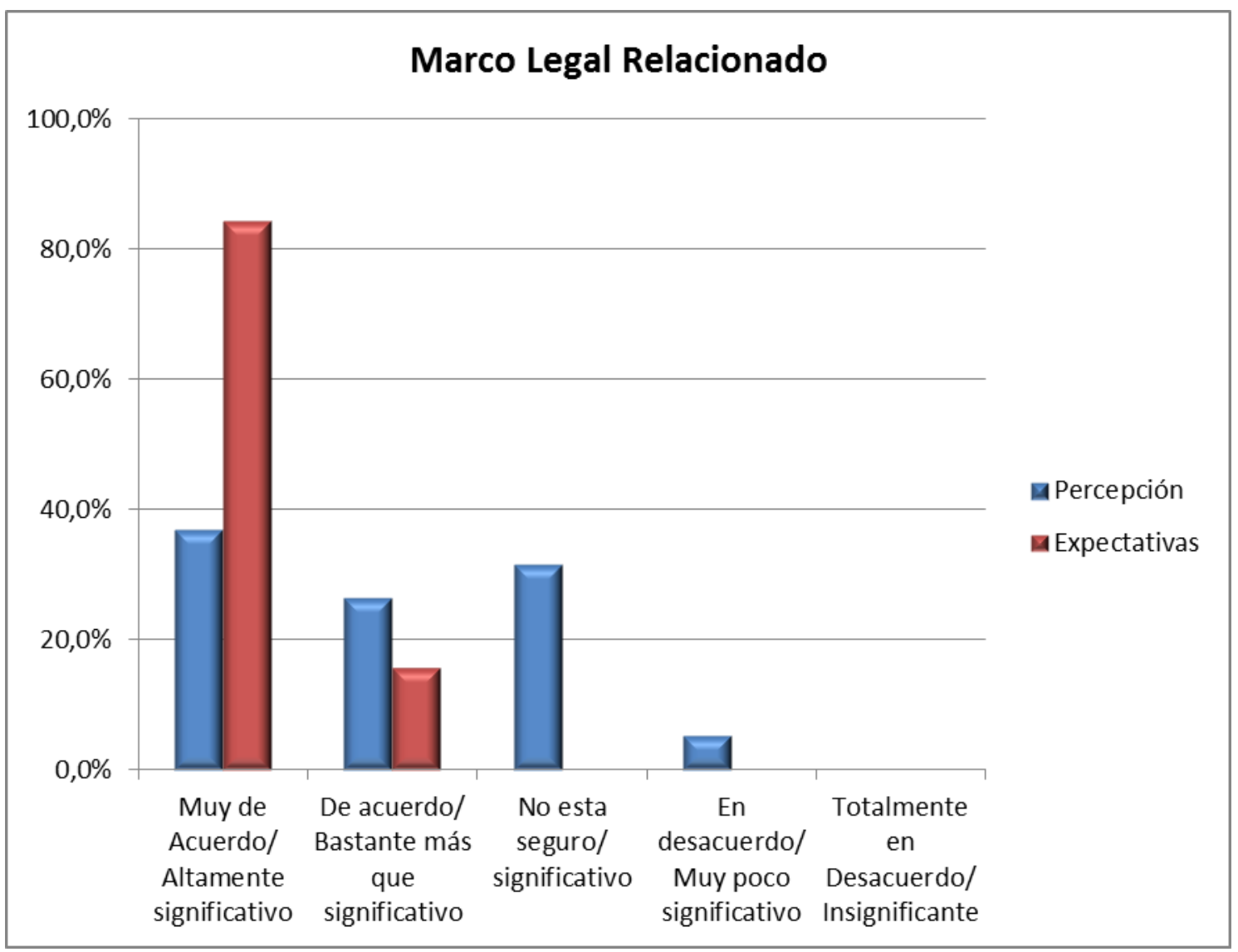

Fuente: Elaboración propia.

\section{Brechas}

El $63 \%$ de los encuestados está satisfecho, el $26 \%$ algo insatisfecho y el $11 \%$ restante entre bastante y muy insatisfecho con la relación que pretenden sobre el entendimiento de las leyes, reglamentos y normas asociadas a la carrera de Enfermería y la comprensión que tiene el graduado al respecto.

El saldo de respuesta de $-0,66$, muestra que los encuestados están entre satisfechos y algo insatisfechos en este tema.

(gráfico en la página siguiente) 


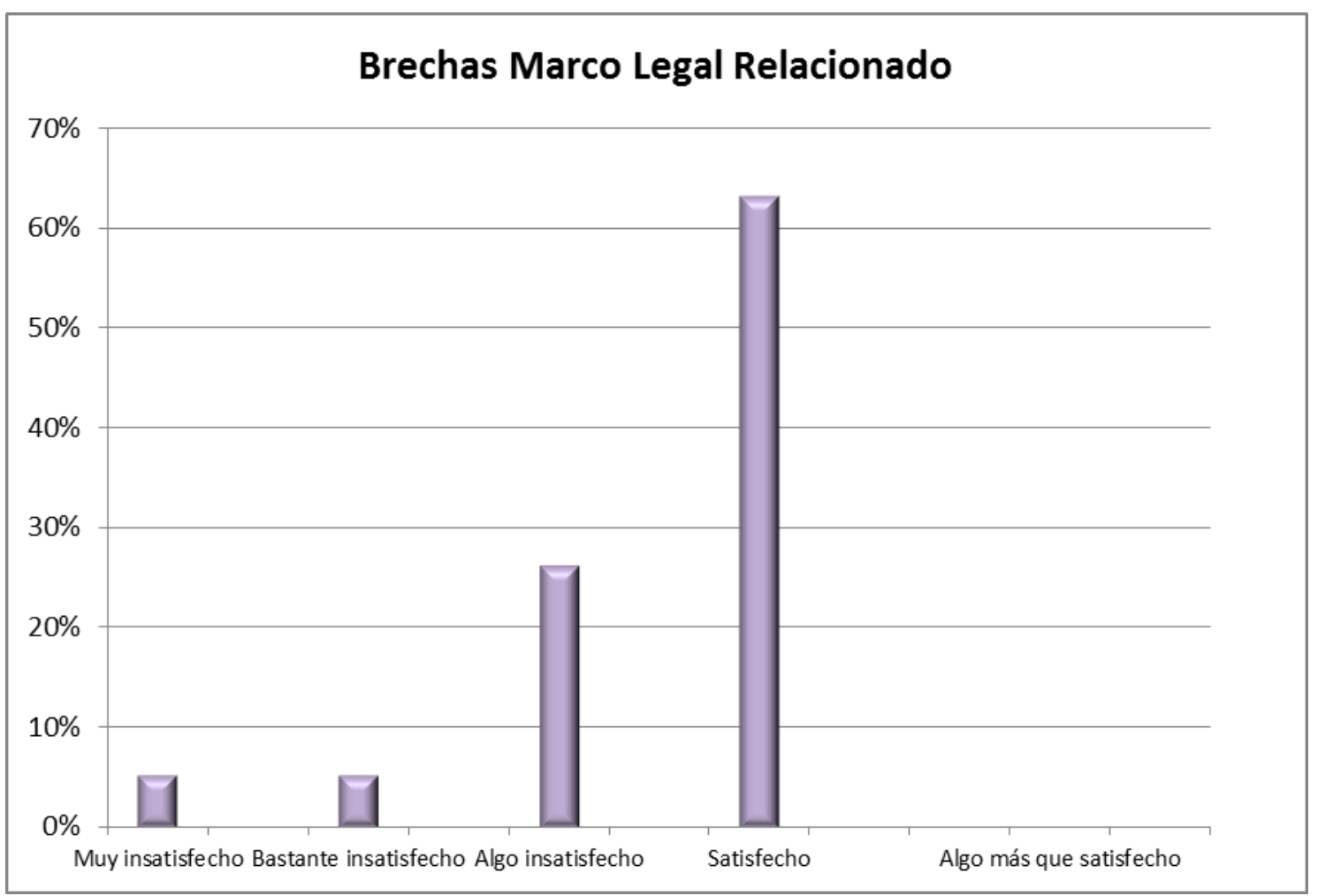

Fuente: Elaboración propia.

\subsubsection{Principios de gestión y negocios relacionados con la Enfermería}

Expectativas y percepción

El $100 \%$ de los encuestados cree que es altamente significativo o bastante más que significativo que el graduado comprenda los principios de gestión y negocios relacionados a la carrera de Enfermería, mientras que poco más del $31 \%$ está muy de acuerdo que el graduado los comprende, el $42 \%$ de acuerdo, el $16 \%$ no está seguro y el restante $10.5 \%$ en desacuerdo de ello.

El saldo de respuesta sobre la expectativa de 1,55 indica que los encuestados creen que es totalmente significativo con tendencia a ser bastante más que significativo que el graduado comprenda estos principios. Y el saldo de respuesta de su percepción, 2,05, denota que están de acuerdo con un leve acercamiento a no estar seguros que los graduados lo comprendan. (gráfico en la página siguiente) 


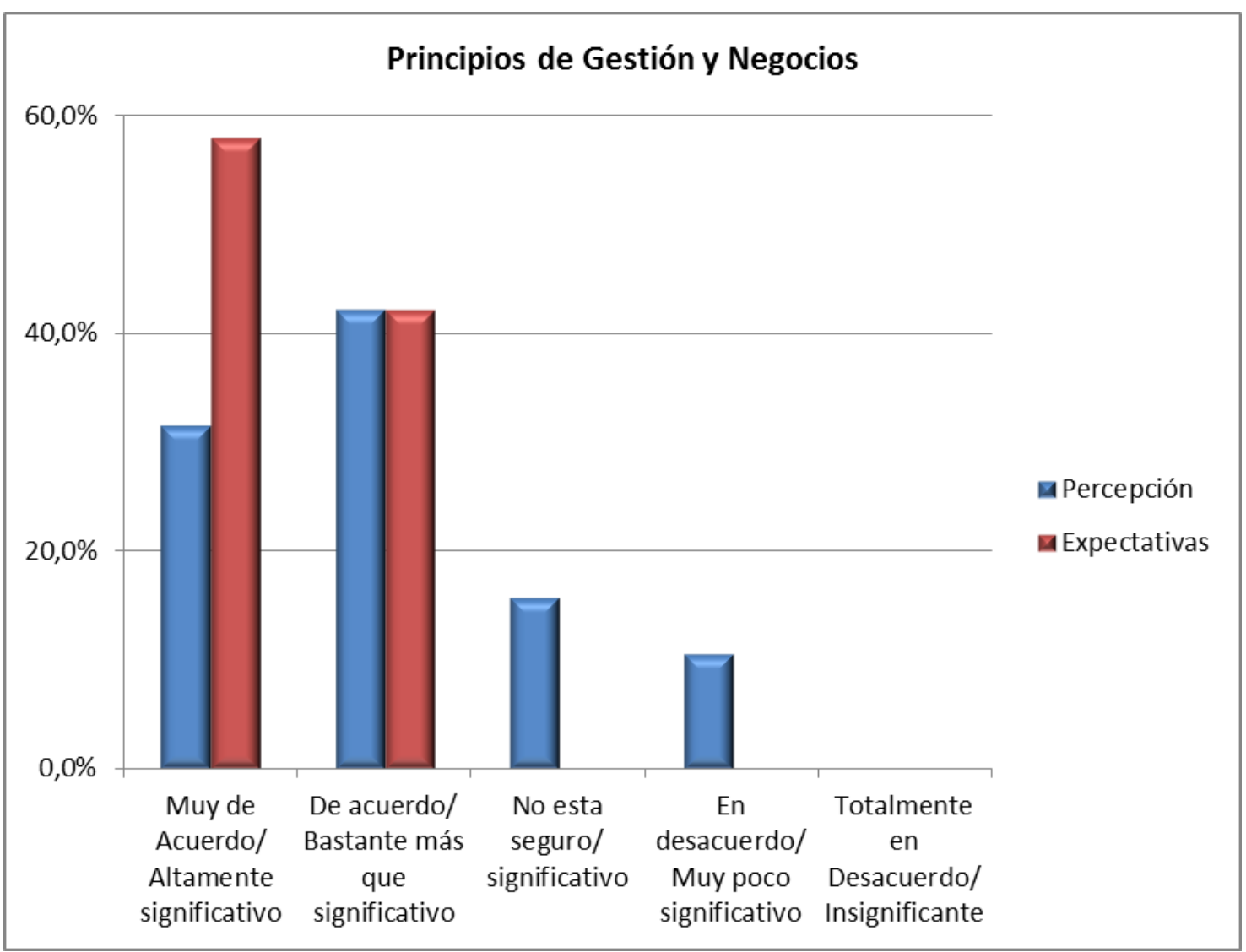

Fuente: Elaboración propia.

\section{Brechas}

El $63 \%$ de los encuestados está satisfecho, el 32\% entre algo insatisfecho y bastante insatisfecho con esta relación, mientras que sólo el 5\% está algo más que satisfecho.

El saldo de respuesta de $-0,50$ demuestra la satisfacción de los encuestados, con una leve tendencia a estar algo insatisfechos.

(gráfico en la página siguiente) 


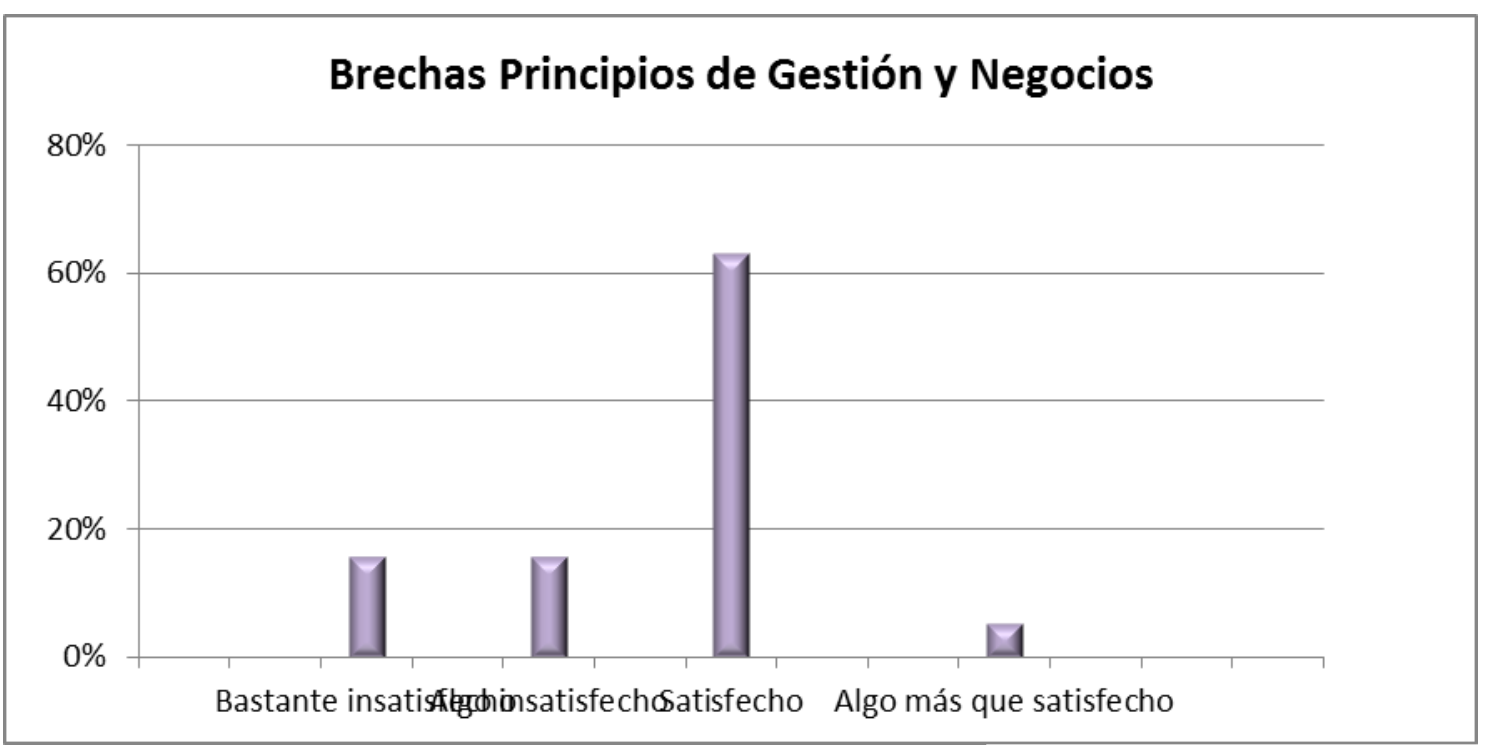

Fuente: Elaboración propia.

\subsubsection{Comprensión de otras disciplinas relacionadas con ciencias de la salud, es decir, psicológicas, humanas y sociales.}

Expectativas y percepción

Casi el $60 \%$ de los encuestados cree que es altamente significativo que el graduado conozca otras disciplinas relacionadas con la ciencia de la salud, mientras que casi el $37 \%$ lo cree bastante más que significativo. Por otro lado, casi el $74 \%$ está entre bastante de acuerdo y muy de acuerdo que éstos las conozcan, el $16 \%$ no está seguro y el $10,5 \%$ está en desacuerdo.

El saldo de respuesta sobre la expectativa, 1,71, indica que los encuestados creen que es bastante más que significativo, con leve acercamiento a ser totalmente significativo, que el graduado comprenda otras disciplinas relacionadas con la ciencias de la salud. Y el saldo de respuesta de su percepción, 1,95, refleja que están de acuerdo con una leve acercamiento a no estar seguros que los graduados lo comprendan.

(gráfico en la página siguiente) 


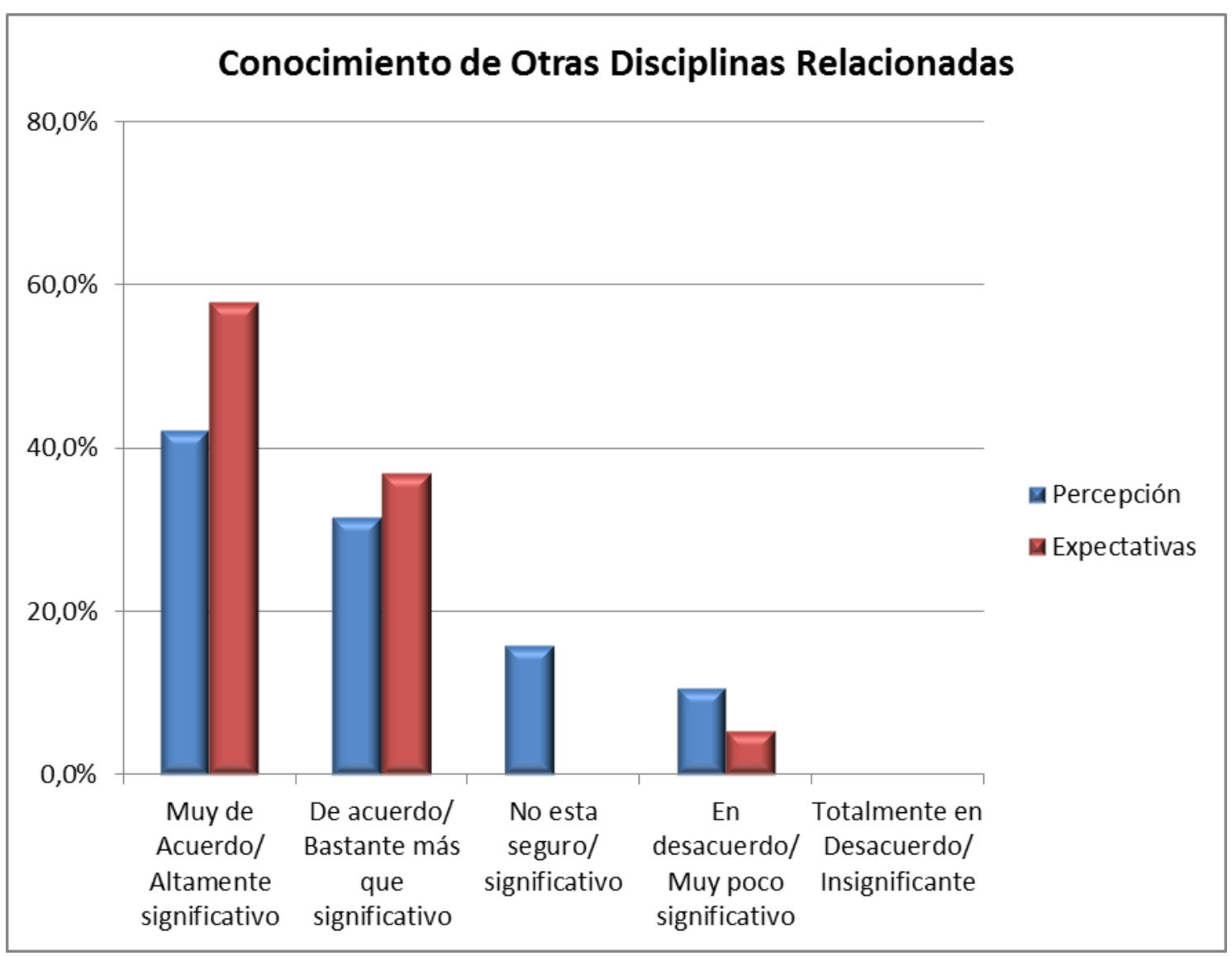

Fuente: Elaboración propia.

\section{Brechas}

En el gráfico de brechas se puede apreciar que más de la mitad de los encuestados están satisfechos, el $27 \%$ entre algo y bastante insatisfecho con esta relación y el $21 \%$ se presenta algo más que satisfecho.

El saldo de respuesta de $-0,24$ demuestra la satisfacción de los encuestados.

(gráfico en la página siguiente) 


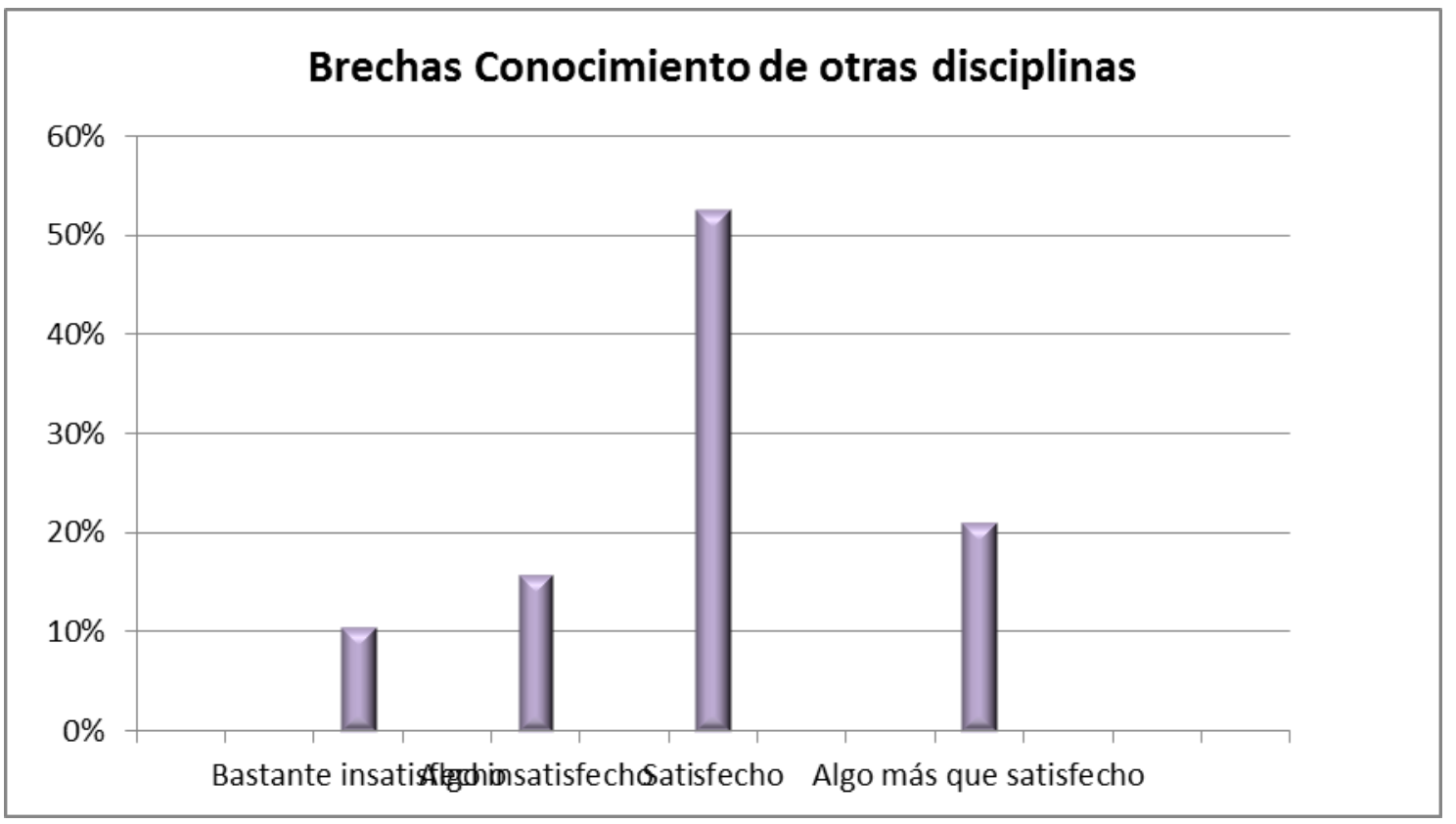

Fuente: Elaboración propia.

\subsubsection{Comprensión de las implicancias y consecuencias económicas} asociadas a las actividades que desarrolla en su trabajo.

Expectativas y percepción

Para el $84 \%$ de los encuestados es altamente significativo que el graduado comprenda las implicancias y consecuencias económicas asociadas a las actividades que desarrolla en su trabajo, y el $18 \%$ restante lo ve bastante más que significativo. A su vez, el $63 \%$ está entre muy de acuerdo y de acuerdo en que esto suceda, el $21 \%$ no está seguro, el $10,5 \%$ está en desacuerdo y poco más del $5 \%$ totalmente en desacuerdo con que los graduados lo comprenden.

El saldo de respuesta sobre la expectativa de 1,26, denota que los encuestados creen que es totalmente significativo que el graduado comprenda las implicancias y competencias económicas, y el saldo de respuesta de su percepción, 2,37, exhibe que están de acuerdo con un leve acercamiento a no estar seguros que los graduados lo comprendan.

(gráfico en la página siguiente) 


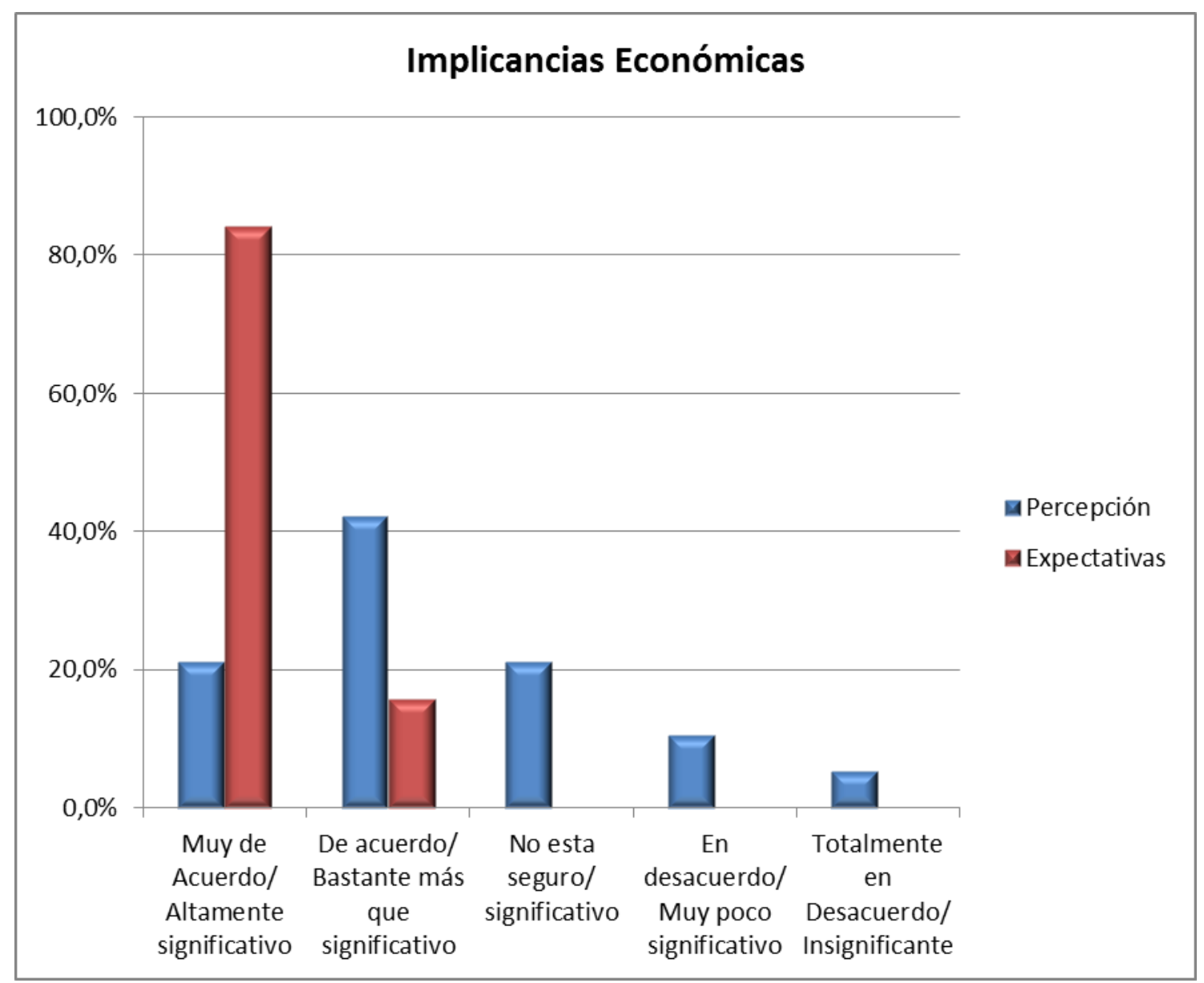

Fuente: Elaboración propia.

\section{Brechas}

El $42 \%$ de los encuestados está satisfecho y el $37 \%$ algo insatisfecho, el $5 \%$ bastante insatisfecho y el $16 \%$ restante entre muy y totalmente insatisfecho con la comprensión de los graduados en lo que refiere las implicancias y consecuencias económicas asociadas a las actividades que desarrolla en su trabajo.

El saldo de respuesta de -1,11 demuestra que los encuestados están algo insatisfechos sobre este tema.

(gráfico en la página siguiente) 


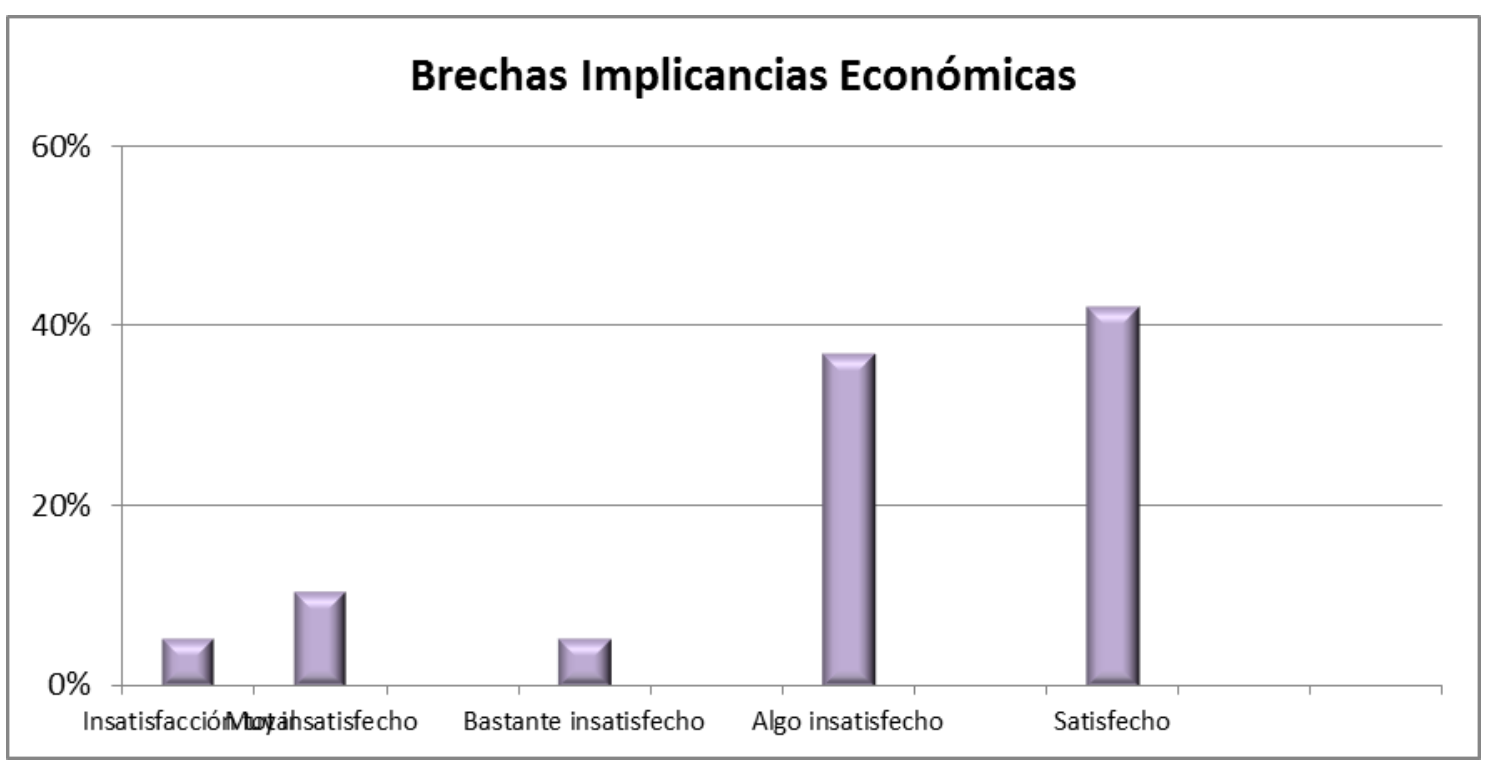

Fuente: Elaboración propia.

\subsubsection{Saldos de respuestas del atributo CONOCIMIENTOS}

Teniendo en cuenta que en lo referido a expectativas, 1 es totalmente significativo y 5 es insignificante, se puede ver que en general los conceptos de conocimientos analizados son totalmente significativos para los encuestados.

En lo referido a percepción, siendo 1 muy de acuerdo y 5 totalmente en desacuerdo, podemos apreciar que en la mayoría de los conceptos analizados el empleador está de acuerdo con una leve tendencia a no estar seguro sobre los conocimientos del graduado.

(gráfico en la página siguiente) 


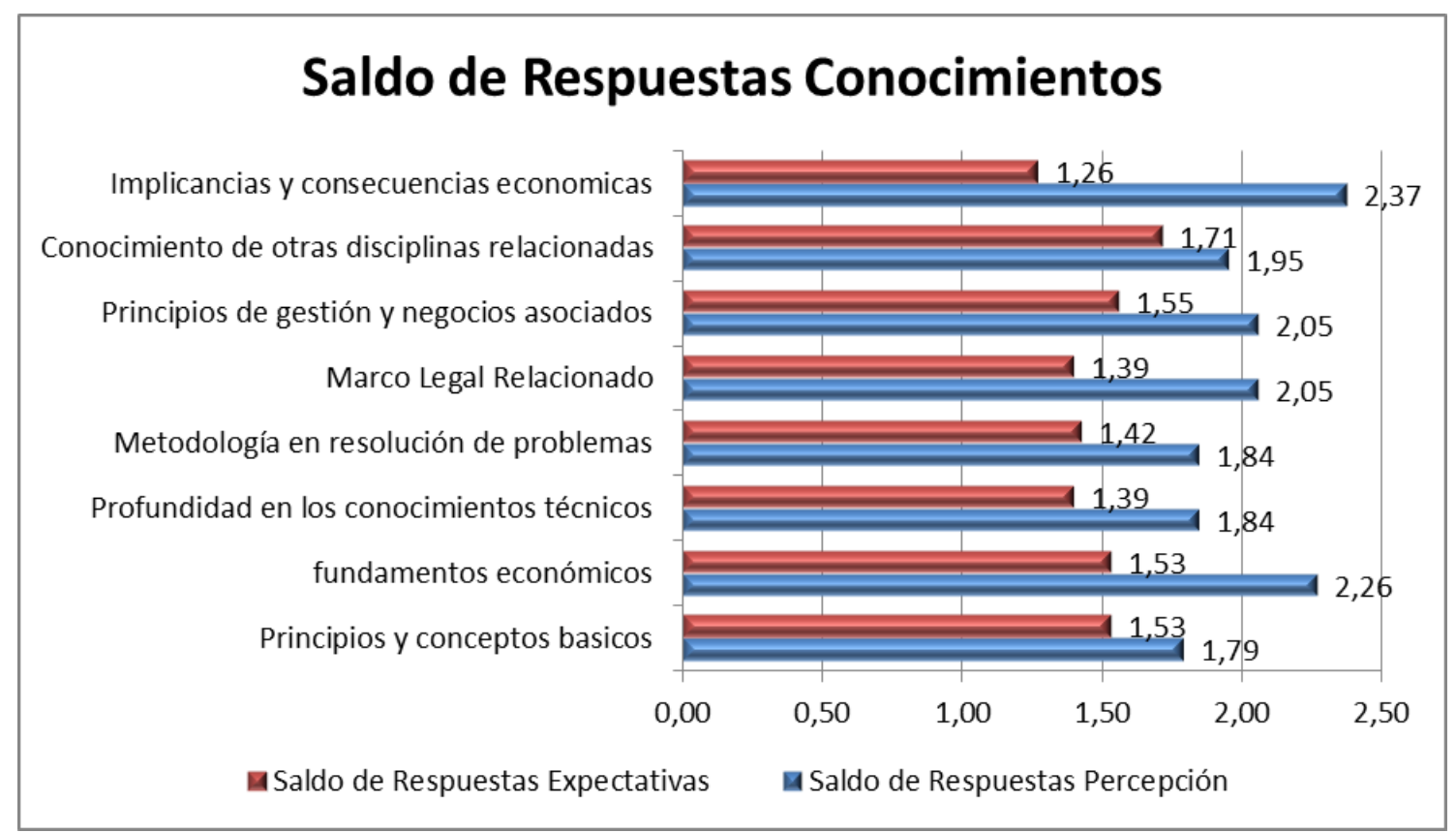

Fuente: Elaboración propia.

\subsubsection{Evaluación de habilidades}

Dentro de Evaluación de habilidades se evalúan nueve cuestiones relacionadas con la capacidad del graduado en el desempeño de su trabajo respecto de la aplicación de los conocimientos técnicos adquiridos en su formación; la utilización apropiada que hace de la tecnología disponible en el puesto de trabajo; la habilidad para acceder, evaluar y sintetizar información; la comunicación efectiva con pacientes, otros profesionales o la comunidad en general; y su funcionamiento eficaz como individuo y como parte de equipos multidisciplinarios con distintas capacidades para afrontar responsabilidad. 


\subsubsection{Aplicación de los conocimientos técnicos adquiridos en la carrera de Enfermería}

\section{Expectativas y percepción}

Se les preguntó a los encuestados acerca de la percepción que tienen sobre los graduados en lo que refiere a la aplicación de los conocimientos técnicos adquiridos en la carrera de Enfermería, y cuan significante es este tema para ellos.

El $100 \%$ de los encuestados cree que es bastante más significativo y altamente significativo que el graduado aplique perfectamente los conocimientos técnicos adquiridos, y casi el mismo porcentaje, 95\%, está de acuerdo y muy de acuerdo con que el graduado lo hace.

El saldo de respuesta sobre la expectativa, 1.61, indica que los encuestados creen que es totalmente significativo con una leve tendencia a altamente significativo que el graduado aplique perfectamente los conocimientos técnicos adquiridos; mientras que el saldo de respuesta de su percepción, 1.63, refleja que están de acuerdo a muy de acuerdo sobre esta aplicación.

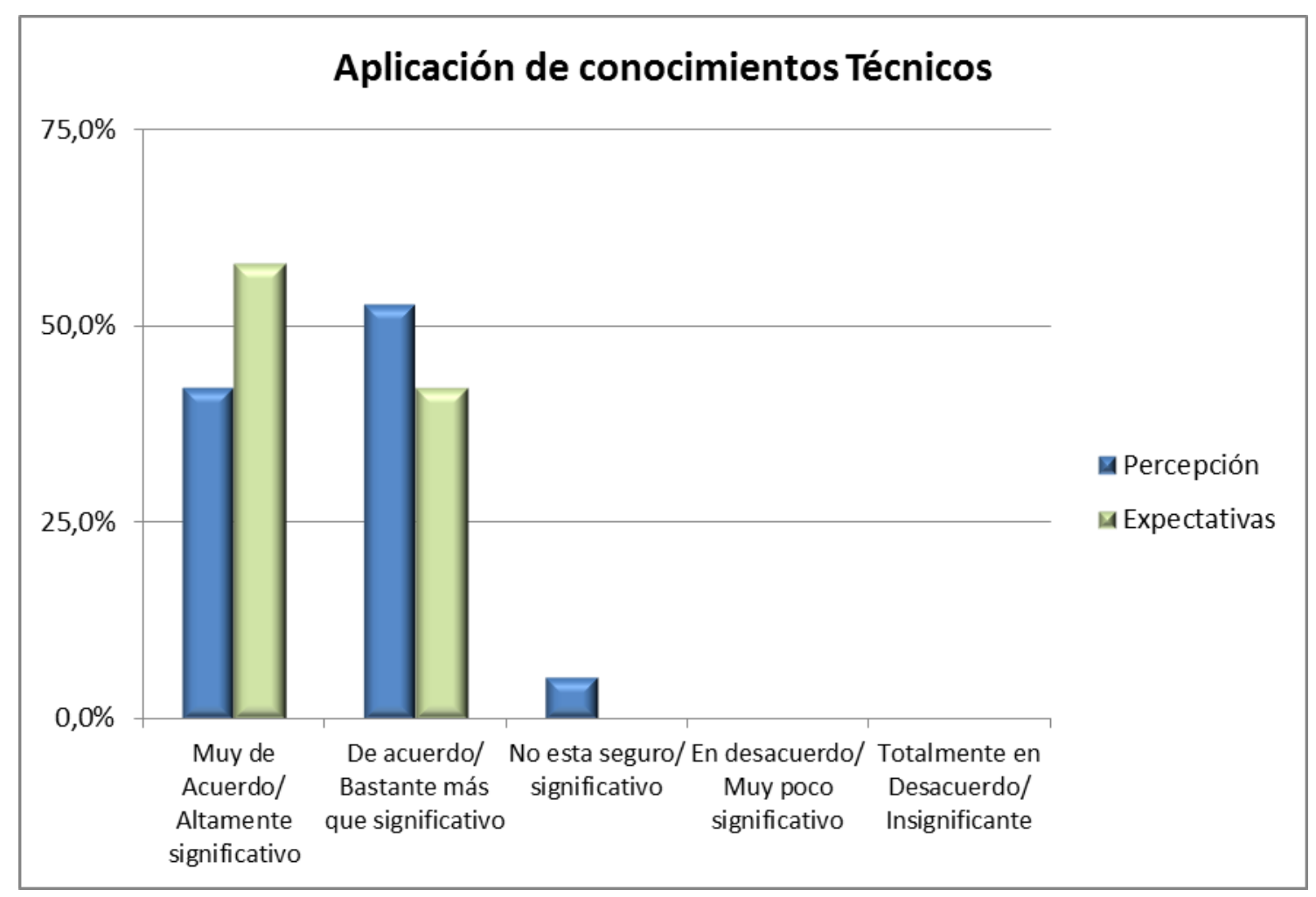

Fuente: Elaboración propia. 
Brechas

$85 \%$ de los encuestados están satisfechos en relación a la aplicación de los conocimientos adquiridos.

El saldo de respuesta de -0,03 demuestra la satisfacción de ellos.

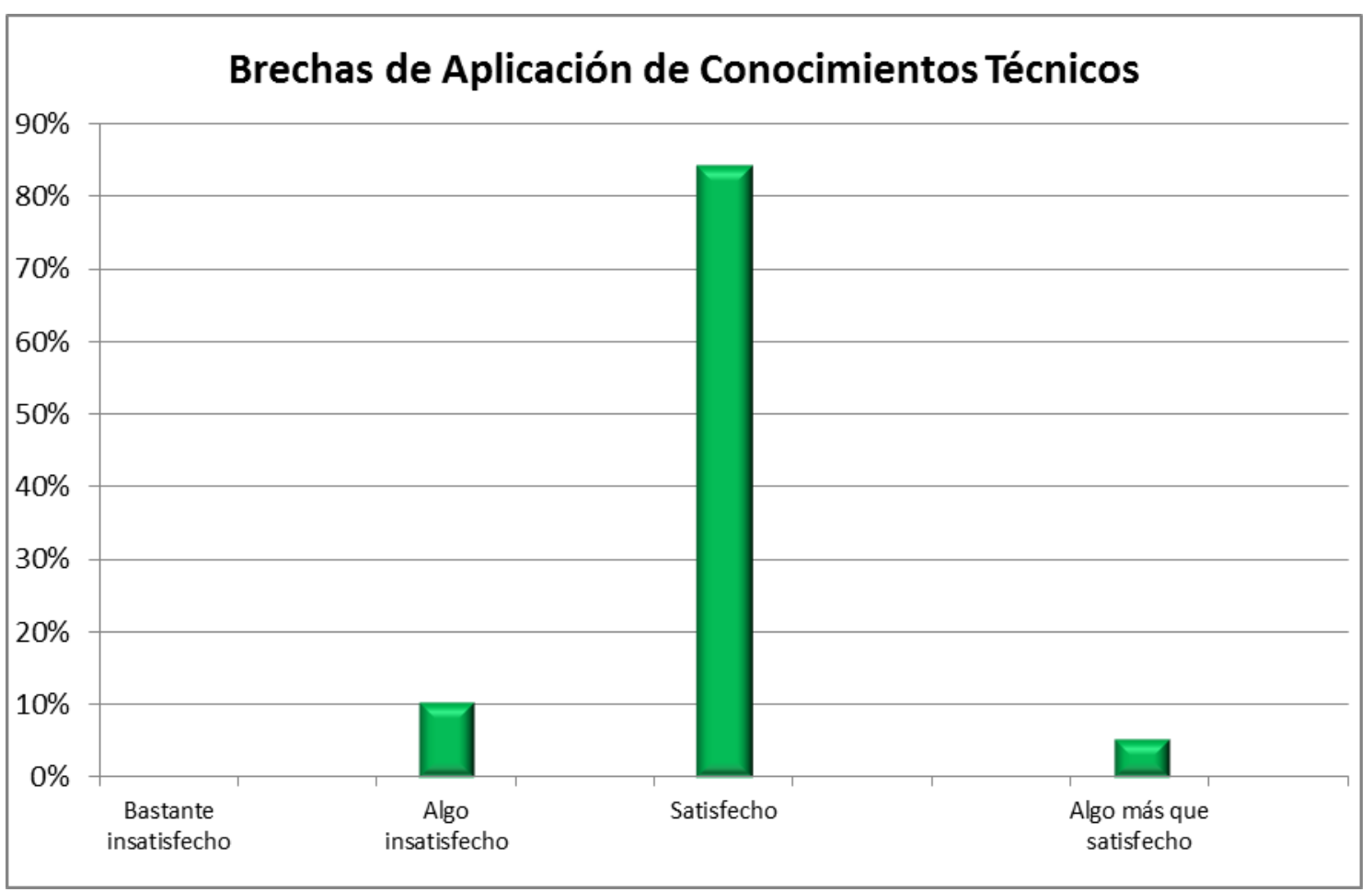

Fuente: Elaboración propia.

\subsubsection{Utilización apropiada de las tecnologías disponibles}

Expectativas y percepción

El 100\% de los encuestados cree que es bastante más que significativo o altamente significativo que el graduado utilice apropiadamente las tecnologías disponibles. A su vez, el $84 \%$ de ellos está de acuerdo o muy de acuerdo con que el graduado las utilice, el $10,5 \%$ no está seguro que así sea y el $5 \%$ restante está en desacuerdo.

El saldo de respuesta sobre la expectativa, 1.63, indica que los encuestados consideran totalmente significativo con una leve tendencia a bastante más que significativo la utilización apropiada de tecnologías 
disponibles. Y el saldo de respuesta de su percepción, 1.79, refleja que están de acuerdo con que los graduados lo comprenden.

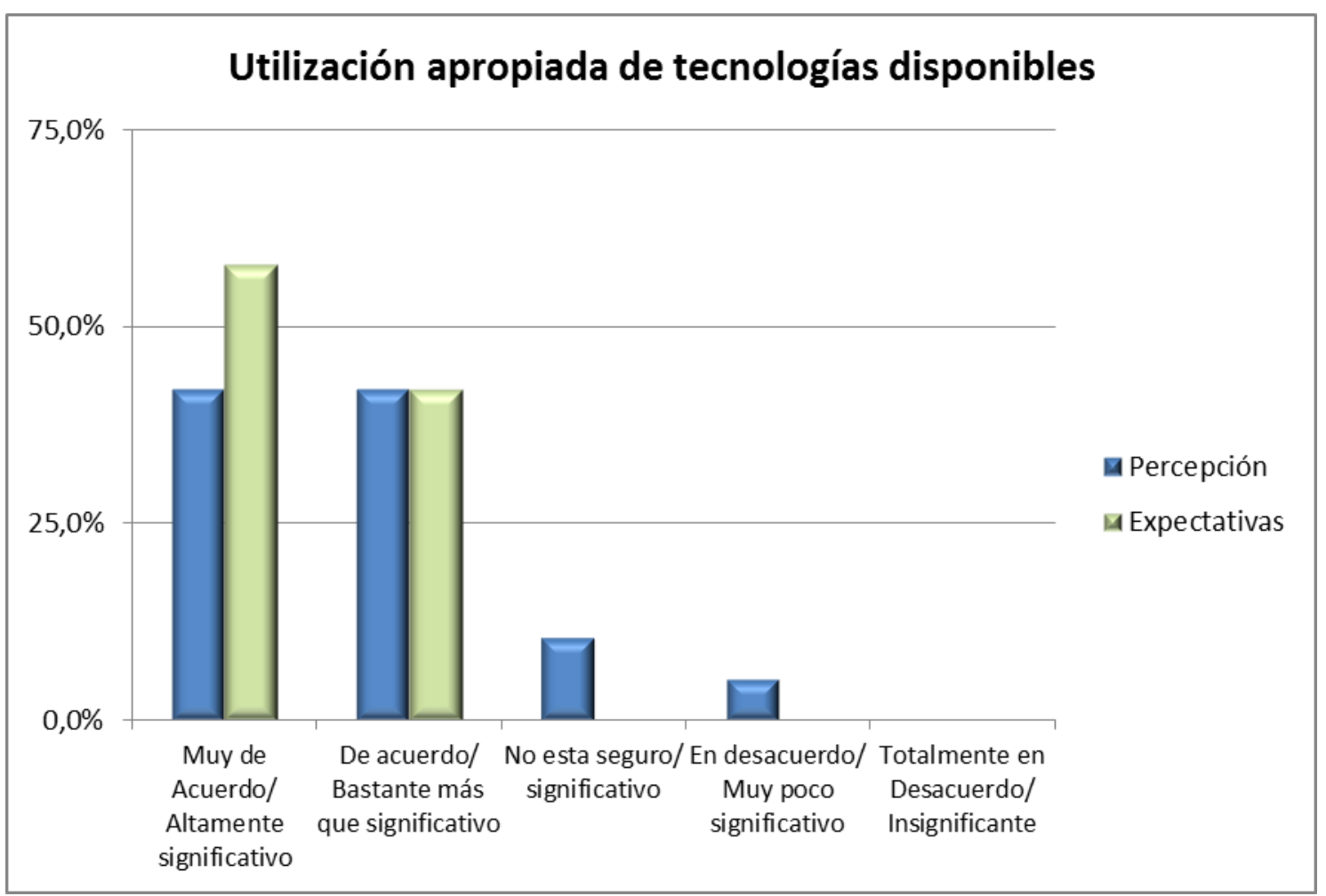

Fuente: Elaboración propia.

\section{Brechas}

Casi el $80 \%$ de los encuestados están satisfechos con la utilización apropiada de las tecnologías por parte del graduado..

El saldo de respuesta de $-0,16$ demuestra la satisfacción de ellos. (gráfico en la página siguiente) 


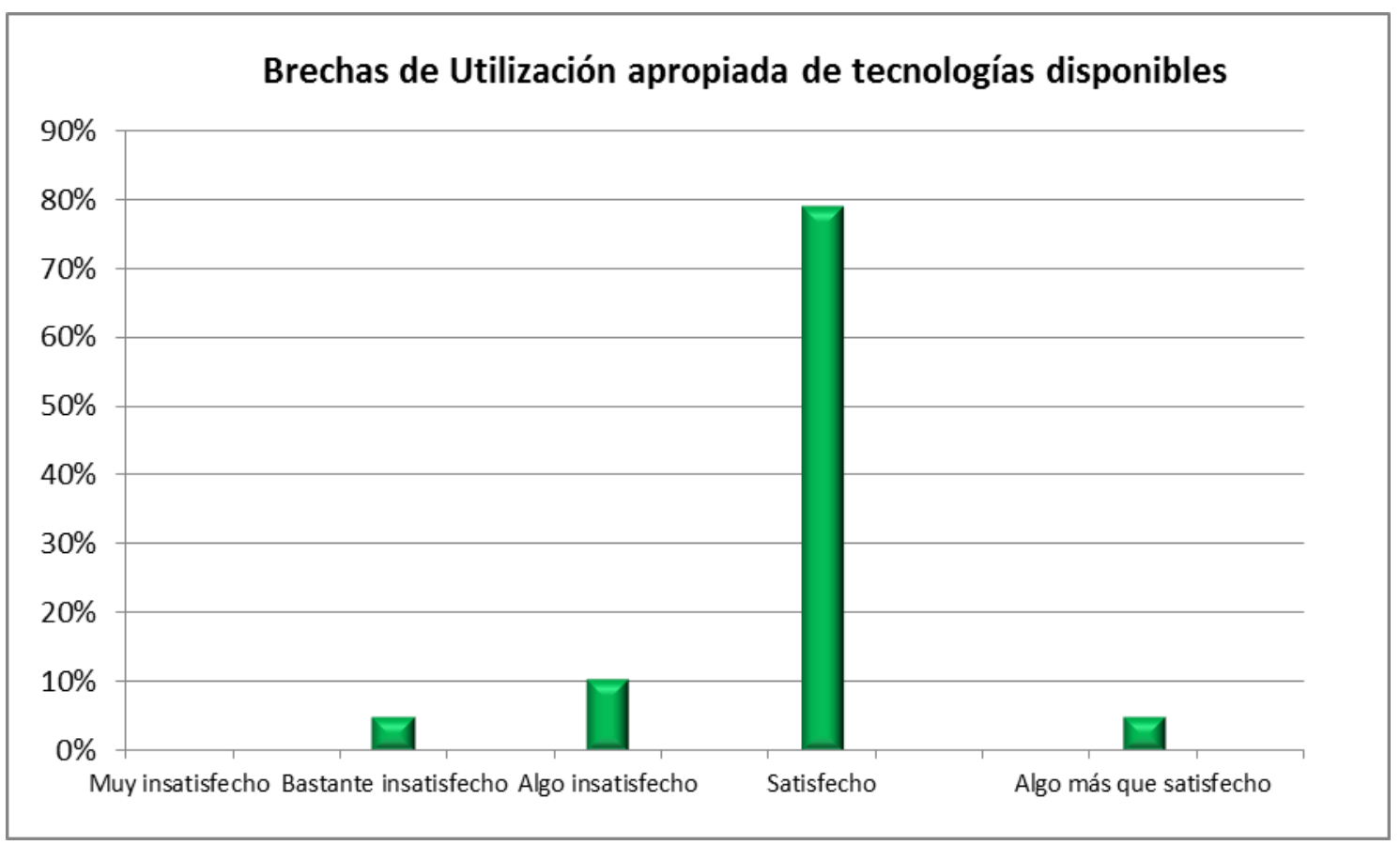

Fuente: Elaboración propia.

\subsubsection{Acceder, evaluar y sintetizar información}

Expectativas y percepción

El $84 \%$ de los encuestados cree que es altamente significativo que el graduado tenga la capacidad de acceder, evaluar y sintetizar información y el restante $16 \%$ cree que es bastante más que significativo. Por otro lado, casi el $69 \%$ está de acuerdo que el graduado lo hace, el $21 \%$ muy de acuerdo y el $10.5 \%$ no está seguro.

El saldo de respuesta sobre la expectativa de 1.50 indica que los encuestados creen que es totalmente significativa esta capacidad. $Y$ el saldo de respuesta de su percepción, 1.89, denota que están de acuerdo con un leve acercamiento a no estar seguros que los graduados lo comprendan. (gráfico en la página siguiente) 


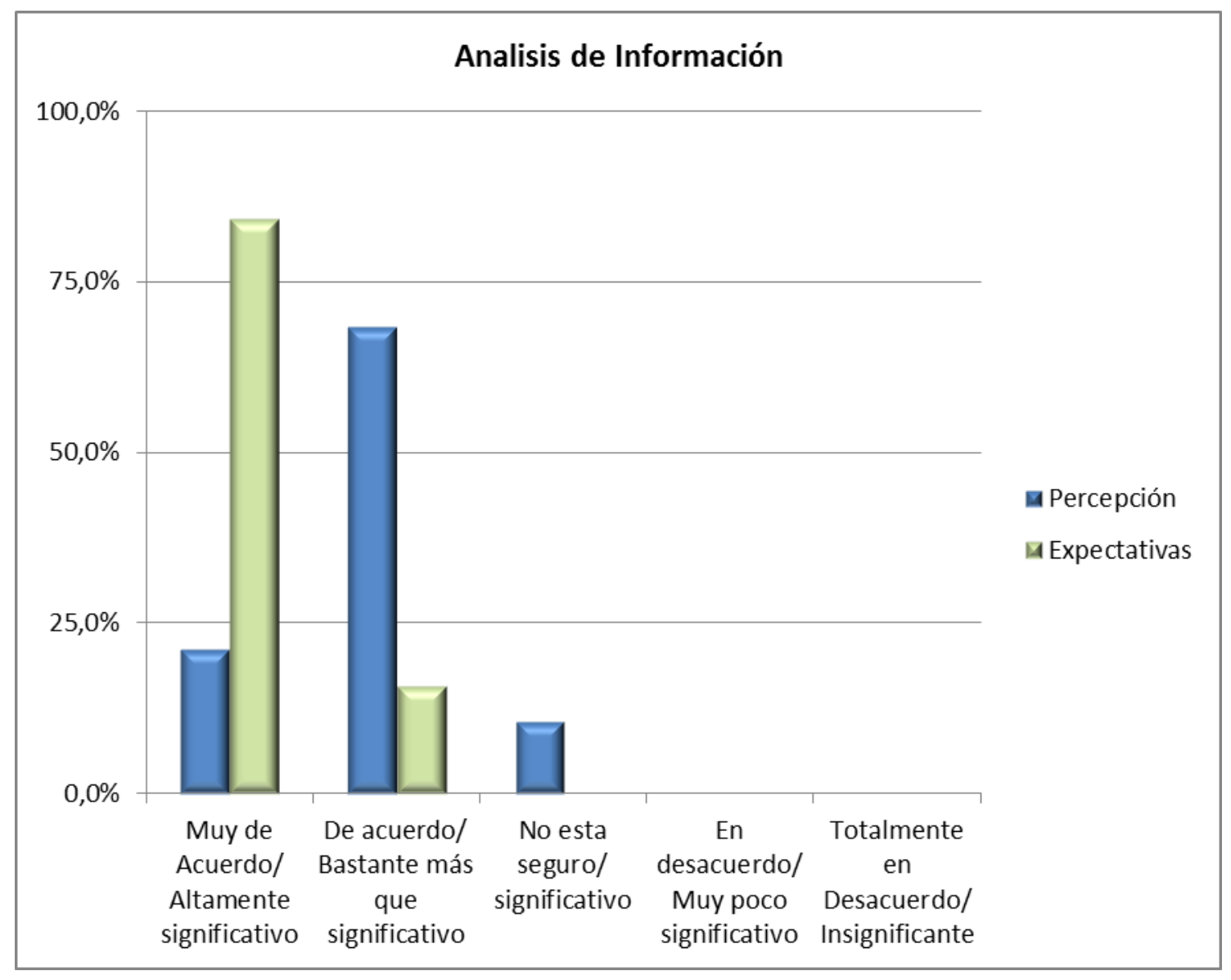

Fuente: Elaboración propia.

\section{Brechas}

El saldo de respuesta de -0.39 , muestra que los encuestados están entre satisfechos en este tema.

(gráfico en la página siguiente) 


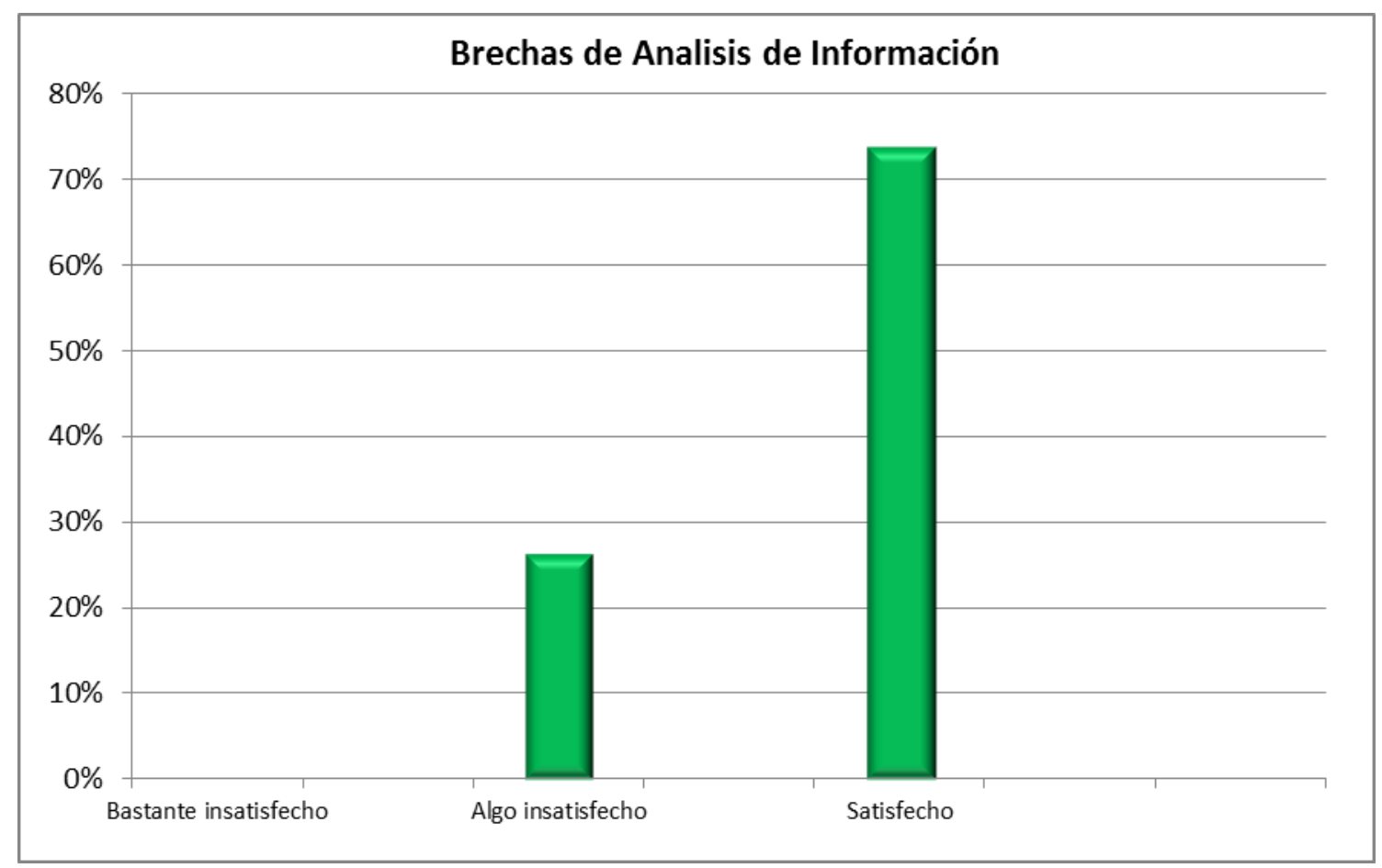

Fuente: Elaboración propia.

\subsubsection{Comunicación efectiva no sólo con los enfermeros sino también con los profesionales de otras disciplinas y la comunidad en general}

\section{Expectativas y percepción}

Para el $84 \%$ de los encuestados es altamente significativo que el graduado pueda comunicarse de manera efectiva con sus pares, con profesionales de otras disciplinas y con la comunidad en general, y para el $16 \%$ restante es bastante más que significativo. A su vez, el 95\% está entre muy de acuerdo y de acuerdo en que esto sucede.

El saldo de respuesta sobre la expectativa de 1.21, denota que los encuestados creen que es totalmente significativo que los graduados puedan comunicarse efectivamente, y el saldo de respuesta de su percepción, 1.68, muestra que están de acuerdo con un leve acercamiento a no estar seguros de ello.

(gráfico en la página siguiente) 


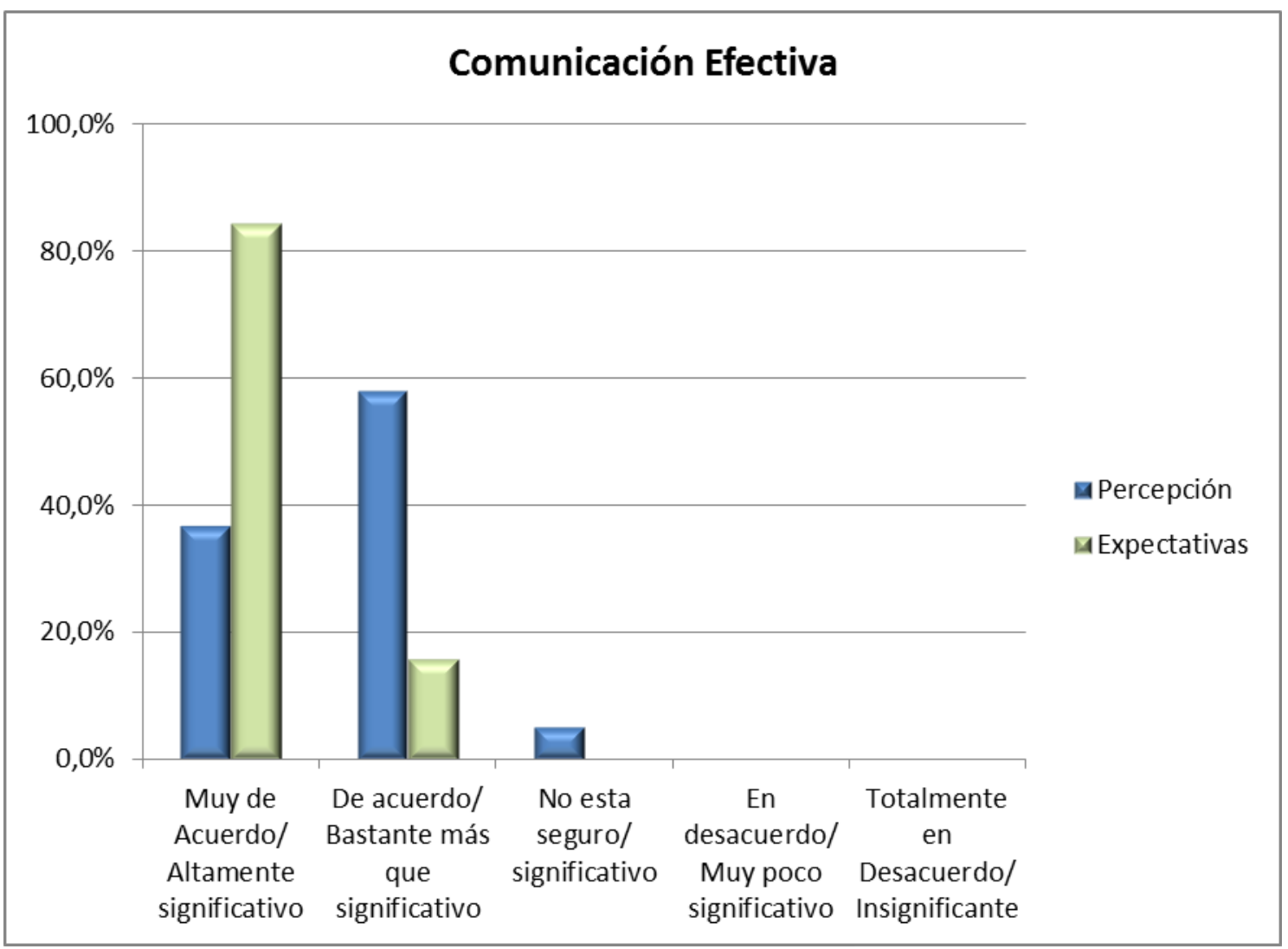

Fuente: Elaboración propia.

Brechas

El saldo de respuesta de las brechas es de -0,47 y muestra que los encuestados están satisfechos con una leve tendencia a estar algo insatisfechos con respecto a este tema.

(gráfico en la página siguiente) 


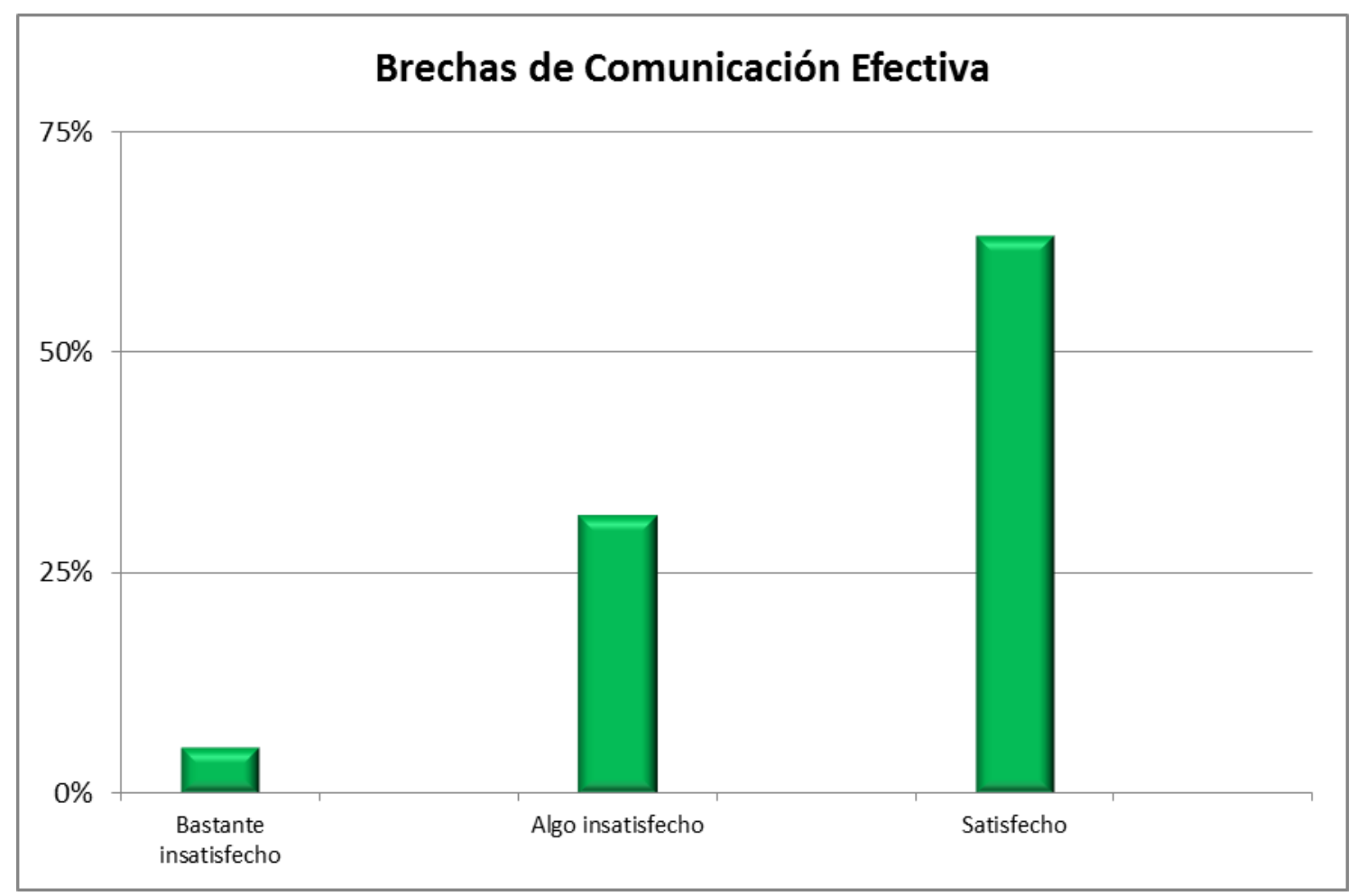

Fuente: Elaboración propia.

\subsubsection{Funcionamiento eficaz como individuo}

Expectativas y percepción

El $100 \%$ de los encuestados encuentra entre bastante más que significativo y altamente significativo que el graduado funcione eficazmente como individuo, mientras que $37 \%$ de ellos está muy de acuerdo, otro $37 \%$ de acuerdo y el restante $26 \%$ está seguro que así sea.

El saldo de respuesta sobre la expectativa, 1,47, indica que los encuestados creen que es totalmente significativo que el graduado funcione eficazmente como individuo. $Y$ el saldo de respuesta de su percepción, 1,89, refleja que están de acuerdo con un leve acercamiento a no estar seguros de ello.

(gráfico en la página siguiente) 


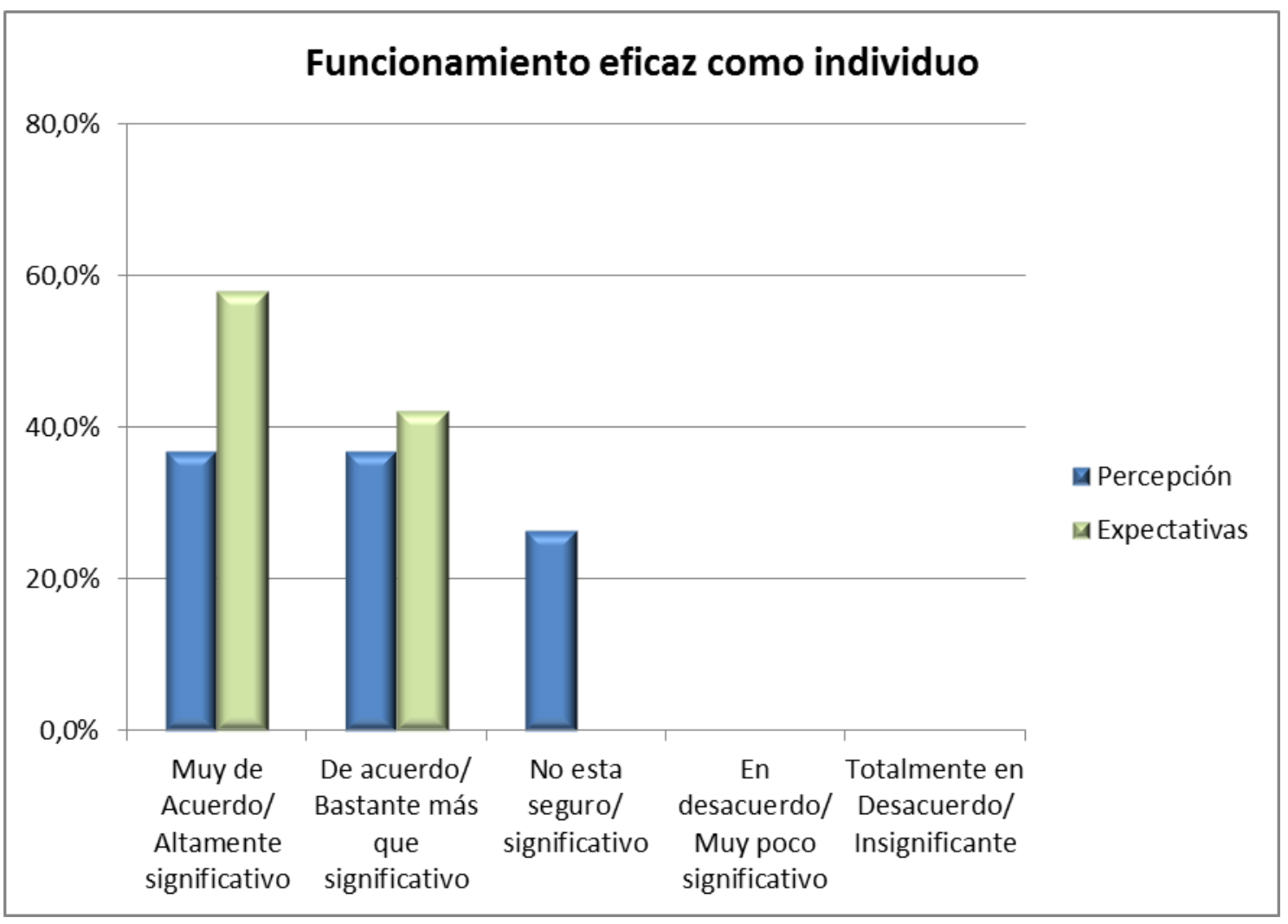

Fuente: Elaboración propia.

\section{Brechas}

El saldo de respuesta del gráfico de brechas de $-0,42$ demuestra la satisfacción de los encuestados sobre este funcionamiento.

(gráfico en la página siguiente) 


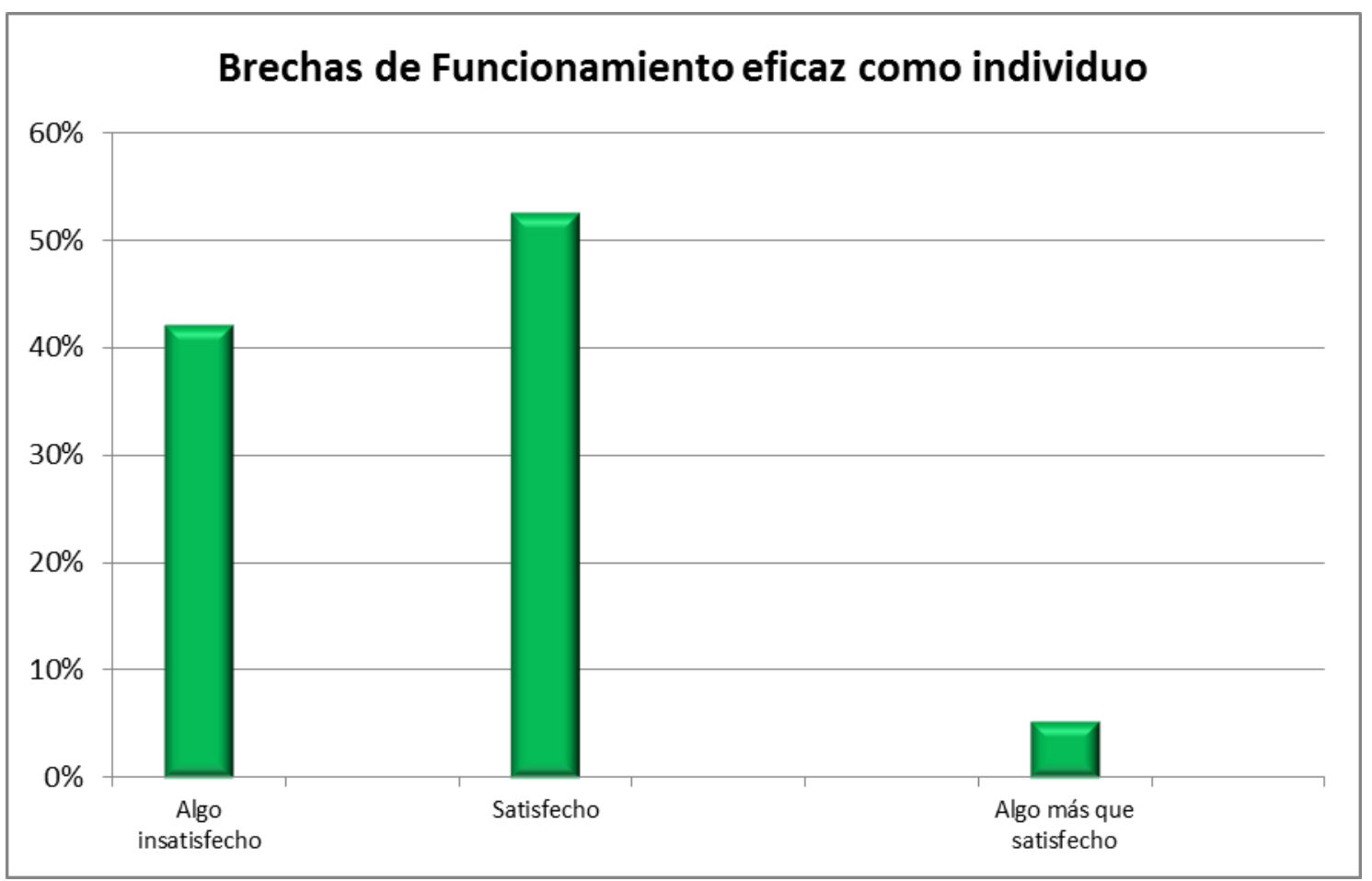

Fuente: Elaboración propia.

\subsubsection{Funcionamiento eficaz en equipos multidisciplinarios 0 multiculturales}

Expectativas y percepción

El $63 \%$ de los encuestados cree que es altamente significativo que el graduado funcione eficazmente en equipos multidisciplinarios y el $37 \%$ lo cree bastante más que significativo. Por otro lado, $42 \%$ está muy de acuerdo que esto sucede, otro $42 \%$ de acuerdo, y el $16 \%$ no está .

El saldo de respuesta sobre la expectativa de 1.61 indica que los encuestados creen que es bastante más que significativo con tendencia a ser totalmente significativo el funcionamiento del graduado en este aspecto. $Y$ el saldo de respuesta de su percepción, 1.74, denota que están de acuerdo con un leve acercamiento a estar muy de acurdo sobre este tema.

(gráfico en la página siguiente) 


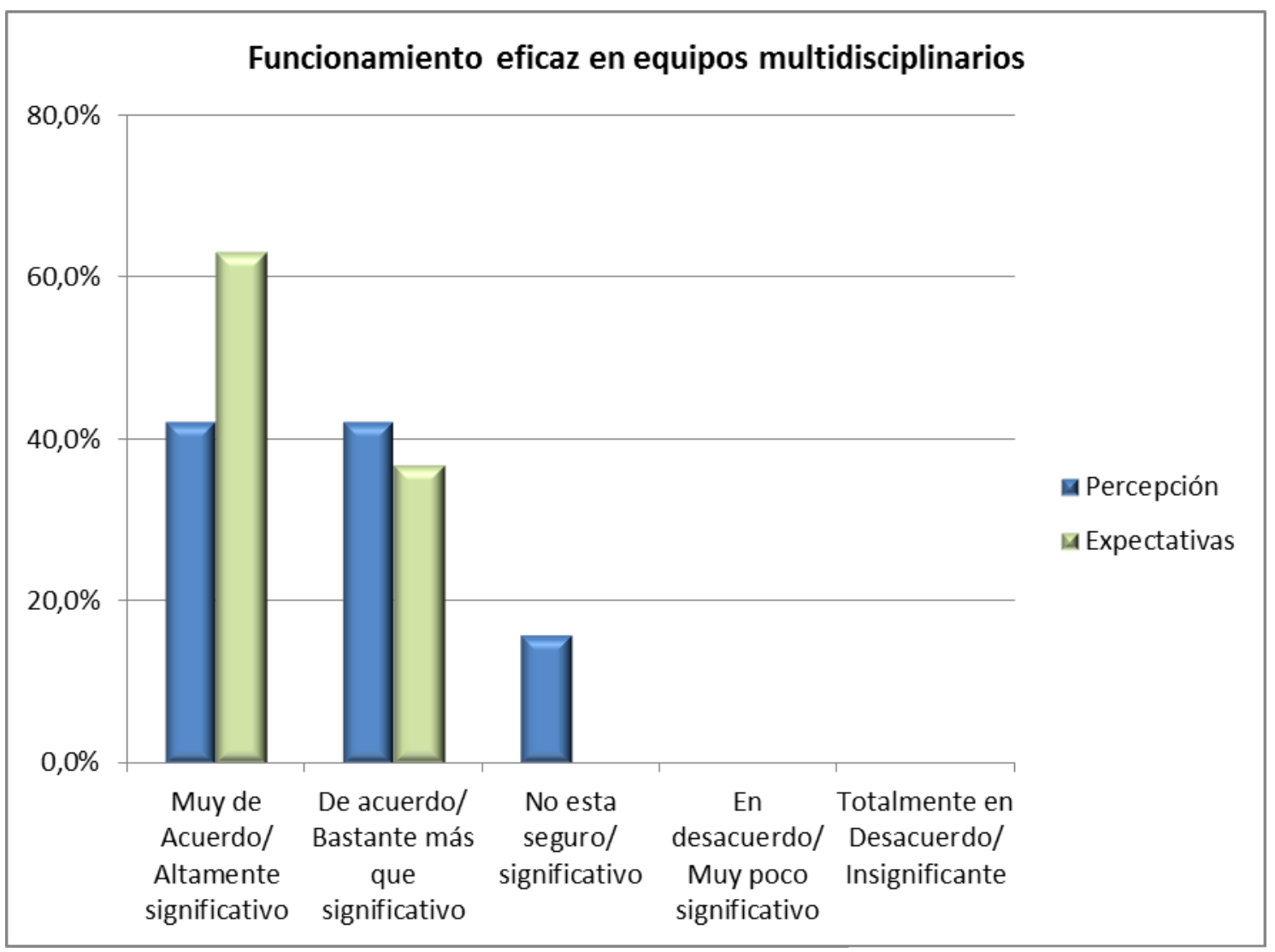

Fuente: Elaboración propia.

\section{Brechas}

El saldo de respuesta de las brechas sobre el funcionamiento eficaz del graduado en equipos multidisciplinarios es de -0,13. Ello demuestra la satisfacción de los encuestados.

(gráfico en la página siguiente) 


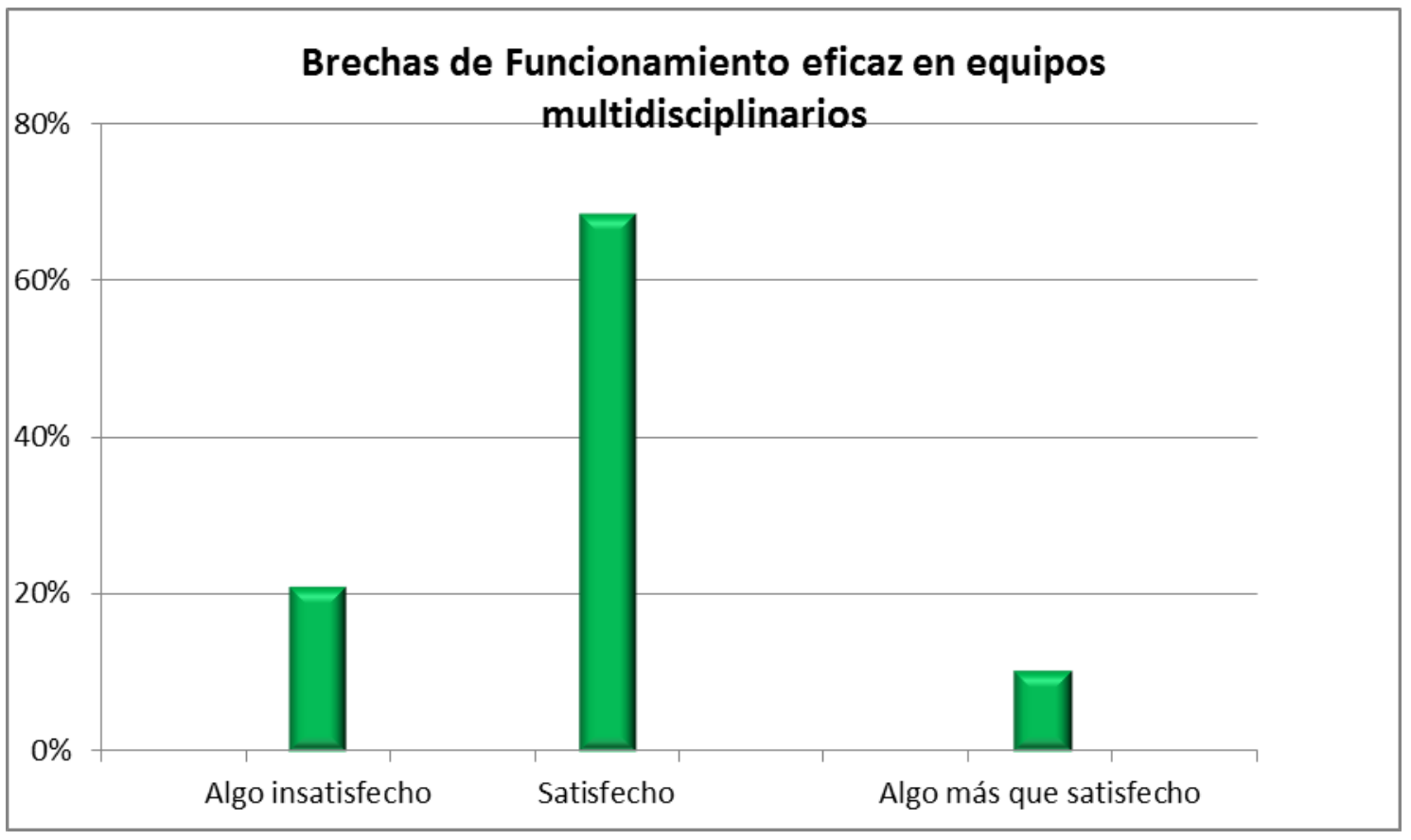

Fuente: Elaboración propia.

\subsubsection{Funcionamiento eficaz en equipos con la capacidad de ser miembros}

Expectativas y percepción

$58 \%$ de los encuestados cree que es altamente significativo que el graduado funcione como miembro en equipos de manera eficaz, $10.5 \%$ lo cree bastante más que significativo, otro $10,5 \%$ significativo y el $21 \%$ restante muy poco significativo. Por otro lado $37 \%$ muy de acuerdo que éstos funcionen de esa manera, el $16 \%$ está bastante de acuerdo, $37 \%$ no está seguro y $10 \%$ está totalmente en desacuerdo.

El saldo de respuesta sobre la expectativa, 2.03, indica que los encuestados creen que es bastante más que significativo, con leve acercamiento a ser totalmente significativo que el graduado funcione eficazmente como miembro en equipos. $Y$ el saldo de respuesta de su percepción, 2.32, refleja que están de acuerdo con una leve acercamiento a no estar que esto suceda.

(gráfico en la página siguiente) 


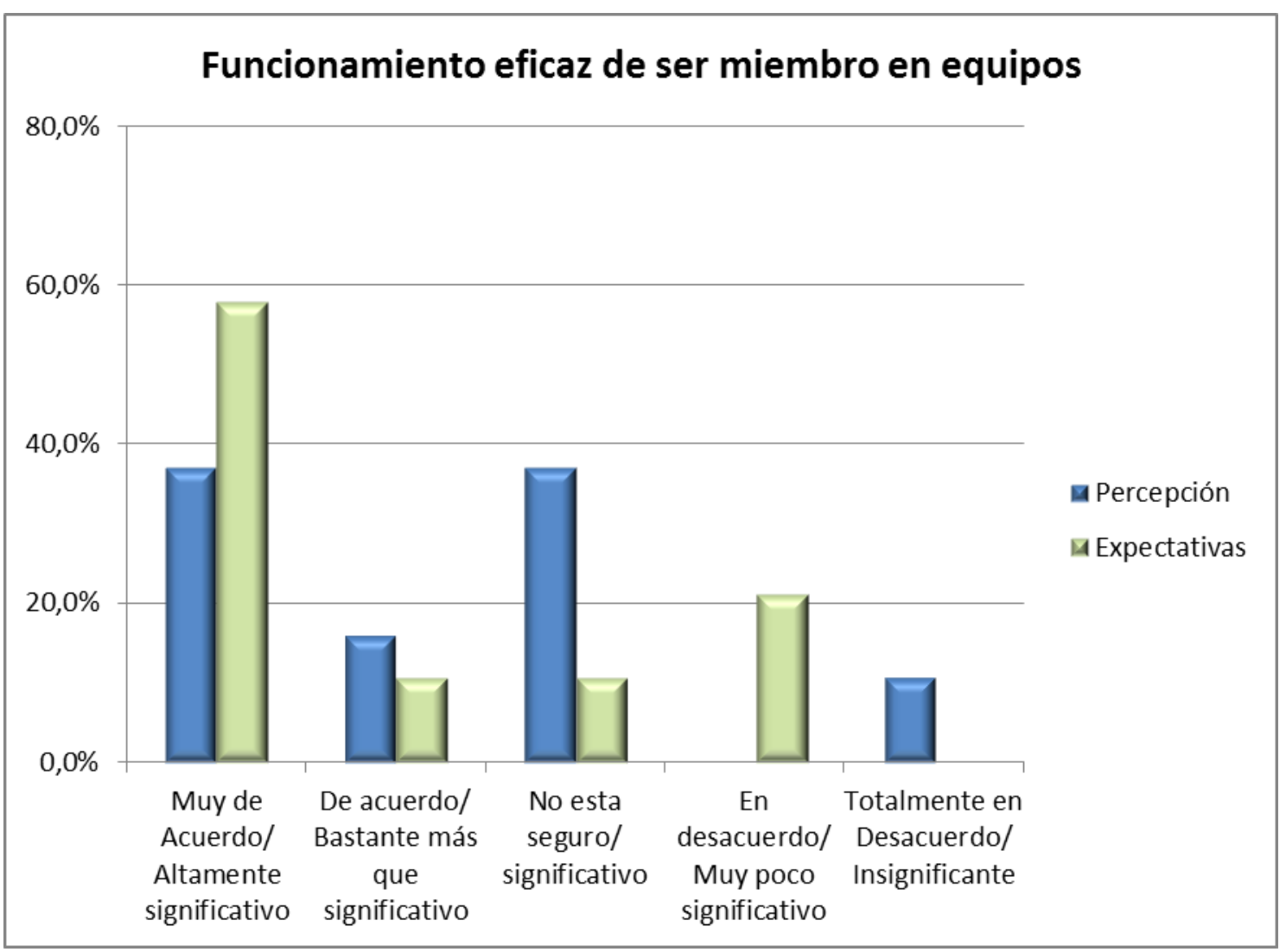

Fuente: Elaboración propia.

\section{Brechas}

El saldo de respuesta de brechas de -0.29 demuestra la satisfacción de los encuestados sobre el funcionamiento de los egresados.

(gráfico en la página siguiente) 


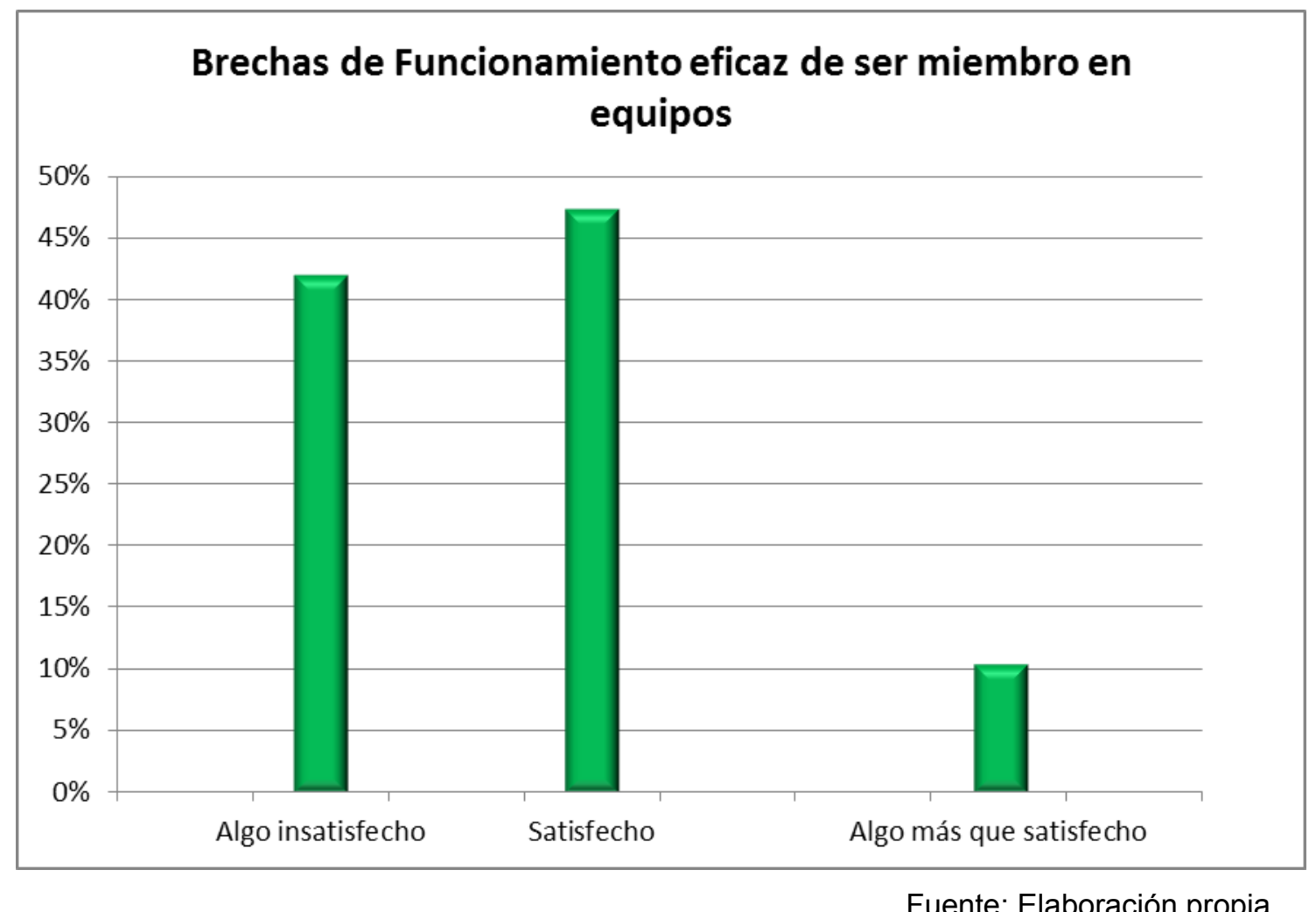

Fuente: Elaboración propia.

\subsubsection{Funcionamiento eficaz en equipos con la capacidad de ser Director}

Expectativas y percepción

Casi el $79 \%$ de los encuestados cree que es insignificante o muy poco significativo que el graduado funcione eficazmente en equipos con capacidad de ser un Director. El $16 \%$ lo ve significativo y el $5 \%$ restante, más que significativo. A su vez, el $42 \%$ de ellos está en desacuerdo que el graduado funcione de esa manera, $26 \%$ totalmente en desacuerdo y $32 \%$ no está seguro de ello.

El saldo de respuesta sobre la expectativa, 3.87, indica que los encuestados consideran muy poco significativo este atributo, y el saldo de respuesta de su percepción, 3.95, refleja que están en desacuerdo con que los graduados funcionen de esa manera. 


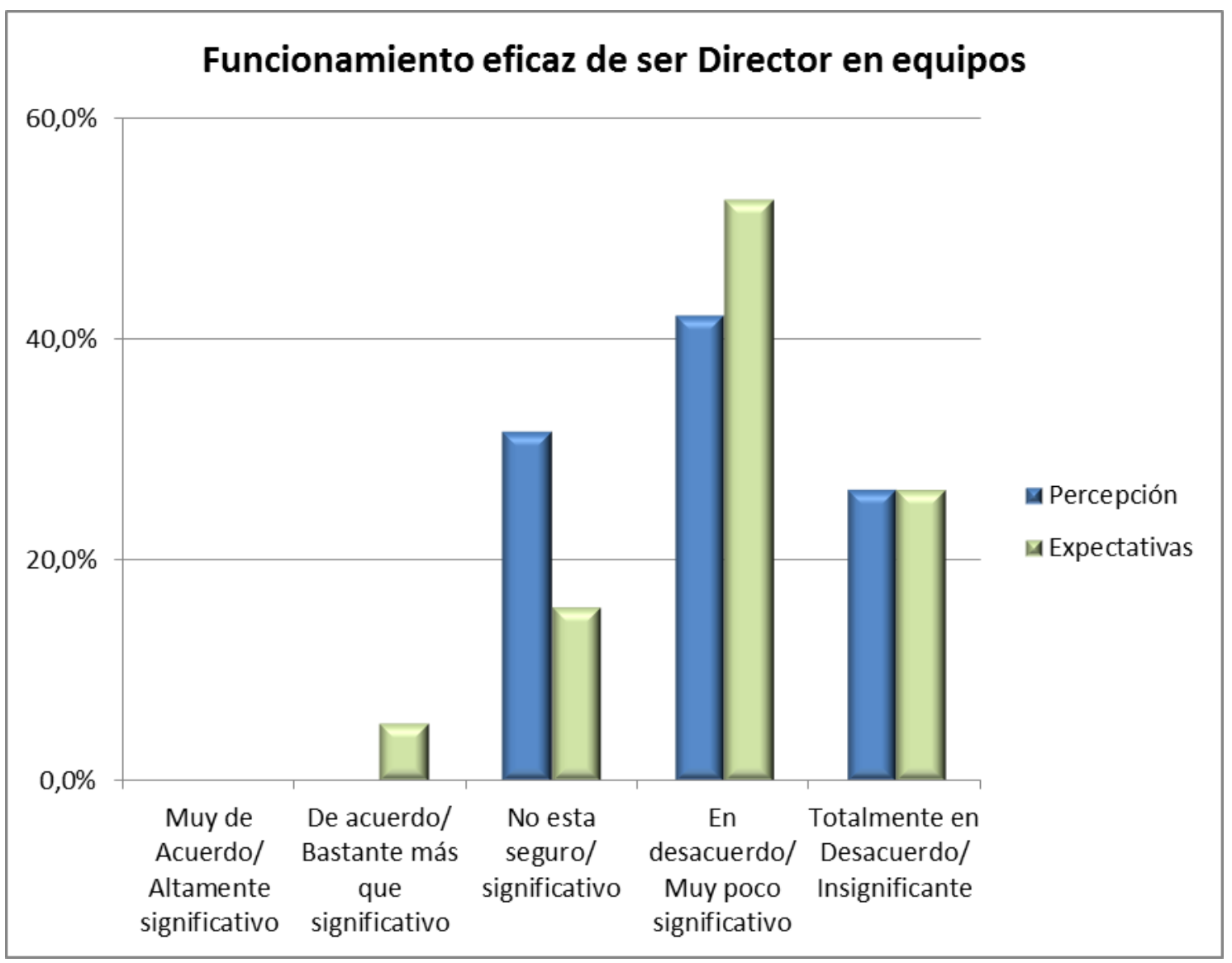

Fuente: Elaboración propia.

\section{Brechas}

El saldo de respuesta de las brechas es de -0.08 y demuestra la satisfacción de los encuestados sobre este tema.

(gráfico en la página siguiente) 


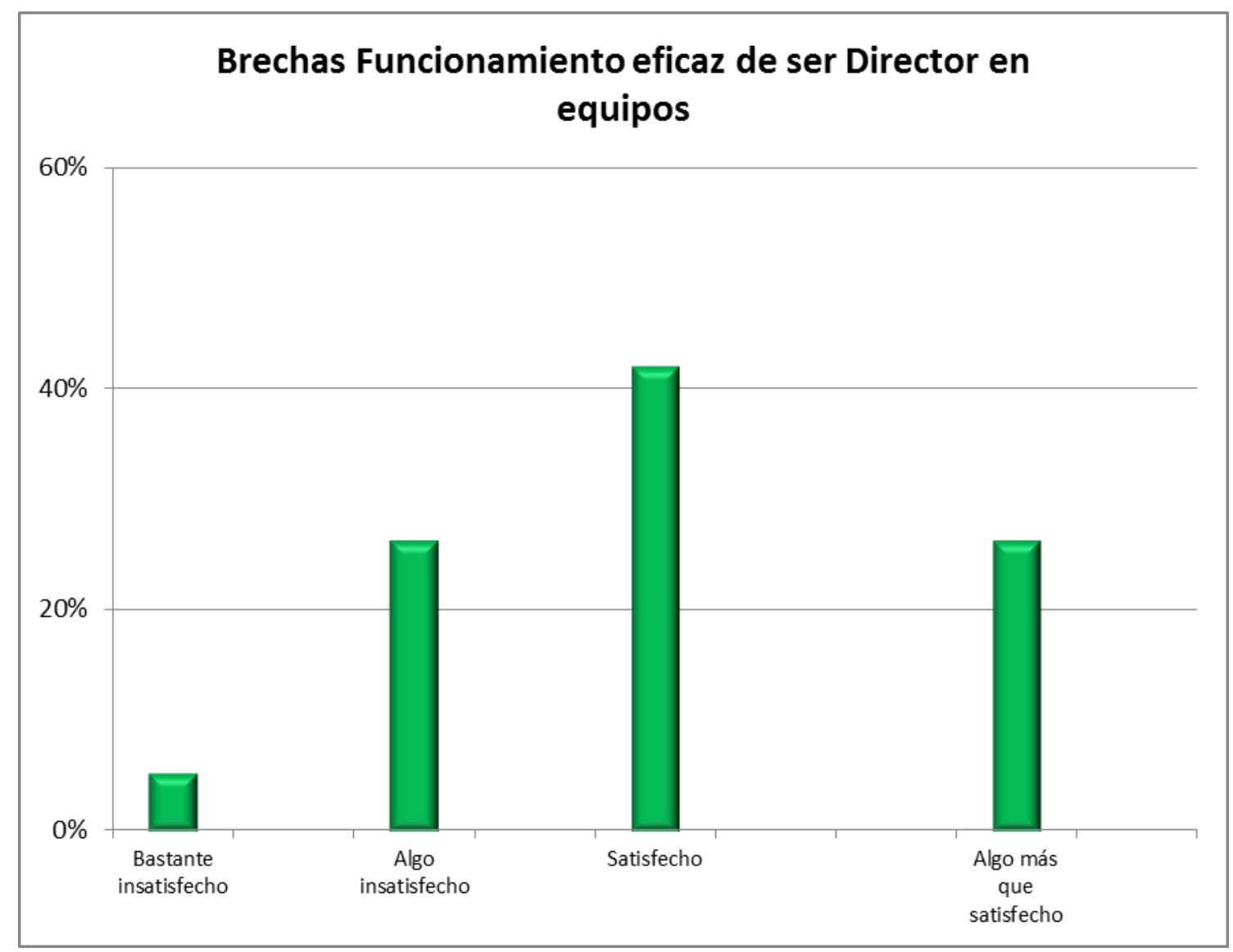

Fuente: Elaboración propia.

\subsubsection{Funcionamiento eficaz en equipos con la capacidad de ser un}

\section{Líder}

Expectativas y percepción

Se ve una gran disparidad en las respuestas de los encuestados al preguntar sobre la expectativa que tienen en lo que refiere al funcionamiento eficaz del graduado en equipos con la capacidad de ser un Líder. 10.5\% cree que es significativo, $47.5 \%$ lo ven entre altamente significativo y bastante más que significativo y el $42 \%$ entre muy poco significativo e insignificante. En cambio $42 \%$ de ellos no está seguro sobre este funcionamiento del graduado, $37 \%$ está en desacuerdo que así sea y el restante $11 \%$ dividen su voluntad en partes iguales entre estar de acuerdo y totalmente en desacuerdo. 
El saldo de respuesta sobre la expectativa, 2.92, denota que los encuestados consideran significativo con una tendencia a bastante más que significativo este atributo, y el saldo de respuesta de su percepción, 3.42, refleja que no están seguros con tendencia a estar en desacuerdo con que los graduados tengan un funcionamiento eficaz en esa capacidad.

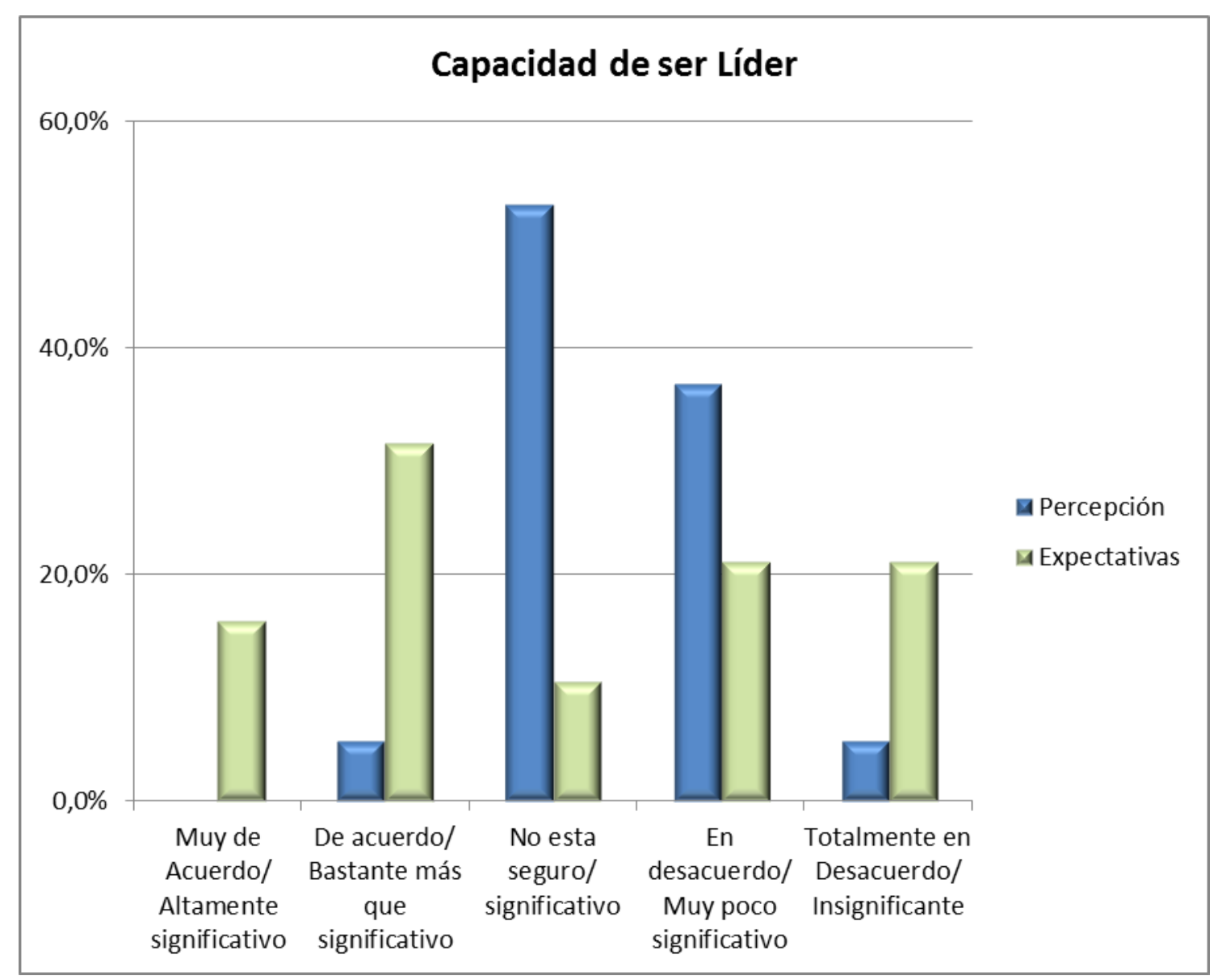

Fuente: Elaboración propia.

\section{Brechas}

El saldo de respuesta de las brechas es de -0.50 y demuestra la satisfacción de los encuestados sobre este tema, con una leve tendencia a estar insatisfechos.

(gráfico en la página siguiente) 


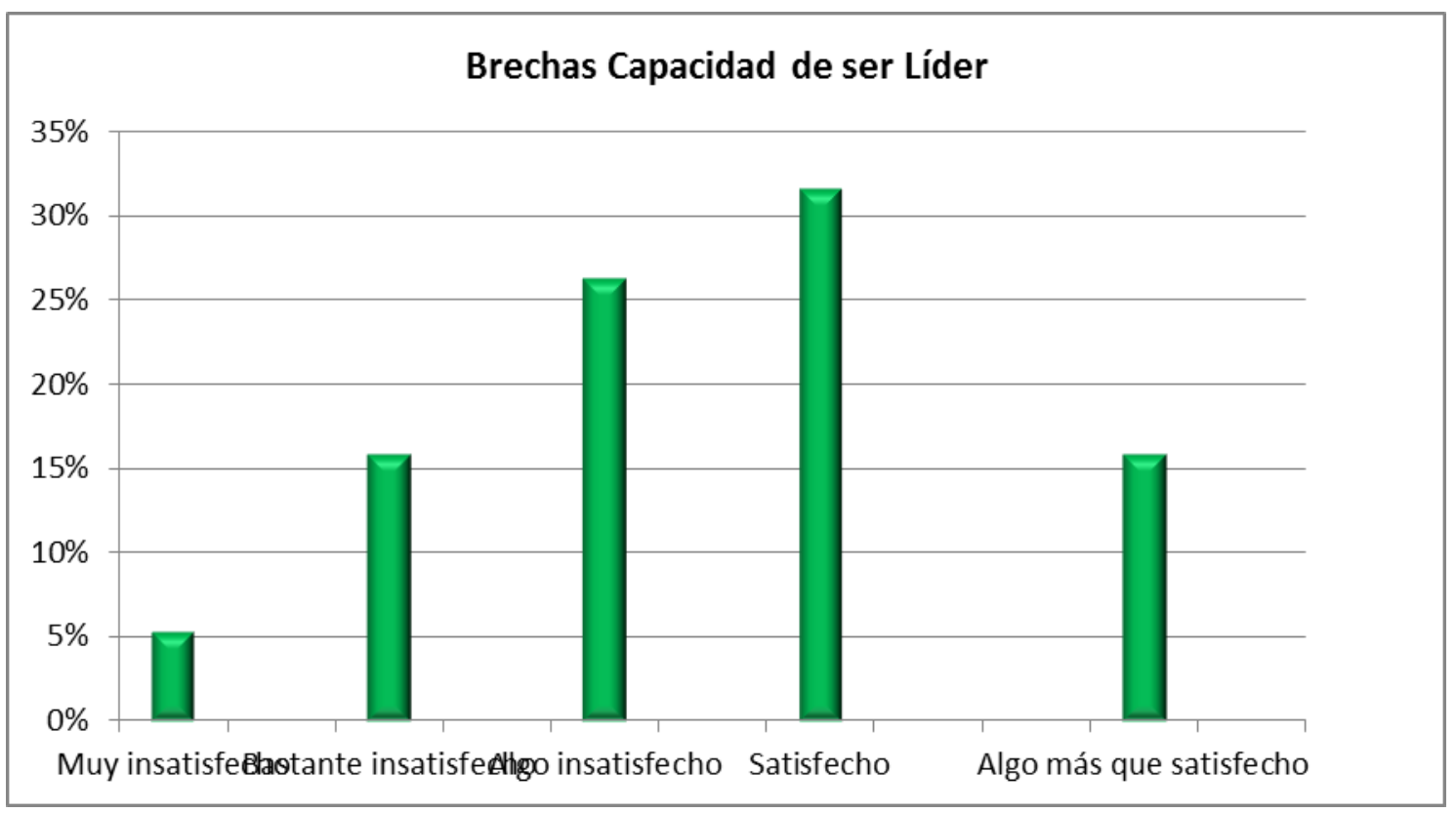

Fuente: Elaboración propia.

\subsubsection{Saldos de respuestas del atributo HABILIDADES}

Reiterando lo ya mencionado. Teniendo en cuenta que en lo referido a expectativas, 1 es totalmente significativo y 5 es insignificante, se puede ver que en general los conceptos de habilidades analizados son bastante más que significativos para los encuestados, a excepción de Capacidad de ser Líder y a Capacidad de ser Director que se consideran muy poco significativos.

En lo referido a percepción, siendo 1 muy de acuerdo y 5 totalmente en desacuerdo, podemos apreciar que en la mayoría de los conceptos analizados el empleador está de acuerdo con una leve tendencia a estar muy de acuerdo sobre las habilidades del graduado, a excepción de Capacidad de ser Líder y a Capacidad de ser Director que se manifiestan en desacuerdo. (gráfico en la página siguiente) 


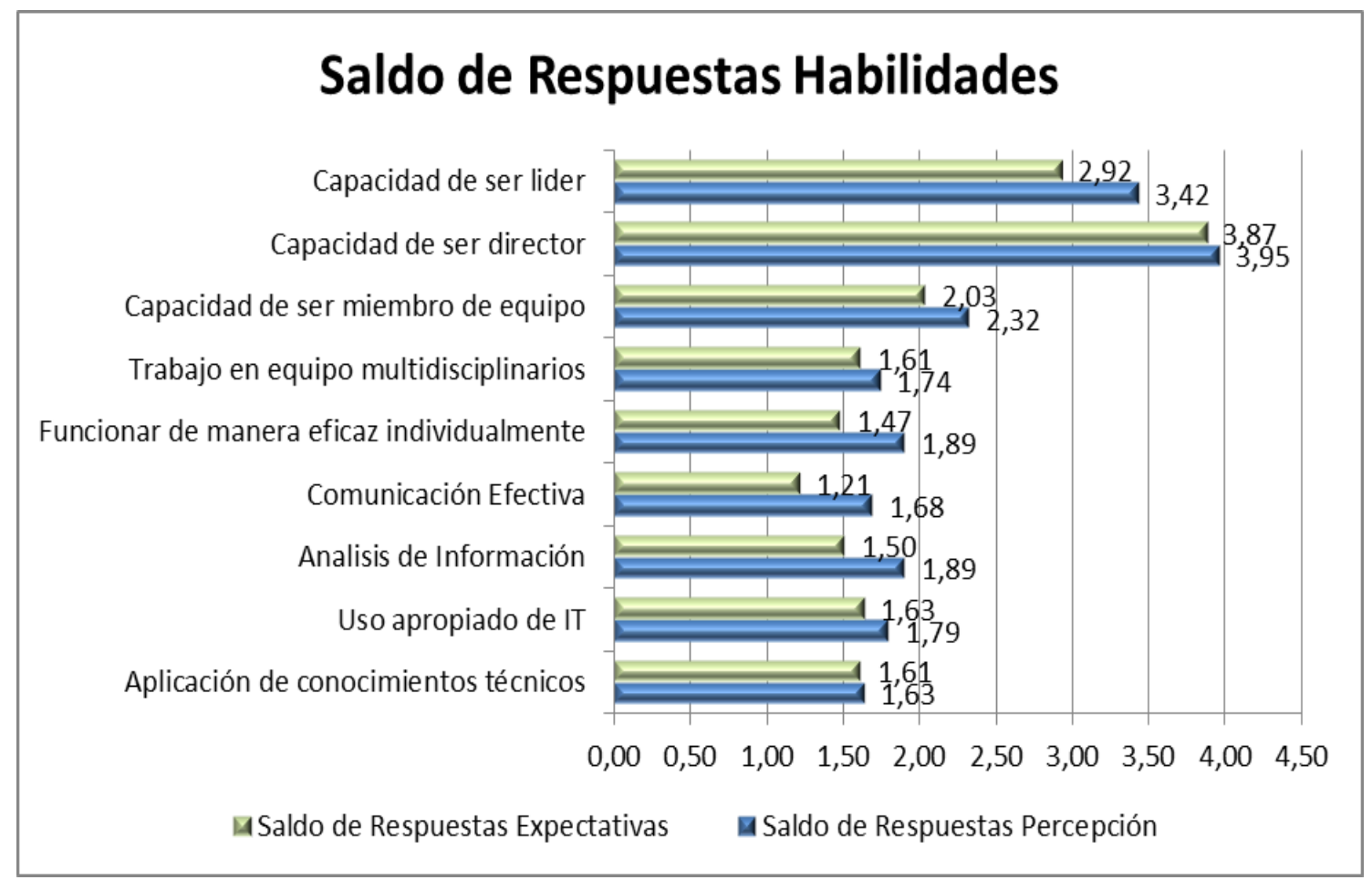

Fuente: Elaboración propia.

\subsubsection{Evaluación sobre actitudes}

Para culminar con la evaluación de los atributos del graduado, se presentan por último las cuestiones relacionadas con la Evaluación sobre actitudes, relacionadas con el pensamiento crítico, creativo y reflexivo en el trabajo, y los compromisos con el aprendizaje permanente, con cumplir responsabilidades éticas en su trabajo, con cuestiones ambientales, para desarrollar habilidades profesionales, para trabajar con diferentes grupos culturales, para utilizar habilidades grupales en el lugar de trabajo y para desarrollar habilidades interpersonales efectivas. 


\subsubsection{Pensamiento crítico, creativo y reflexivo en el trabajo}

\section{Expectativas y precepción}

El $95 \%$ de los encuestados cree que es altamente significativo que el graduado sea capaz de pensar crítica, creativa y reflexivamente en su trabajo y el $5 \%$ restante lo cree bastante más que significativo. A su vez, el $84 \%$ está entre muy de acuerdo y de acuerdo en que esto sucede.

El saldo de respuesta sobre la expectativa de 1.16 indica que los encuestados creen que es totalmente significativo que el graduado sea capaz de pensar de esa manera. $Y$ el saldo de respuesta de su percepción, 1.95, denota que están de acuerdo con un leve acercamiento a no estar seguro al respecto.

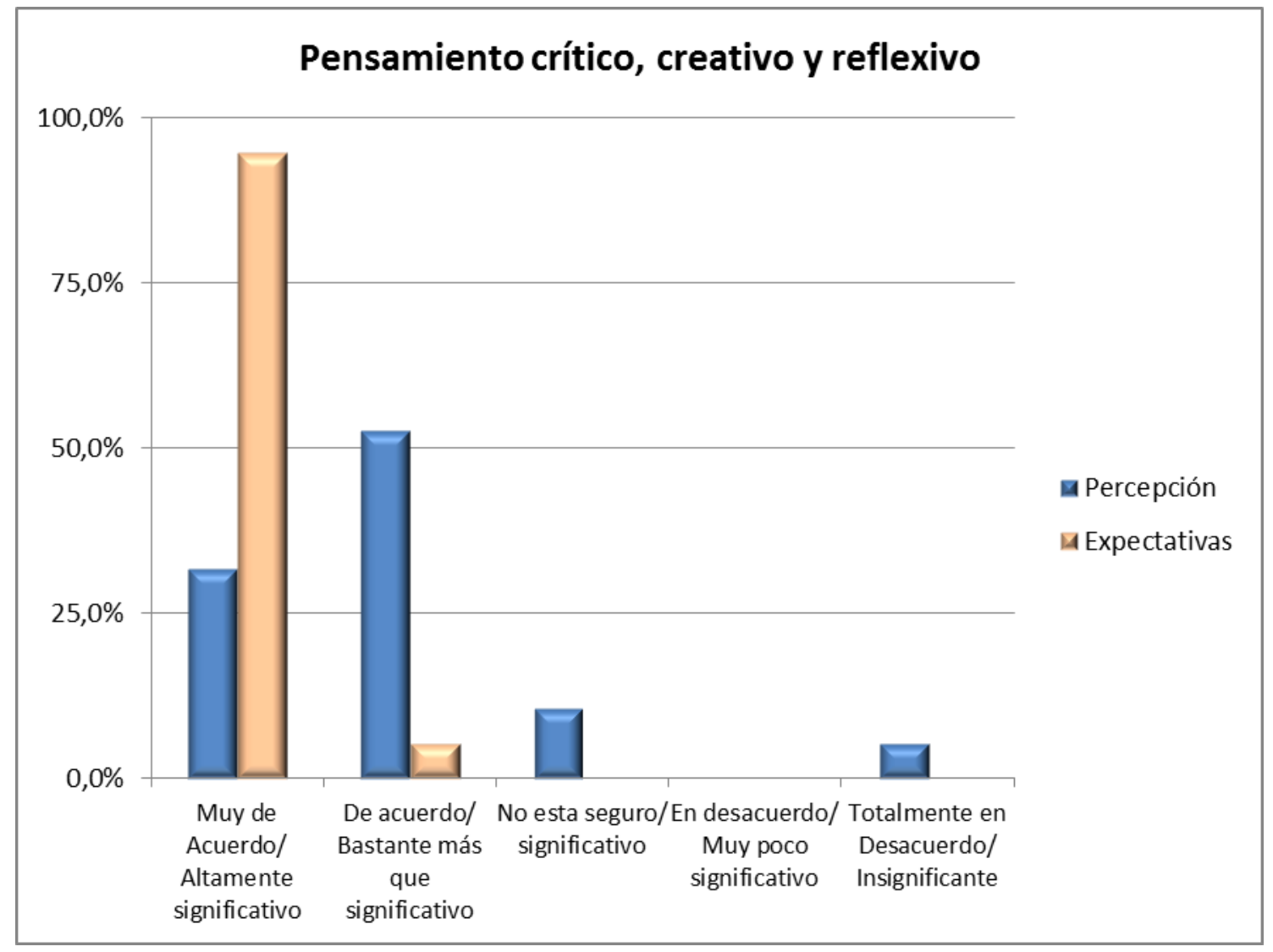

Fuente: Elaboración propia. 
Brechas

El saldo de respuesta del gráfico de brechas de -0.79 demuestra la satisfacción de los encuestados sobre este funcionamiento con una leve tendencia a estar algo insatisfechos.

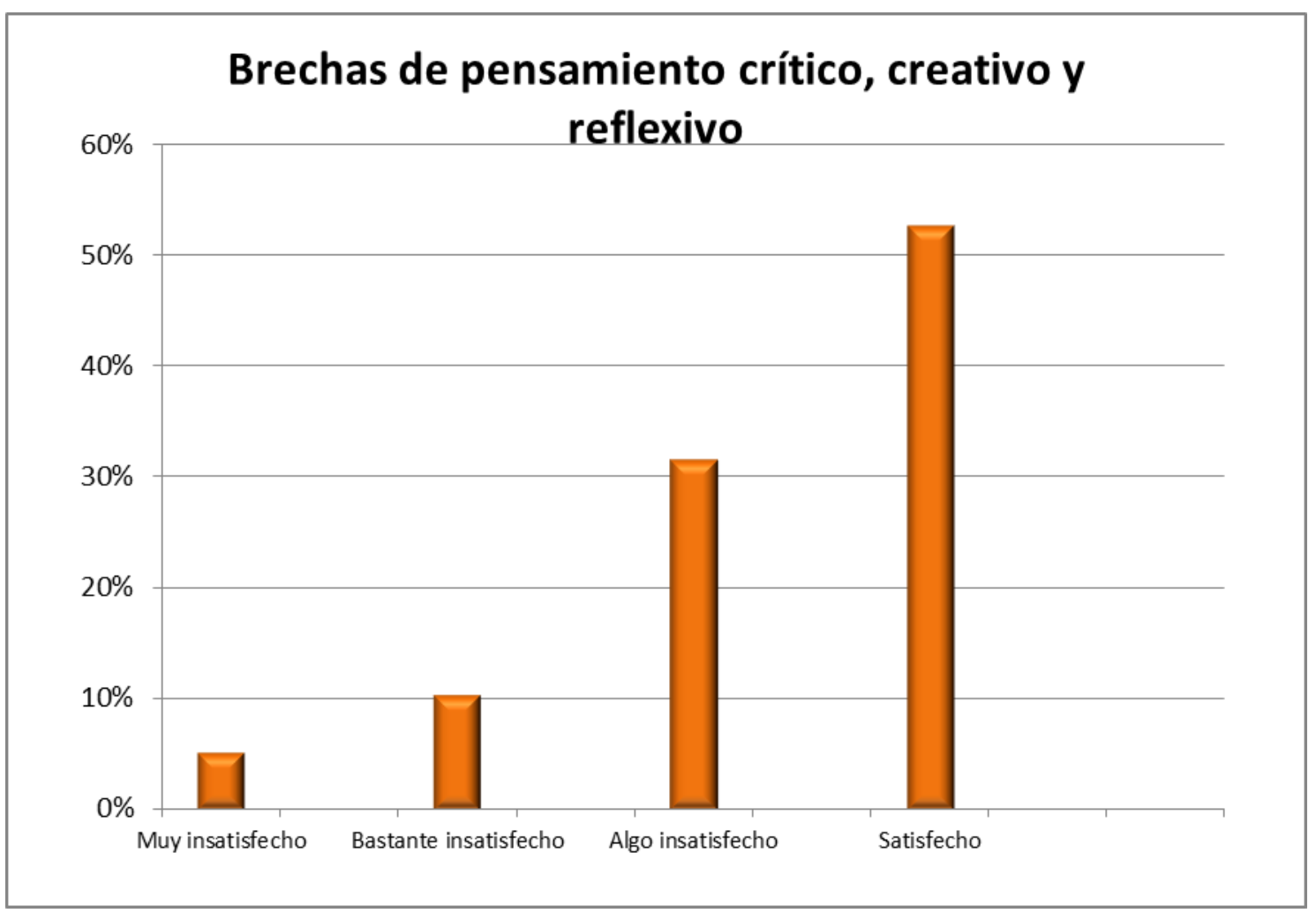

Fuente: Elaboración propia.

\subsubsection{Compromiso al aprendizaje permanente}

\section{Expectativas y percepción}

El $95 \%$ de los encuestados cree que es altamente significativo que el graduado sea capaz de comprometerse al aprendizaje permanente y el $5 \%$ restante lo cree bastante más que significativo. A su vez, $42 \%$ está de acuerdo que esto sucede, $37 \%$ muy de acuerdo, $16 \%$ no está seguro y sólo el $5 \%$ está totalmente de desacuerdo. 
El saldo de respuesta sobre la expectativa es de 1.18 e indica que los encuestados creen que es totalmente significativo que el graduado adquiera ese compromiso. Y el saldo de respuesta de su percepción, 1.95, denota que están de acuerdo con un leve acercamiento a no estar seguro al respecto.

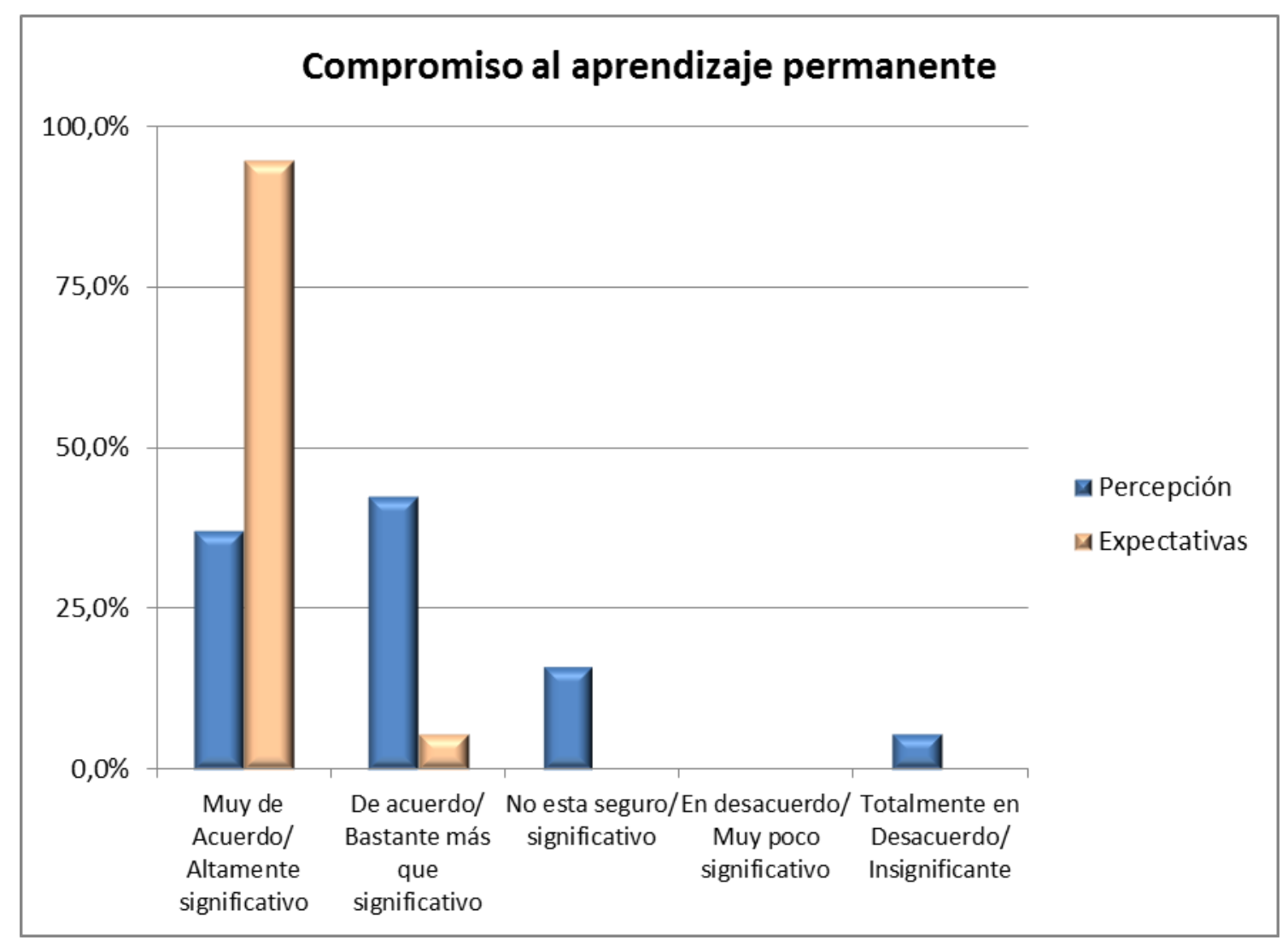

Fuente: Elaboración propia.

\section{Brechas}

El saldo de respuesta del gráfico de brechas de -0.76 demuestra la satisfacción de los encuestados sobre este funcionamiento con una leve tendencia a estar algo insatisfechos.

(gráfico en la página siguiente) 


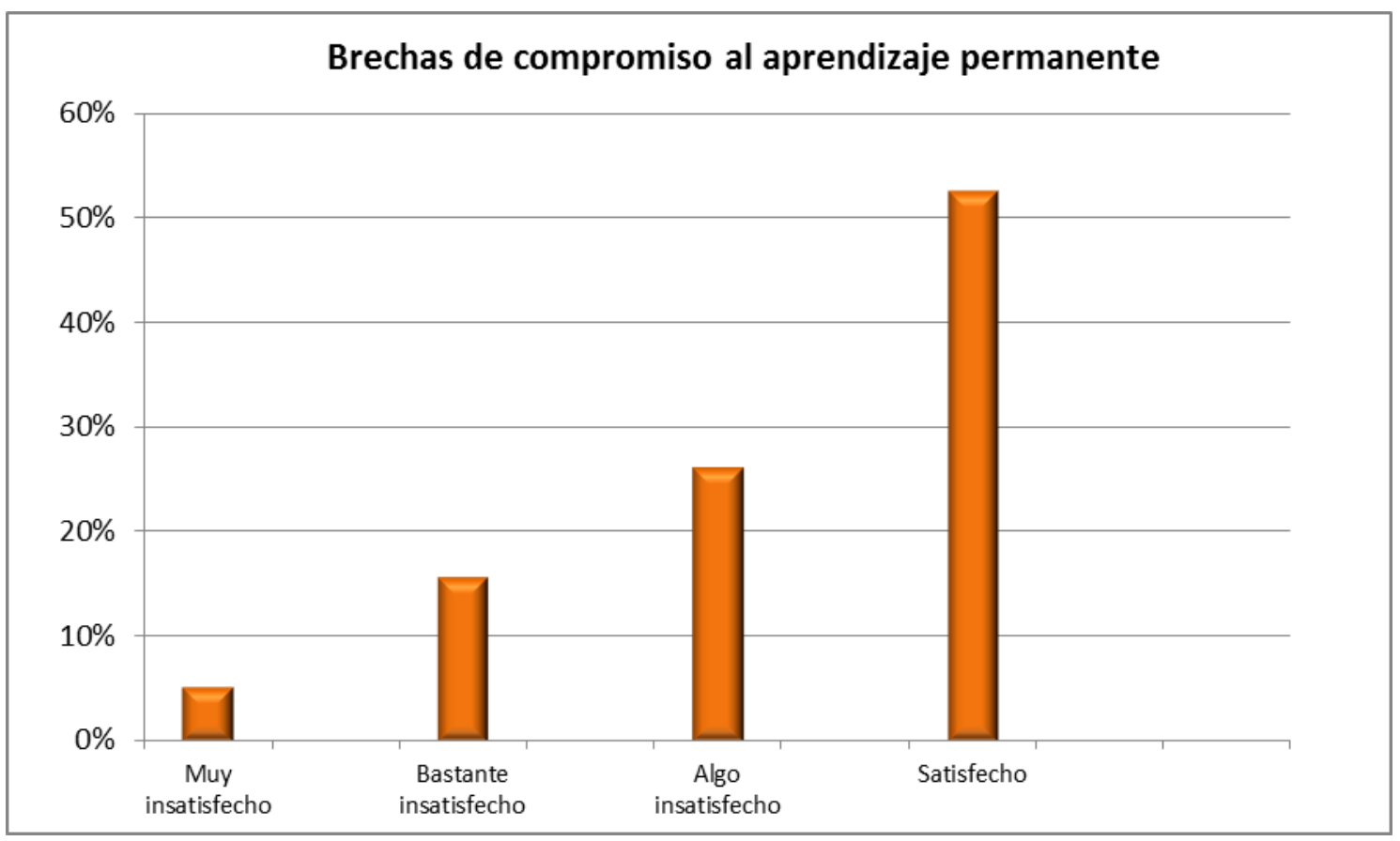

Fuente: Elaboración propia.

\subsubsection{Compromiso a cumplir responsabilidades éticas en su trabajo}

\section{Expectativas y percepción}

Poco más del $47 \%$ de los encuestados cree que es altamente significativo que el graduado sea capaz de comprometerse a cumplir con las responsabilidades éticas en su trabajo. En tanto $26 \%$ cree que es bastante más que significativo y el restante $26 \%$, significativo. Por otro lado, $26 \%$ está muy de acuerdo que esto sucede, $37 \%$ está de acuerdo, $31.5 \%$ no está seguro y $5 \%$ está totalmente en desacuerdo.

El saldo de respuesta sobre la expectativa de 1.95 indica que los encuestados creen que es totalmente significativo, con tendencia a ser bastante más que significativo el compromiso del graduado con las responsabilidades éticas en el trabajo. $\mathrm{Y}$ el saldo de respuesta de su percepción, 2.21, denota que están de acuerdo.

(gráfico en la página siguiente) 


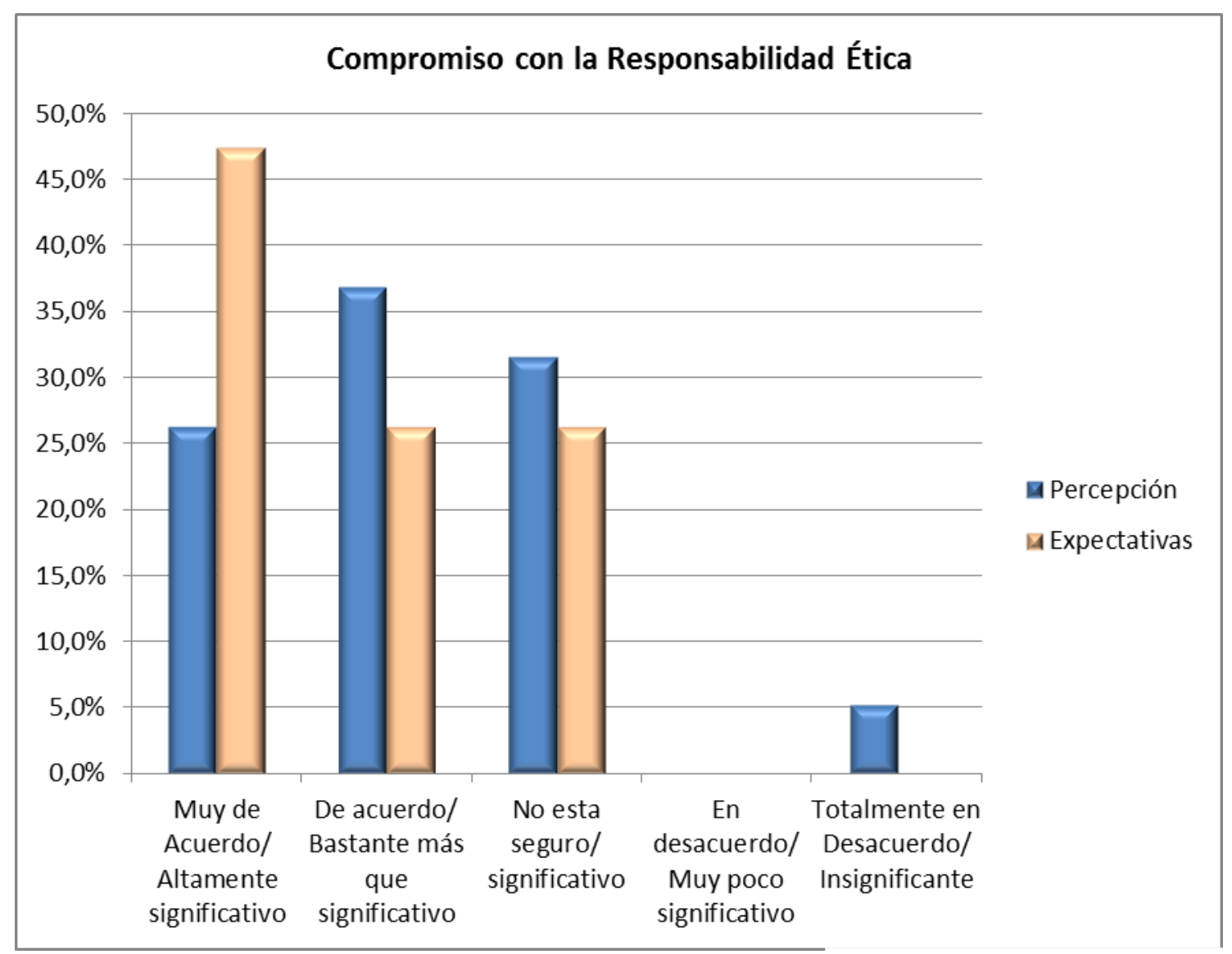

Fuente: Elaboración propia.

\section{Brechas}

El saldo de respuesta de las brechas sobre el compromiso con la responsabilidad ética es de $-0,26$. Ello demuestra la satisfacción de los encuestados.

(gráfico en la página siguiente) 


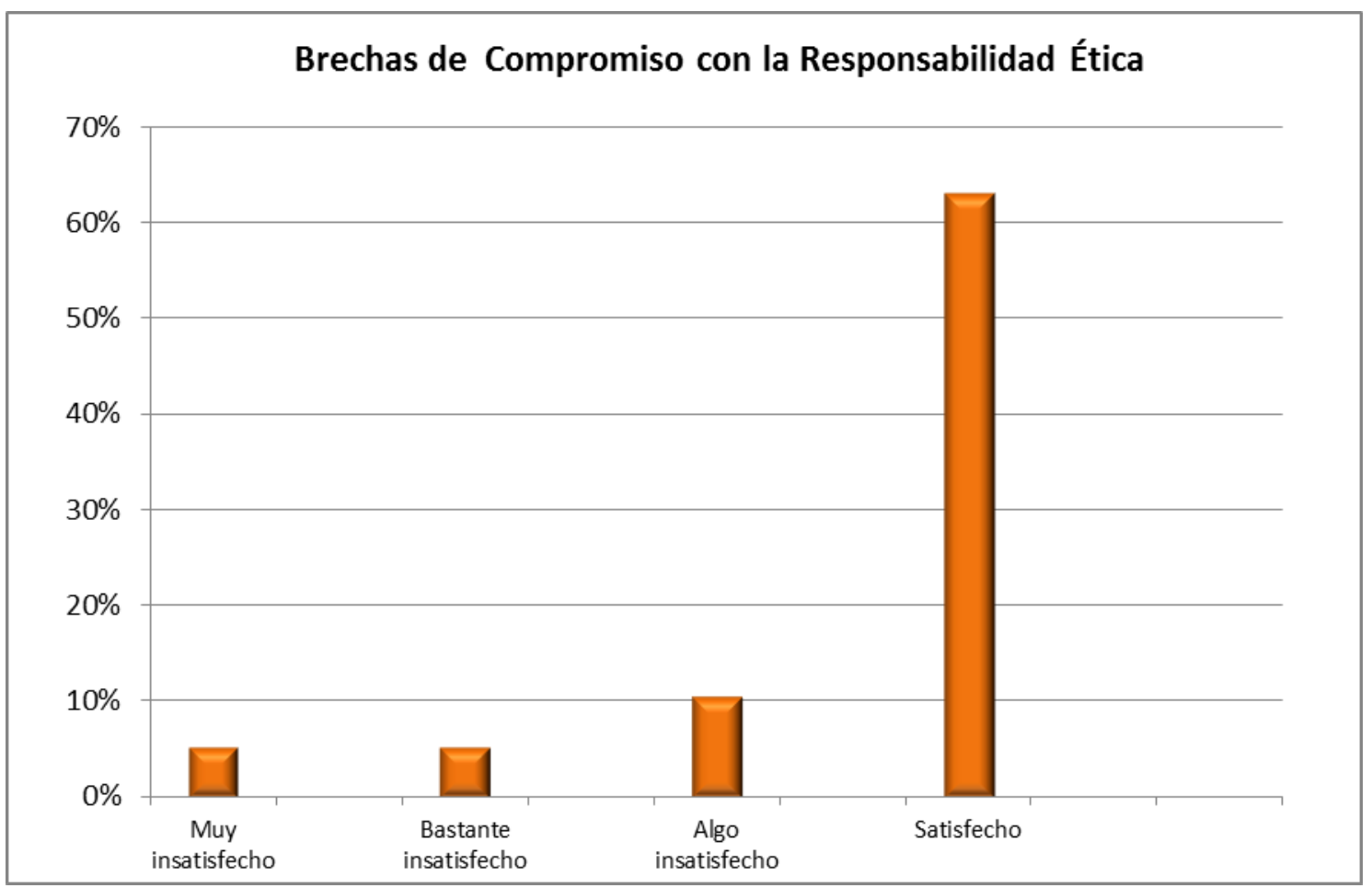

Fuente: Elaboración propia.

\subsubsection{Compromiso a cumplir responsabilidades ambientales en su trabajo}

Expectativas y percepción

Nuevamente, poco más del $47 \%$ de los encuestados cree que es altamente significativo que el graduado sea capaz de comprometerse a cumplir con las responsabilidades ambientales en su trabajo. En tanto $21 \%$ cree que es bastante más que significativo, $5 \%$ significativo y poco más del $26 \%$ que es muy poco significativo. Por otro lado, casi el 16\% está muy de acuerdo que esto sucede, $47 \%$ está de acuerdo, $31.5 \%$ no está seguro y $5 \%$ está totalmente en desacuerdo.

El saldo de respuesta sobre la expectativa de 2.18 indica que los encuestados creen que es bastante más que significativo el compromiso del graduado con las responsabilidades ambientales en el trabajo. $\mathrm{Y}$ el saldo de respuesta de su percepción, 2.32, denota que están de acuerdo con ello, pero con una leve tendencia a no estar seguros. 


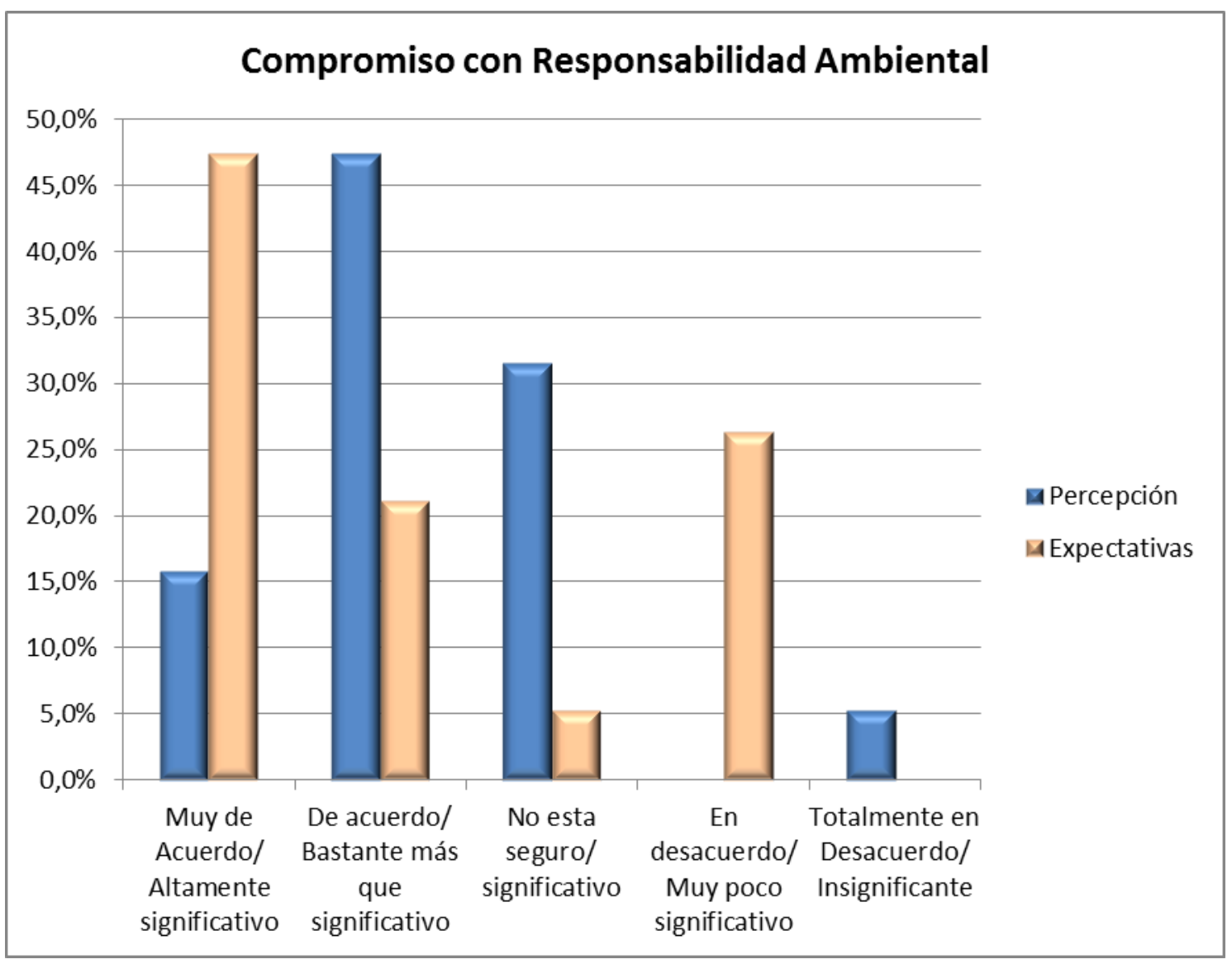

Fuente: Elaboración propia.

\section{Brechas}

El saldo de respuesta de las brechas sobre el compromiso con la responsabilidad ambiental en el trabajo es de -0,13. Ello demuestra la satisfacción de los encuestados.

(gráfico en la página siguiente) 


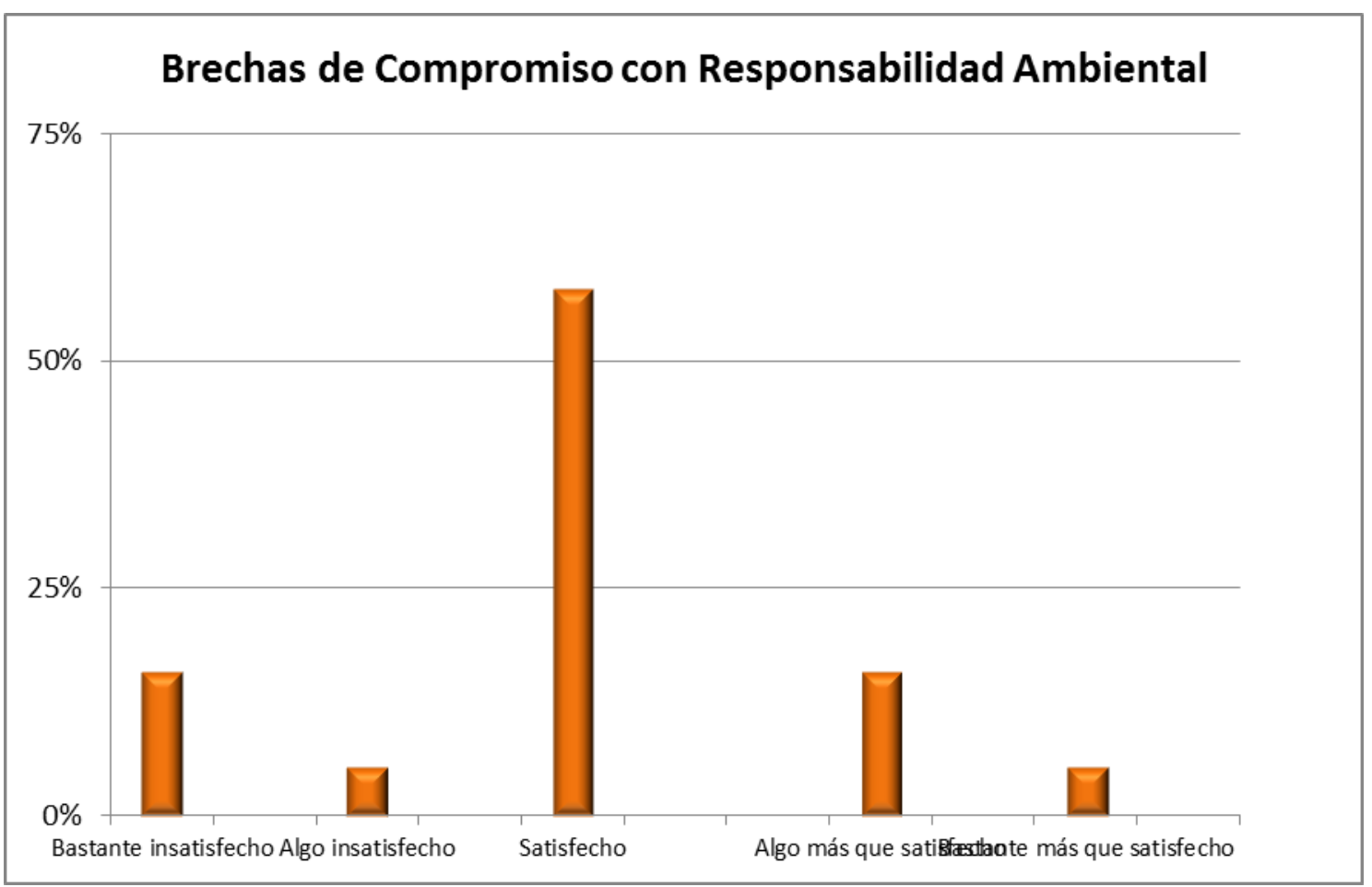

Fuente: Elaboración propia.

\subsubsection{Trabajo con perspectivas internacionales y mundiales} adecuándose a las mismas.

Expectativas y percepción

El $84 \%$ de los encuestados cree que es altamente significativo que el graduado sea capaz de trabajar con perspectivas internacionales y mundiales adecuándose a las mismas y el 16\% restante lo cree bastante más que significativo. A su vez, $52 \%$ está de acuerdo que esto sucede, $31.5 \%$ muy de acuerdo, $10.5 \%$ no está seguro y sólo el $5 \%$ está totalmente en desacuerdo.

El saldo de respuesta sobre la expectativa es de 1.34 e indica que los encuestados creen que es totalmente significativo que el graduado adquiera ese compromiso. Y el saldo de respuesta de su percepción, 1.95, denota que están de acuerdo con un leve acercamiento a no estar seguro al respecto. (gráfico en la página siguiente) 


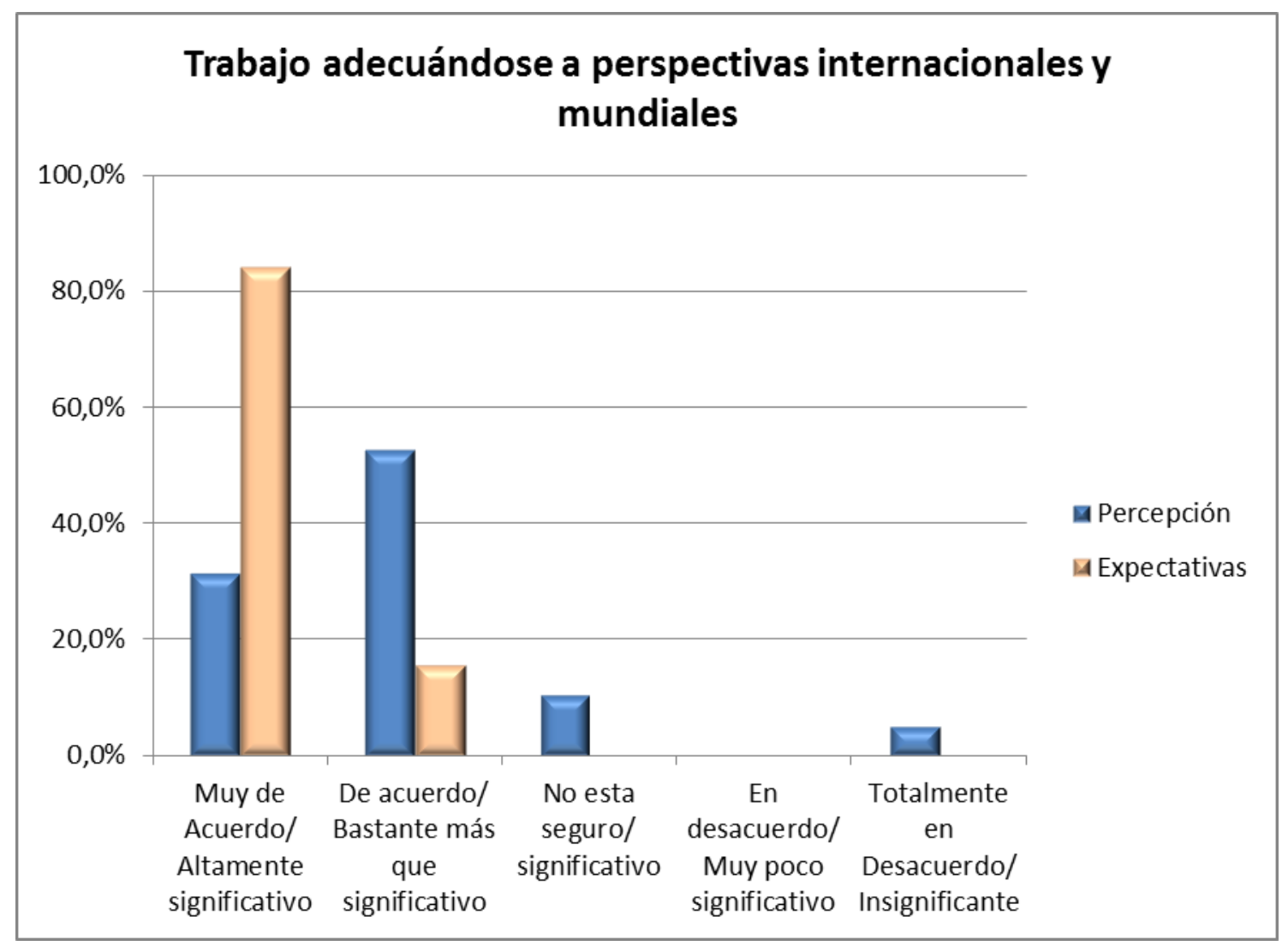

Fuente: Elaboración propia.

\section{Brechas}

El saldo de respuesta del gráfico de brechas de -0.61 demuestra la satisfacción de los encuestados sobre esta actitud del graduado con una leve tendencia a estar algo insatisfechos.

(gráfico en la página siguiente) 


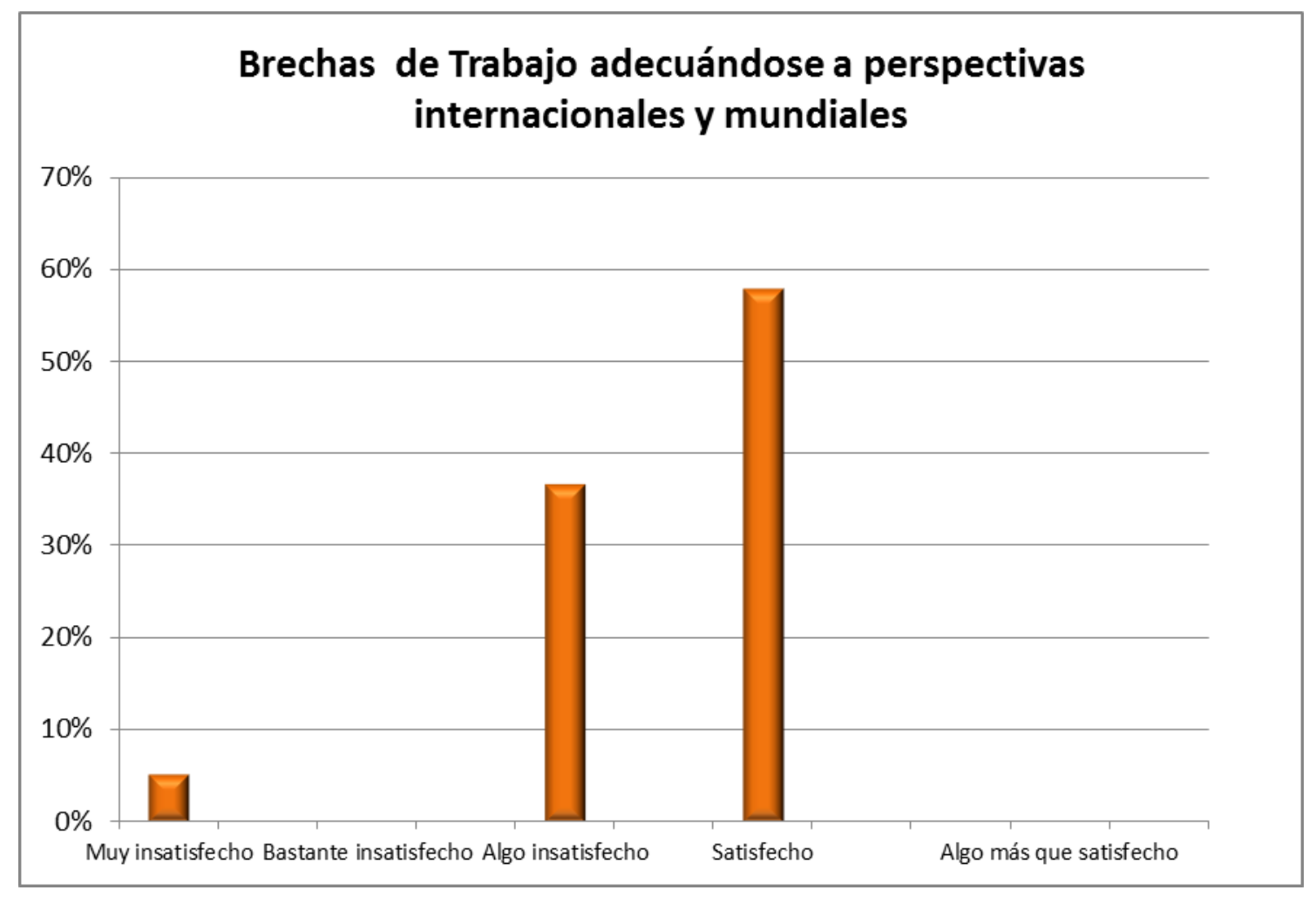

Fuente: Elaboración propia.

\subsubsection{Compromiso a desarrollar aún más sus habilidades profesionales}

Expectativas y percepción

Casi el $74 \%$ de los encuestados cree que es altamente significativo que el graduado sea capaz de comprometerse a desarrollar aún más sus habilidades profesionales y el resto lo cree bastante más que significativo. En ese sentido, el $68.5 \%$ está de acuerdo que esto sucede, el $21 \%$ muy de acuerdo y el restante $10.5 \%$ se divide en partes iguales entre los que no están seguros y los que están totalmente en desacuerdo.

El saldo de respuesta sobre la expectativa es de 1.47 e indica que los encuestados creen que es totalmente significativo, con una leve tendencia a bastante más que significativo, que el graduado adquiera ese compromiso. Y el saldo de respuesta de su percepción, 2.00, denota que están de acuerdo con un leve acercamiento a no estar seguro al respecto.

(gráfico en la página siguiente) 


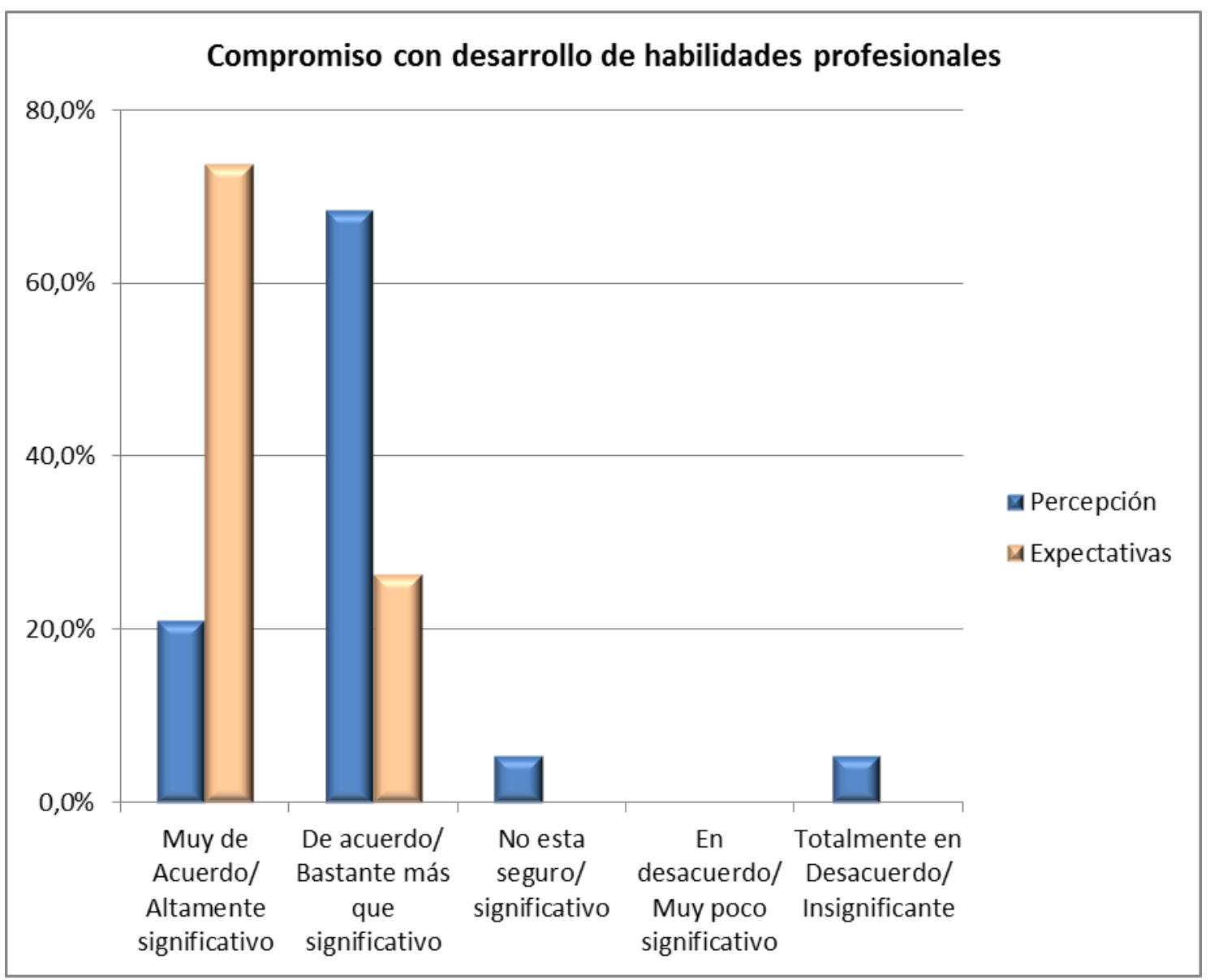

Fuente: Elaboración propia.

\section{Brechas}

El saldo de respuesta del gráfico de brechas de -0.53 demuestra la satisfacción de los encuestados sobre este compromiso, con una leve tendencia a estar algo insatisfechos.

(gráfico en la página siguiente) 


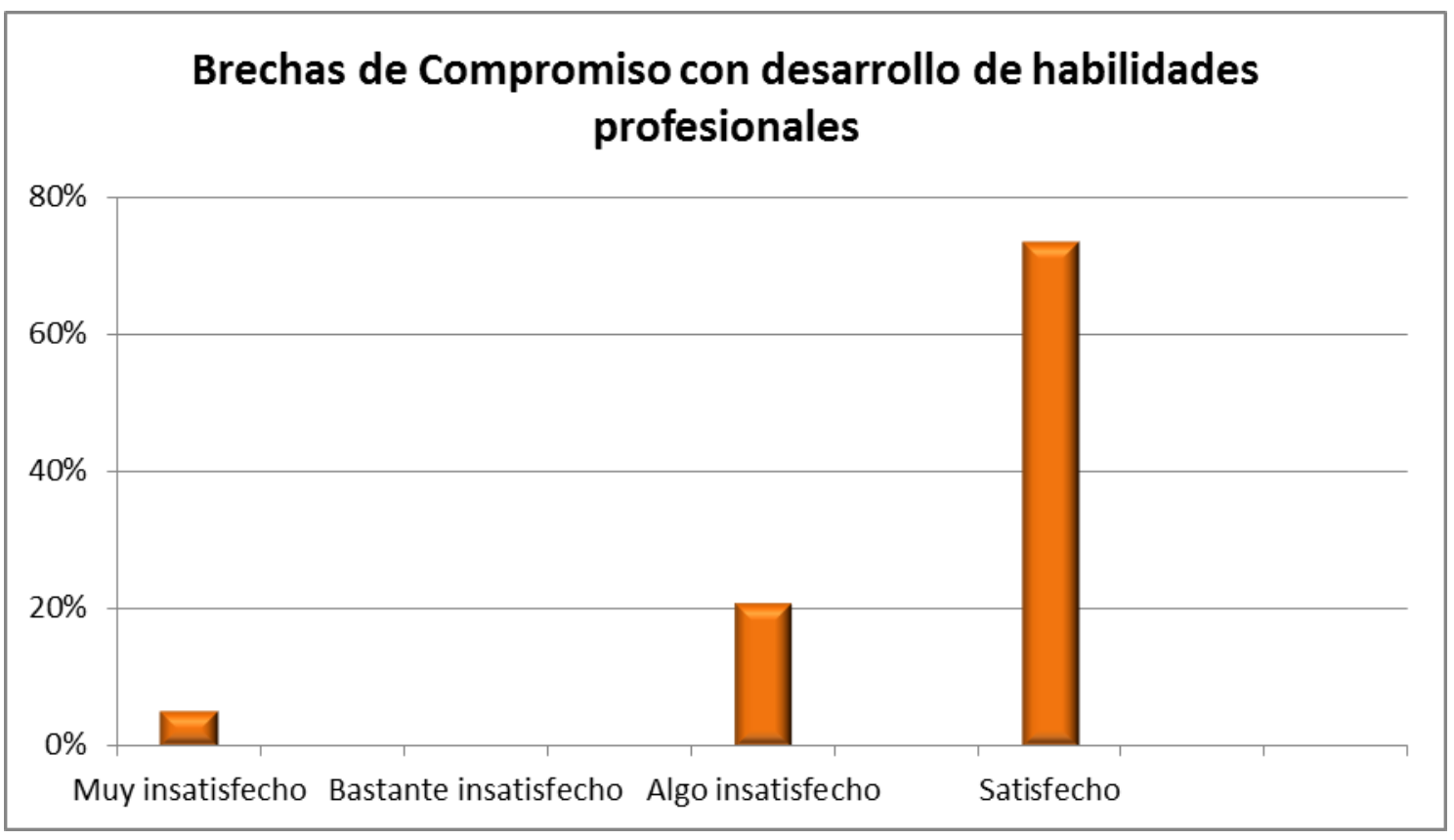

Fuente: Elaboración propia.

\subsubsection{Compromiso a trabajar efectivamente con diferentes grupos culturales}

Expectativas y percepción

El $63 \%$ de los encuestados cree que es altamente significativo que el graduado sea capaz de comprometerse a trabajar efectivamente con diferentes grupos culturales y el $37 \%$ restante lo cree bastante más que significativo. A su vez, $47.5 \%$ está de acuerdo que esto sucede, $42 \%$ muy de acuerdo y el restante $10.5 \%$ se divide en partes iguales entre los que no están seguros y los que están totalmente en desacuerdo.

El saldo de respuesta sobre la expectativa es de 1.53 e indica que los encuestados creen que es totalmente significativo, con una tendencia a bastante más que significativo que el graduado adquiera ese compromiso. Y el saldo de respuesta de su percepción, 1.79, muestra que están de acuerdo con un leve acercamiento a no estar seguro al respecto.

(gráfico en la página siguiente) 


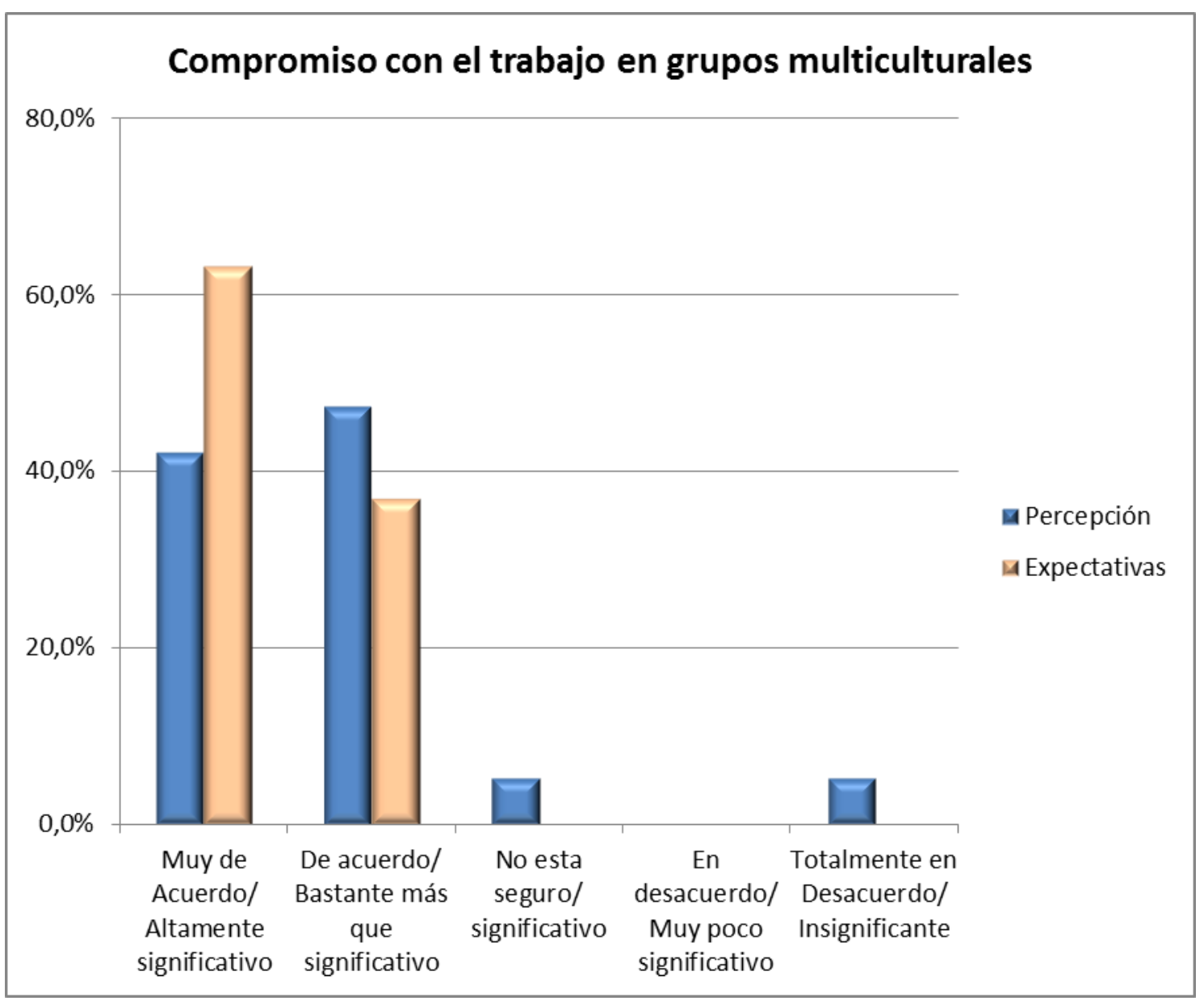

Fuente: Elaboración propia.

\section{Brechas}

El saldo de respuesta de las brechas sobre el compromiso con el trabajo en grupos multiculturales es de $-0,26$. Ello demuestra la satisfacción de los encuestados.

(gráfico en la página siguiente) 


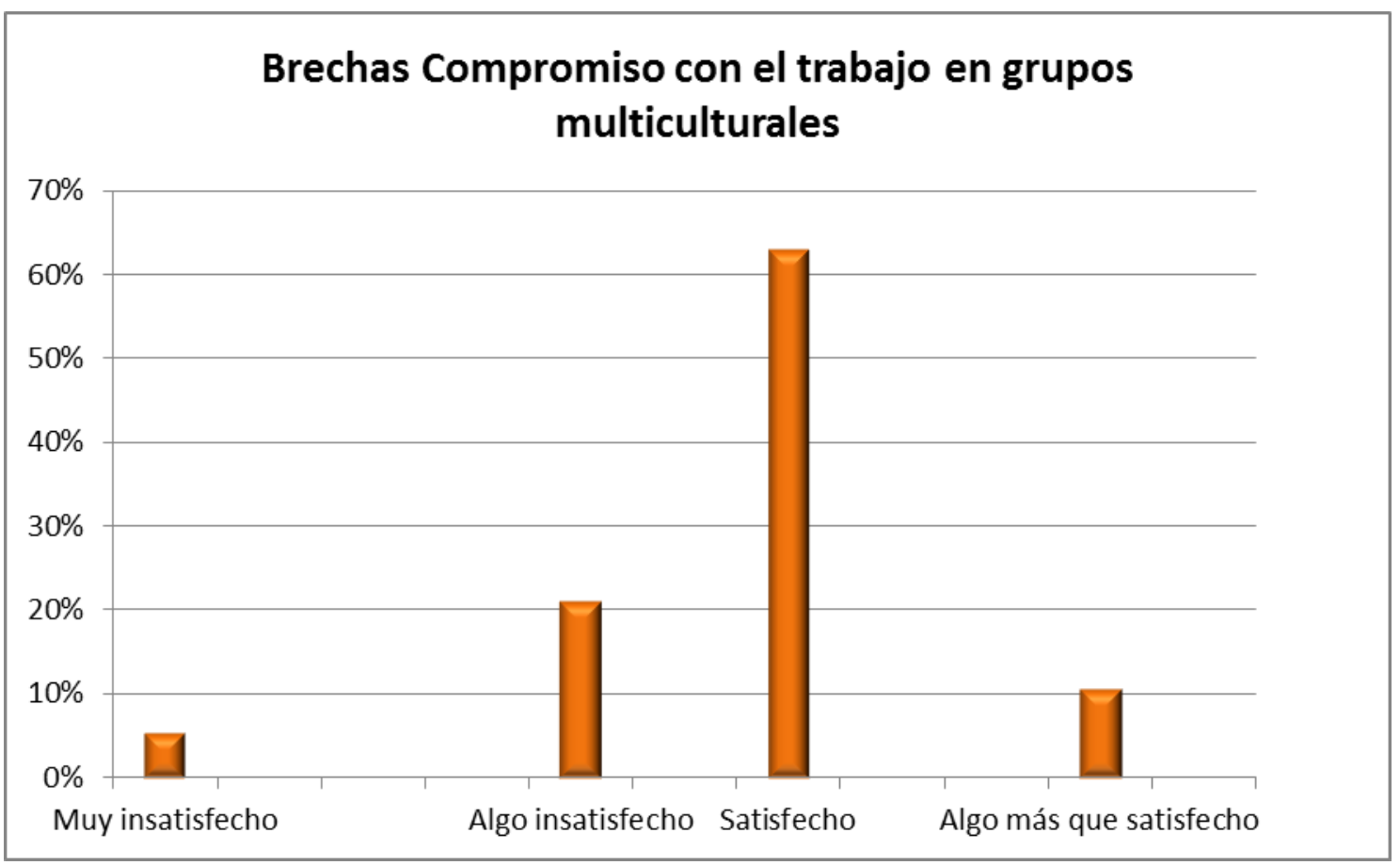

Fuente: Elaboración propia.

\subsubsection{Compromiso para utilizar sus habilidades grupales en su lugar de trabajo}

Expectativas y percepción

El $68.5 \%$ de los encuestados cree que es altamente significativo que el graduado sea capaz de comprometerse a utilizar sus habilidades grupales en su lugar de trabajo y el $31.8 \%$ restante lo cree bastante más que significativo. A su vez, $63 \%$ está de acuerdo que esto sucede, el $21 \%$ muy de acuerdo, el $10.5 \%$ no está seguro y el restante $5.5 \%$ totalmente en desacuerdo.

El saldo de respuesta sobre la expectativa es de 1.50 e indica que los encuestados creen que es totalmente significativo, con una tendencia a bastante más que significativo que el graduado adquiera ese compromiso. Y el saldo de respuesta de su percepción, 2.05, muestra que están de acuerdo con un leve acercamiento a no estar seguro al respecto.

(gráfico en la página siguiente) 


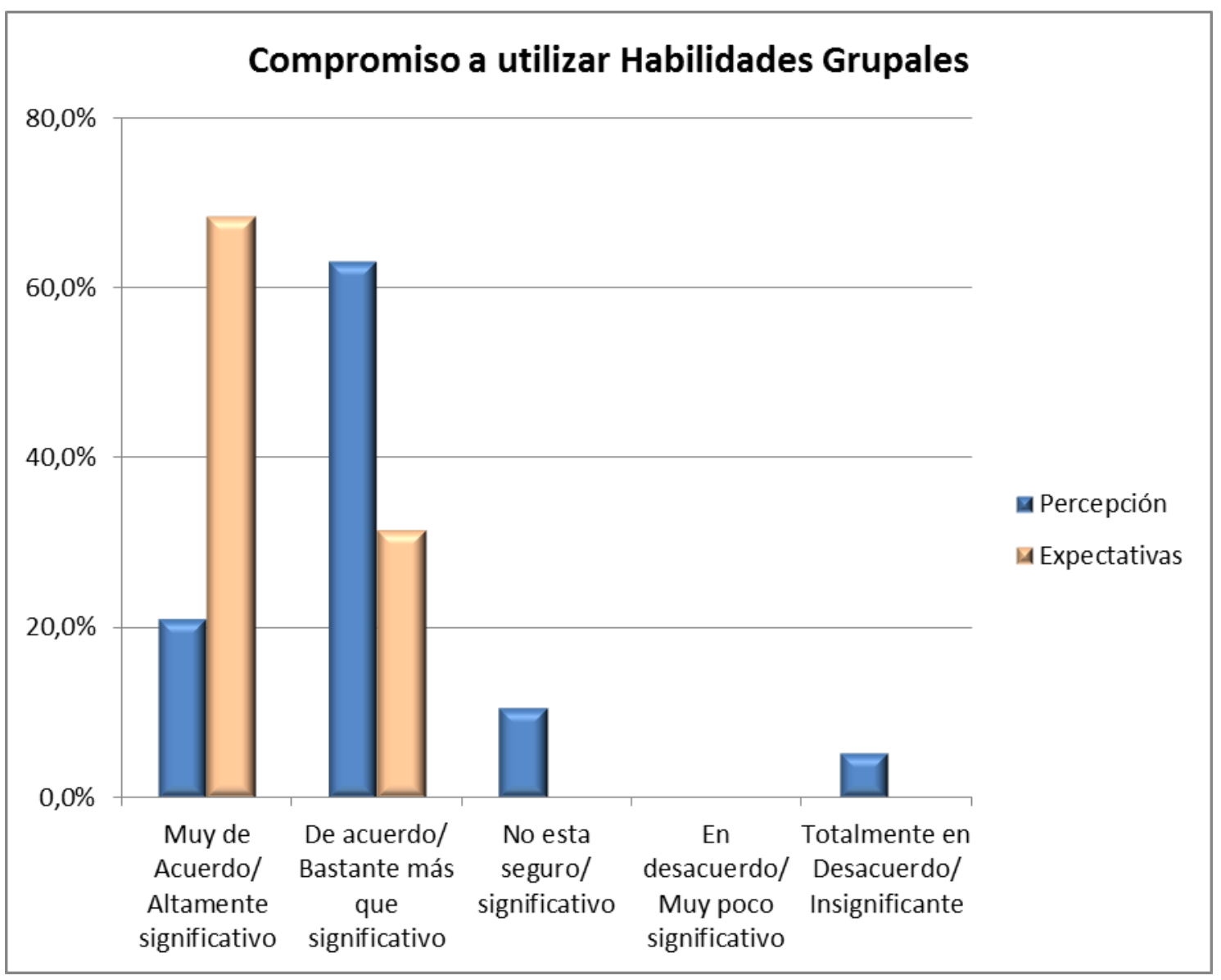

Fuente: Elaboración propia.

\section{Brechas}

El saldo de respuesta de las brechas sobre el compromiso con el trabajo en grupos multiculturales es de $-0,55$. Ello demuestra la satisfacción de los encuestados sobre este compromiso, con una leve tendencia a estar algo insatisfechos.

(gráfico en la página siguiente) 


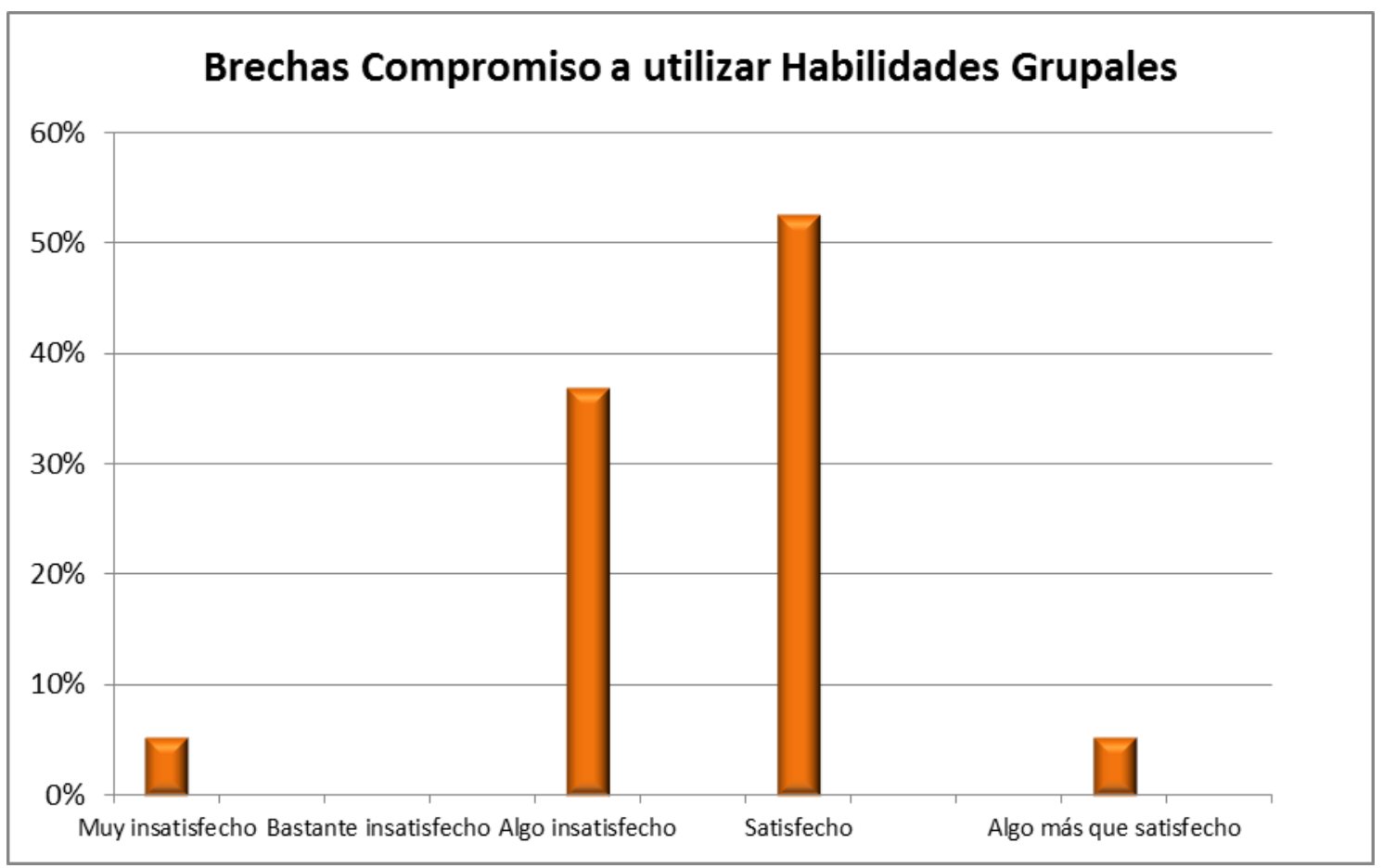

Fuente: Elaboración propia.

\subsubsection{Compromiso para desarrollar habilidades interpersonales efectivas en su lugar de trabajo.}

Expectativas y percepción

Casi el $74 \%$ de los encuestados cree que es altamente significativo que el graduado sea capaz de comprometerse a desarrollar habilidades interpersonales efectivas en su lugar de trabajo y el $26 \%$ restante lo cree bastante más que significativo. Por otro lado, $68.5 \%$ no está seguro que esto suceda, poco más del $26 \%$ está de acuerdo y el resto está en desacuerdo.

El saldo de respuesta sobre la expectativa es de 1.37 e indica que los encuestados creen que es totalmente significativo, con una tendencia a bastante más que significativo que el graduado adquiera ese compromiso. Y el saldo de respuesta de su percepción, 2.79, muestra que no están seguros con un leve acercamiento a estar de acuerdo.

(gráfico en la página siguiente) 


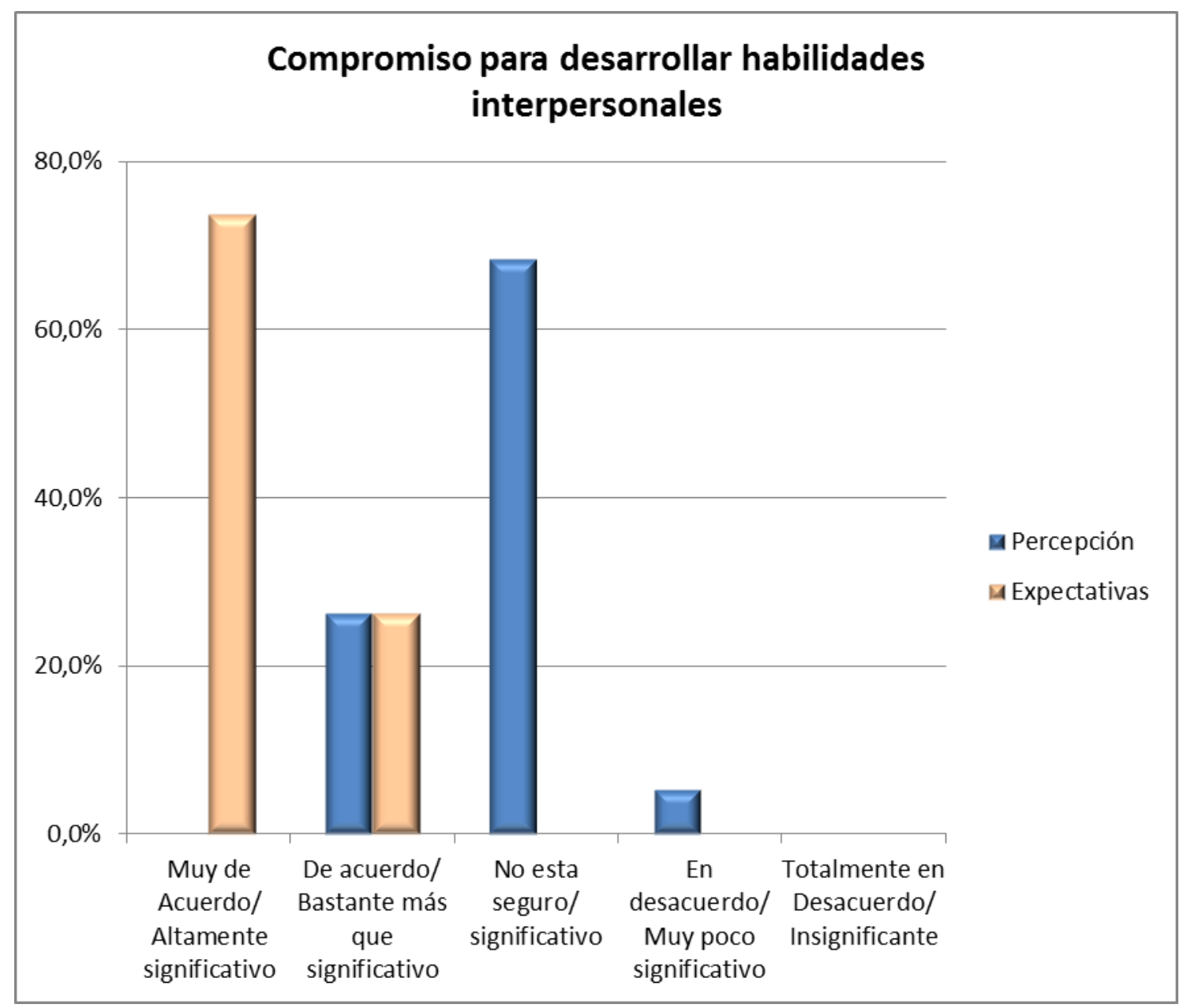

Fuente: Elaboración propia.

\section{Brechas}

El saldo de respuesta de las brechas sobre el compromiso para desarrollar habilidades interpersonales es de -1,42. Ello demuestra que los encuestados se encuentran algo insatisfechos sobre este compromiso, con una leve tendencia a estar bastante insatisfechos.

(gráfico en la página siguiente) 


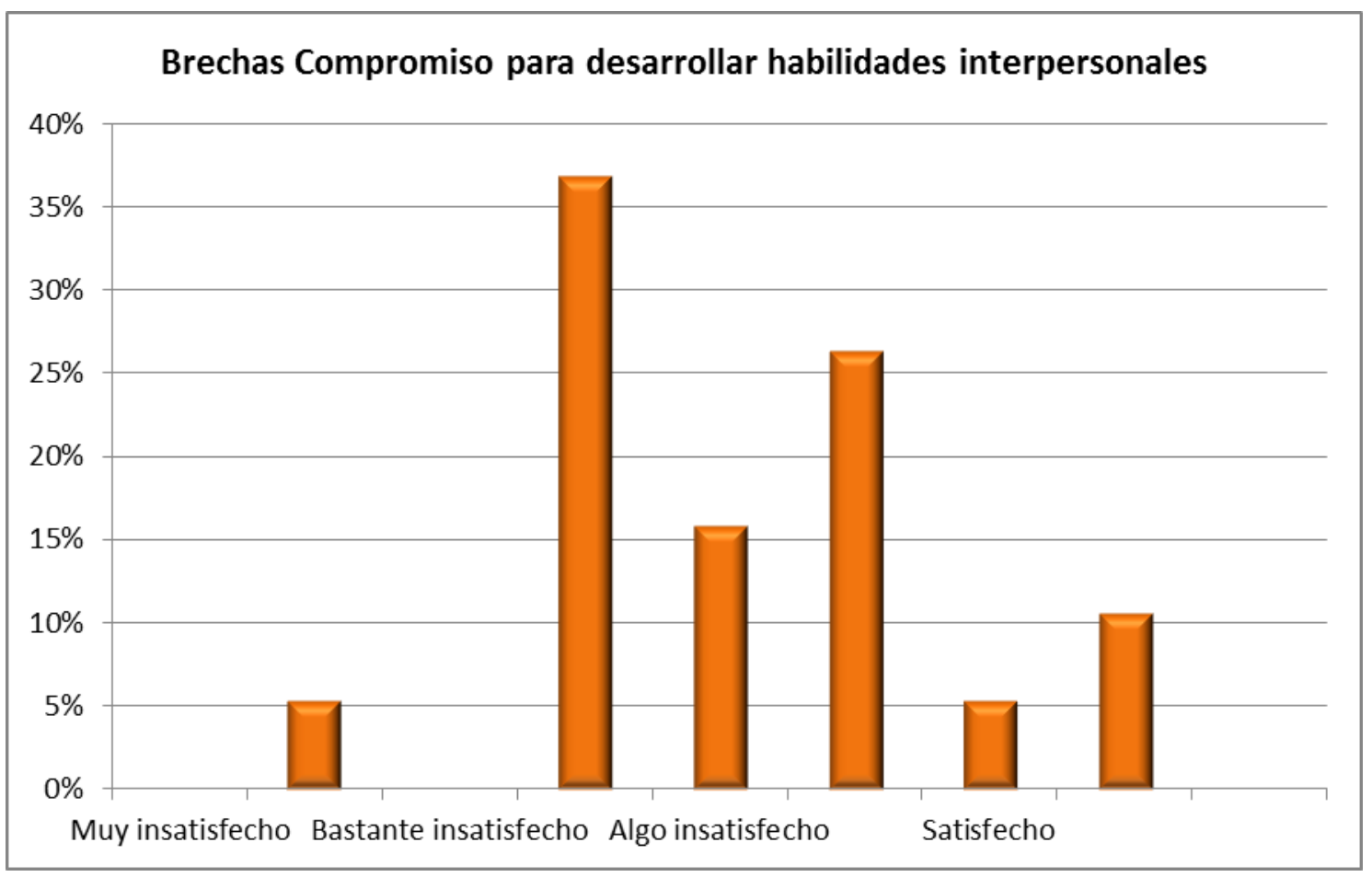

Fuente: Elaboración propia.

\subsubsection{Saldos de respuestas del atributo ACTITUDES}

Teniendo en cuenta que en lo referido a expectativas, 1 es totalmente significativo y 5 es insignificante, se puede ver que, en general, los conceptos de actitudes analizados resultan totalmente significativos para los encuestados, a excepción de Responsabilidad ética y Responsabilidad Ambiental que se consideran bastante más que significativos.

En lo referido a percepción, siendo 1 muy de acuerdo y 5 totalmente en desacuerdo, podemos apreciar que en la mayoría de los conceptos analizados el empleador está de acuerdo con las actitudes del graduado, a excepción de Desarrollo de habilidades interpersonales en el que no está seguro que así sea. (gráfico en la página siguiente) 


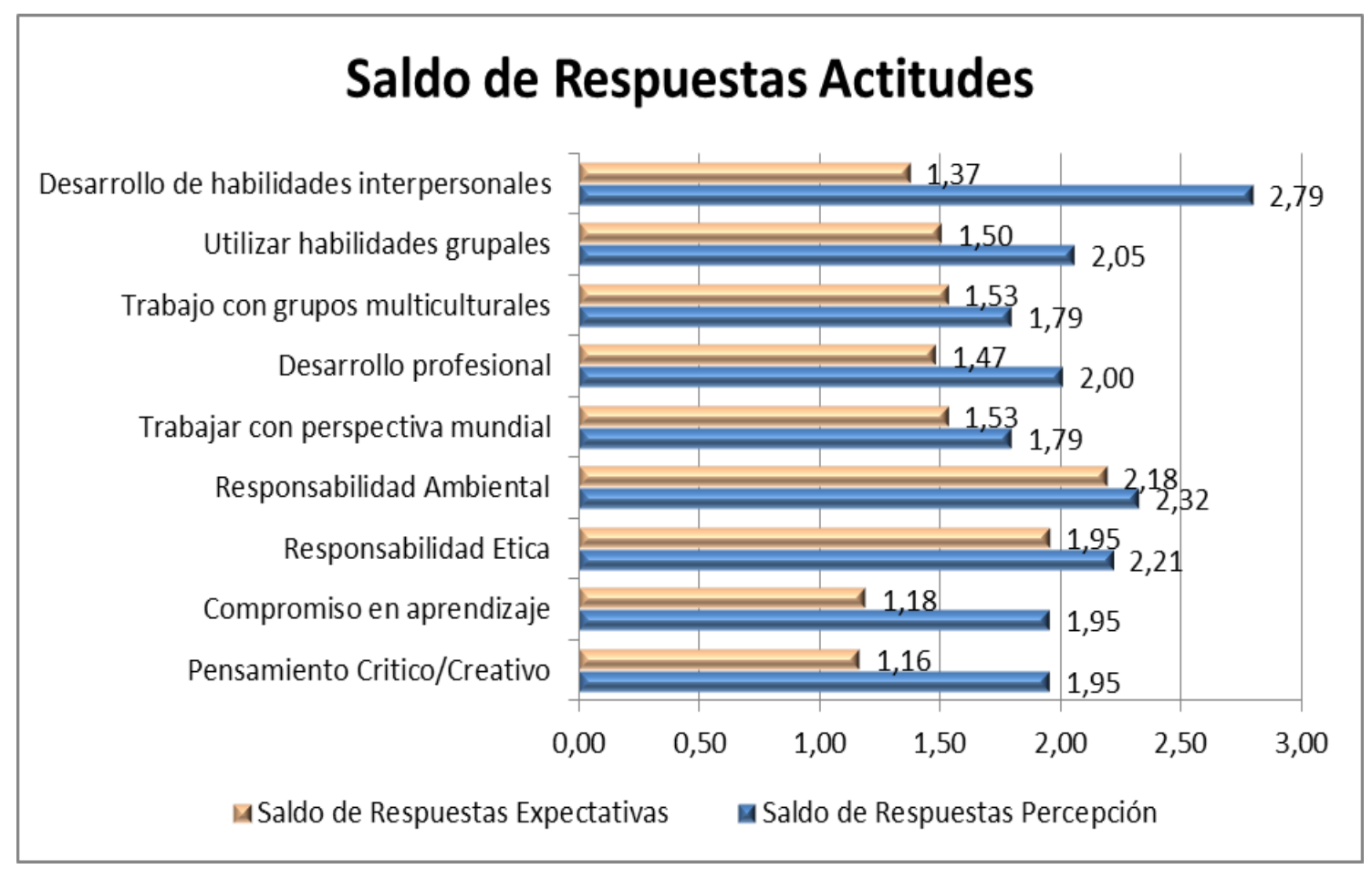

Fuente: Elaboración propia.

\subsection{Desempeño en el trabajo por parte del graduado}

Duración y Calidad del trabajo realizado por los graduados

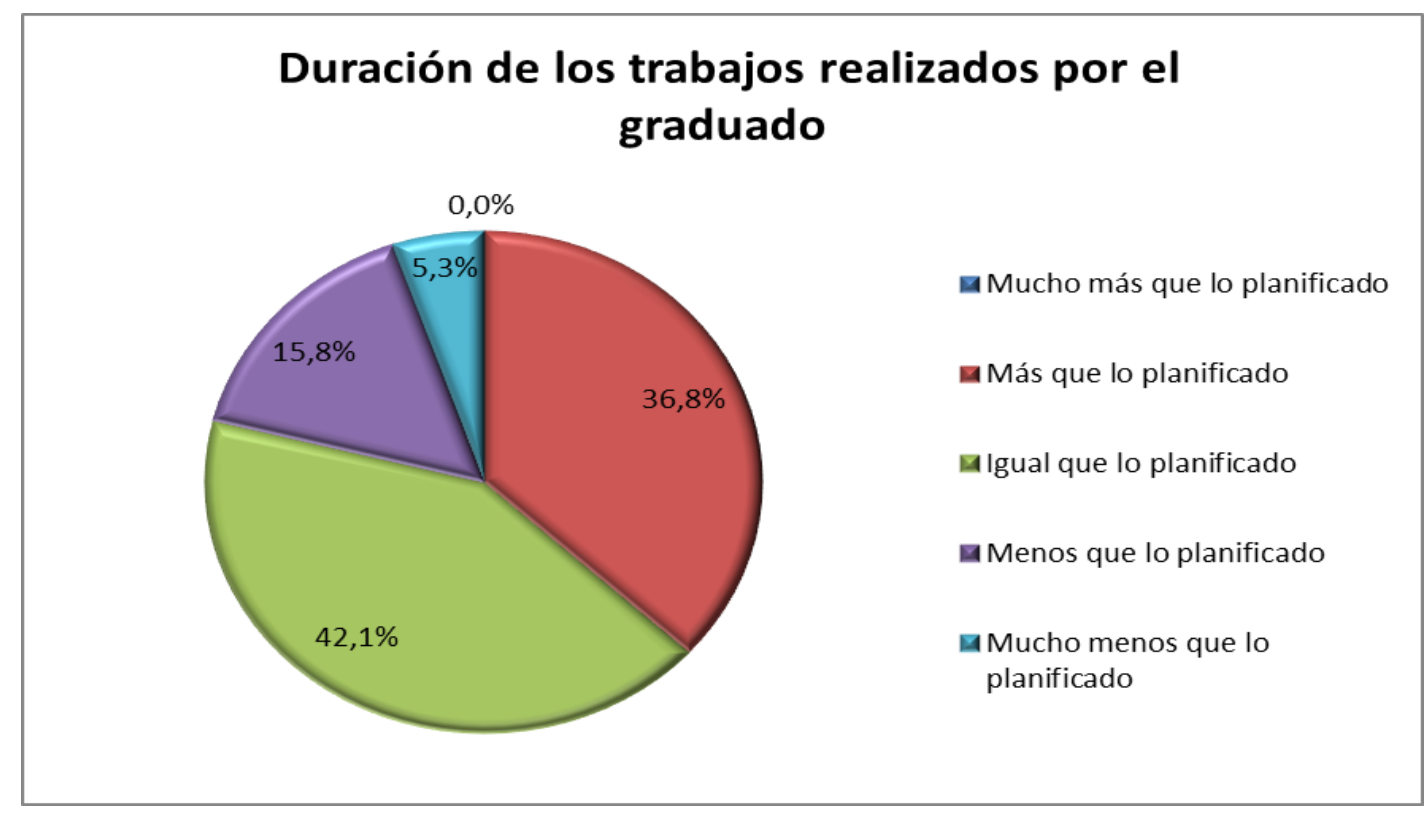

Fuente: Elaboración propia. 
Al preguntar sobre la duración de los trabajos realizados por el graduado, poco más del $42 \%$ de los encuestados afirmó que el tiempo fue igual a lo planificado, casi el $37 \%$ que fue más que ello, el $15.8 \%$ menos, y sólo el $5.3 \%$ mucho más que lo planificado.

El saldo de respuesta de 2.89 indica que la duración real del trabajo realizado por el graduado es igual a lo planificado, con una leve tendencia a más de lo planificado.

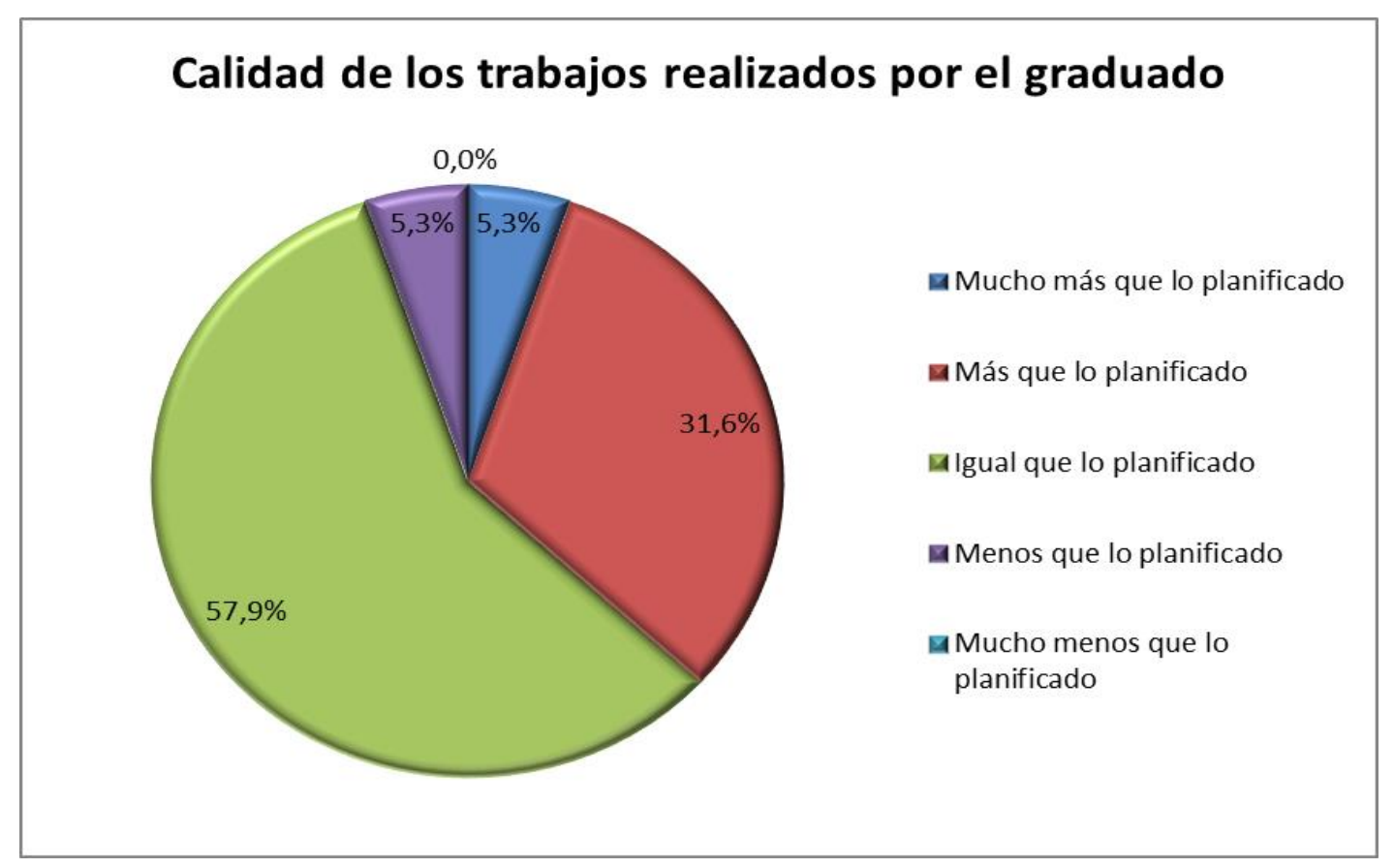

En lo que refiere a la calidad de los trabajos, ce Fuente: Elaboración propia.

fue igual a lo que se planificó, el $31.6 \%$ que fue más de lo planificado, el $5.3 \%$ menos, y el restante $5.3 \%$ mucho más que lo planificado.

El saldo de respuesta de 3.37 indica que la calidad del trabajo realizado por el graduado es igual a lo planificado, con una leve tendencia a más de lo planificado. 


\subsection{Satisfacción de los empleadores respecto del trabajo de los graduados}

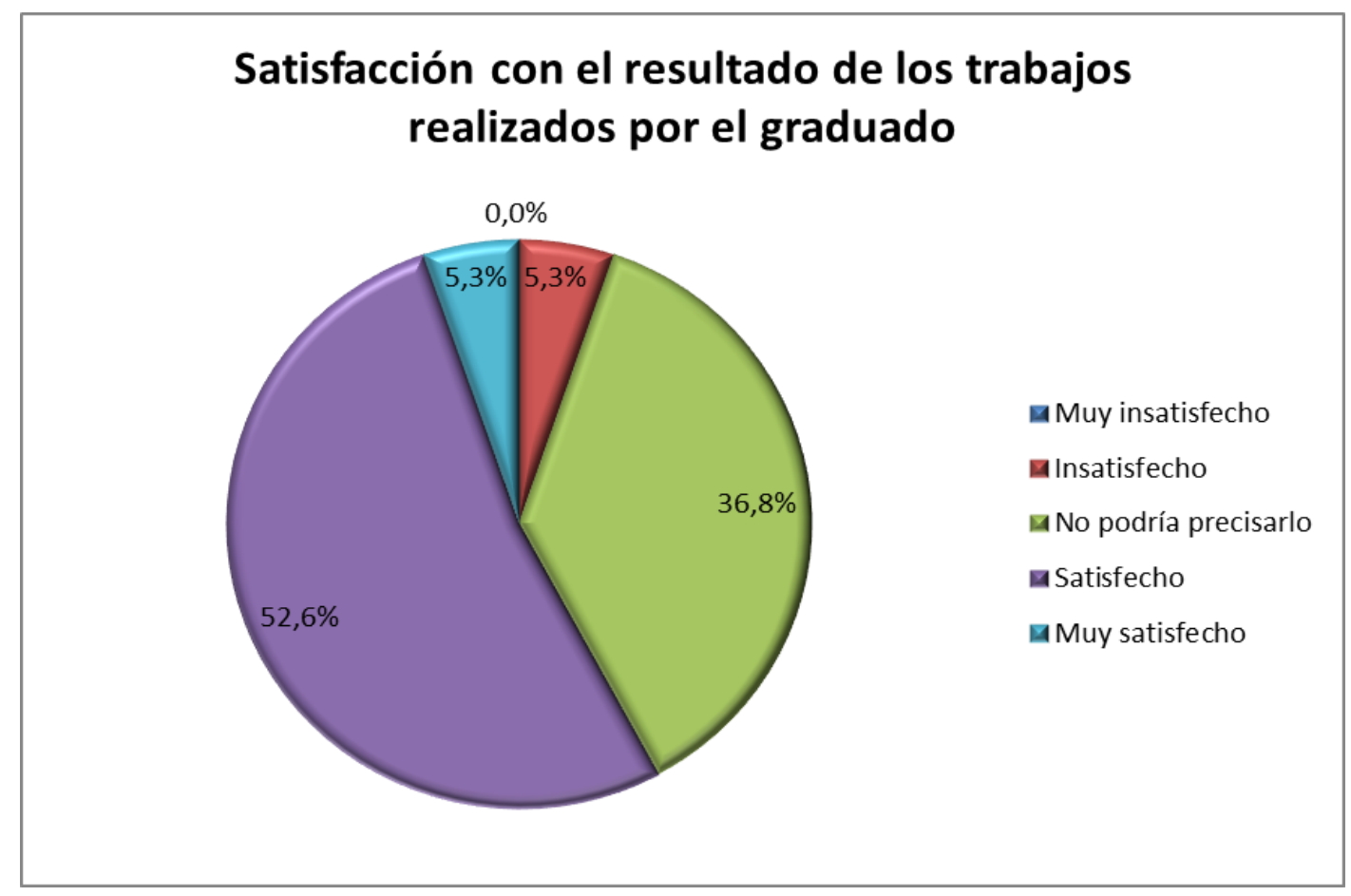

Fuente: Elaboración propia.

En términos generales, el $52.6 \%$ de los encuestados está satisfecho con los resultados de los trabajos realizados por el graduado, el $36.6 \%$ no podría precisarlo, el 5.3\% está insatisfecho y el restante 5.3\% muy insatisfecho.

El saldo de respuesta de 3.58 de los resultados de los trabajos realizados por el graduado, indica que los encuestados están satisfechos al respecto, pero tienen una leve tendencia a no poder precisar su satisfacción. 


\section{Conclusiones}

Planteado y evaluado el problema de investigación, formulados los objetivos de la misma, y habiendo relevado y procesado toda la información de fuente primaria originada en la muestra específica de empleadores de graduados en Enfermería, se pudieron presentar, en el apartado anterior, los resultados a los que se llegó siguiendo la metodología específica de investigación que se decidió emplear. Sobre esos resultados, se formulan las siguientes conclusiones:

- En general, en el análisis que los empleadores hacen sobre la calidad profesional de los graduados, se manifiesta, para todos los atributos, que el nivel de expectativa sobre el desempeño en el desarrollo de las distintas tareas está por encima de lo que se percibe como desempeño real. Esto permite afirmar que, en base a los resultados del estudio, existe una brecha de calidad entre lo que demandan los empleadores y lo que, dado su nivel de calidad, están en condiciones de ofrecer los graduados.

- Se puede considerar que los empleadores son conscientes del nivel de calidad que demandan a quienes ocupan los puestos de trabajo que ellos ponen a disposición en el mercado de trabajo. En base a la muestra relevada, cuatro quintos de los empleadores tienen más de dos años de experiencia en los puestos que implican la jefatura y/o supervisión de los graduados en Enfermería (y la mitad de la muestra, más de tres años). De este nivel de experiencia, se puede concluir que los empleadores tienen conocimiento suficiente de qué tienen que exigir de un graduado en cuanto a requisitos de calidad.

- Además, en cuanto a relaciones de jefatura y/o supervisión, la totalidad de los empleadores tienen con los graduados un vínculo de este tipo, descartando como se vio en los resultados cualquier otro tipo de vínculo menos directo. Esto reafirma la conclusión del buen conocimiento que tienen los empleadores sobre el 
desempeño y la persona de los graduados, validando aún más las mediciones obtenidas en cuanto a expectativas y percepción de desempeños en los puestos de trabajo.

- Casi el $70 \%$ de los empleadores trabajan en centros u organizaciones de salud de La Plata, ciudad de la zona alcanzada por la investigación en donde se registran una mayor cantidad en relación a la población total de centros de mediana y alta complejidad. Esto permite afirmar que la muestra de empleadores maneja en promedio criterios de calidad por encima de valores medios, validando también las mediciones sobre expectativas y percepción.

- Las brechas de calidad que en general se registraron entre las expectativas y las percepciones de los empleadores respecto del desempeño real de los graduados, podría haber sido mayor si no fuera que dos terceras partes de estos últimos han continuado capacitándose luego de su graduación terciaria. Además, casi el $70 \%$ de lo que decidieron seguir capacitándose lo hicieron eligiendo la Licenciatura, oferta académica de mayor exigencia profesional que la de Vacunación.

- Si a lo dicho en el ítem anterior se le suma la consideración de que las dos terceras partes de los graduados recibe capacitación en el lugar de trabajo, y que la totalidad de los graduados tiene más de dos años de experiencia en sus puestos, se puede concluir que existe una buena base en cuanto a la calidad innata de graduados para intentar reducir la brecha entre expectativas y percepción. (Resta sobre lo considerado el hecho de que las capacitaciones en el lugar de trabajo no sean esfuerzos prolongados: cuatro quintos de estas acciones de capacitación duran menos de dos meses.)

- En cuanto a los atributos de los graduados referidos a sus conocimientos, se puede apreciar una satisfacción con una leve 
tendencia a estar algo insatisfechos en los ítems definidos. La mayor insatisfacción se registra en las mediciones que tienen que ver con las implicancias y consecuencias económicas y con los fundamentos económicos en el desarrollo de las tareas. Se nota entonces que los graduados registran falencias en la consideración de las consecuencias y lo determinantes de su desempeño sobre las organizaciones de salud consideradas como negocio, algo que puede ser puntualmente perjudicial para el caso de las organización privadas con fines de lucro (en las que cobran especial trascendencia el desempeño de los graduados como aportantes al valor de las empresas).

- Por el contrario, registran mejores mediciones los atributos también referidos a los conocimientos pero que tienen que ver con las cuestiones troncales del trabajo de los graduados, las más relacionadas con su parte "técnica". Es así como las mediciones mejoran en situaciones en las que el graduado aplica los principios y conceptos básicos de sus tareas, con profundidad de sus conocimientos técnicos al momento de analizar situaciones y aplicar una metodología para la resolución de problemas.

- Sobre los atributos referidos a las habilidades de los graduados se puede concluir que, en general, los empleadores se encuentran satisfechos con el desempeño de los graduados. Esta consideración es de gran importancia al sumarle al análisis que los de habilidades son atributos altamente ponderados por los empleadores, por lo que, más allá de la general para todos los atributos existencia de brechas entre expectativa y percepción, no son malas las mediciones de este apartado.

- Mención especial sobre habilidades de los graduados debe hacerse sobre sus capacidades para ser líderes, directores o trabajar como miembros de un equipo. Estas tres cuestiones son las que registran las peores mediciones del apartado habilidades, algo que puede relacionarse con la incapacidad registrada, en 
algunos atributos de conocimientos, para ser conscientes los graduados de la "esfera económica" de sus tareas. Como atenuante de esto último, las cuestiones mencionadas son las menos ponderadas por los empleadores.

- En cuanto al tercer grupo de atributos que fuera medido, el de las actitudes (muy ponderado por los empleadores), se puede concluir que se mantienen como en todas las mediciones en general las brechas negativas entre las expectativas y la percepción del desempeño real de los graduados. No obstante, las mediciones arrojan los mejores resultados en el pensamiento crítico y creativo y en el compromiso con el aprendizaje por parte de los graduados, a lo que se puede sumar el desarrollo de habilidades interpersonales que pueden ser utilizadas en grupo. Esto denota una visión sobre el graduado que, si bien mantiene un desempeño inferior a las expectativas, está capacitado y tiene actitud para mejorar su calidad profesional e incrementar su desempeño laboral.

- Otro aspecto que colabora a la existencia de brechas de calidad entre expectativas y percepciones es el la duración de los trabajos realizados por el graduado, ya que si bien el $40 \%$ se desarrolla según lo planificado, solo un $15 \%$ se hace en un tiempo menor, y cerca de otro $40 \%$ por encima de lo planificado. Como contrapartida, no son malas las mediciones sobre la calidad de los trabajos realizados (casi $60 \%$ de desempeño real igual a lo planificado) y la satisfacción sobre el resultado de los mismos (más de la mitad de los registro con valores positivos).

\section{A modo de epílogo}

En la región de La Plata, Berisso y Ensenada, el ámbito geográfico alcanzado por la investigación, existen gran cantidad y variedad de organizaciones públicas y privadas que tienen por objeto de existencia la atención y el cuidado de la salud. Por la naturaleza de los servicios que 
brindan, de buena parte del personal que en ellas trabajan se requiere un nivel de formación profesional determinado, que asegure niveles mínimos de estándares de calidad. En cuanto a la disponibilidad de profesionales de la Enfermería, la región no registra déficit en su oferta de graduados, situación generada con seguridad en la existencia de una oferta educativa suficiente en la que estos últimos pueden formarse.

Pero de la investigación, sí surge un déficit en cuanto a la calidad profesional de los profesionales de la Enfermería, medida en el ámbito en donde cobra mayor validez: el puesto de trabajo donde desempeñan sus tareas día a día.

El estudio permitió observar que en los distintos atributos sobre los que se juzga la calidad por parte de los empleadores en la relación laboral con los graduados, estos registran niveles de calidad en su desempeño siempre inferiores a las expectativas previamente existentes. Por esto es que se puede afirmar que existe una brecha a cubrir en la calidad de los graduados, que seguramente podrá ser removida trabajando en la mejora de toda la cadena de educación, capacitación y formación profesional continua. La responsabilidad sobre esto último recae seguramente tanto en las instituciones educativas y las organizaciones de salud como en los propios graduados y sus empleadores, consideración esta última cuyo análisis sin duda excede el alcance del presente trabajo de tesis.

Como atenuante, puede afirmarse que la calidad no se encuentra tan afectada como pudiera estar, porque las cuestiones en donde peor desempeño registran los graduados son por fortuna las menos ponderadas por los empleadores.

Para terminar, la región cuenta con buena disponibilidad de profesionales de la Enfermería, que representan una oferta laboral con niveles aceptables de calidad profesional, probada en donde interesa, en los puestos de trabajo; pero, esos niveles de calidad, si bien aceptables, parecen ser insuficientes desde el punto de vista de lo exigido por la demanda, lo que genera una buena 
oportunidad de trabajar en toda la cadena de mejora continua en los niveles de calificación de dicha oferta. 


\section{Bibliografía consultada}

- Bernillón, A.; Cerutti, O. (1989). Implantar y gestionar la calidad total. Gestión 2.000, Barcelona

- Braslavsky, C. y Tiramonti, G. (1990). Conducción educativa y calidad de la enseñanza media. FLACSO, Buenos Aires

- Dewey, John (1995). Democracia y educación. Editorial Morata, Madrid

- Dona Bedián, a. (1991). La calidad de la atención médica. Definición y métodos de evaluación. México: La Prensa Médica Mexicana.

- Donnelly, M. \& Shiu, E. (1999). Assessing Service Quality and its Link with value for Money in a UK Local Authority's Housing Repairs Service Using the SERVQUAL Approach. Total Quality Management, 10(4/5), 498-506.

- Drummond, H. (1995). Qué es hoy la calidad total: el movimiento de la calidad. Deusto, Bilbao

- Edwards Risopatrón, Verónica (1991). El concepto de calidad de la educación. UNESCO/OREALC, Chile

- Galgano, A. (1995): Los siete instrumentos de la calidad total: manual operativo. Díaz de Santos, Madrid

- Grima Cintas, P; Tort-Martorell, J (1995). Técnicas para la gestión de la calidad. Díaz de Santos, Madrid

- Quesada, G. (2005). Calidad en la Educación. Ed. Gestiópolis

- Kotler, P. \& Lee, N. (2007). Marketing en el sector público. Prentice Hall, Madrid

- Puiggros, Adriana (2004). La otra reforma. Desde la educación menemista al fin de siglo. Editorial Galerna, Buenos Aires

- Sander, Benno (1996) "Gestión educativa en América Latina. Construcción y reconstrucción del conocimiento." Editorial Troquel Buenos Aires 
Paginas consultadas:

- http://manuelgross.bligoo.com/conozca-3-tipos-de-investigaciondescriptiva-exploratoria-y-explicativa

- http://unesdoc.unesco.org/images/0022/002273/227336s.pdf

- http://www.eco.unrc.edu.ar/wp-content/uploads/2010/05/Sforzini.A.pdf

- $\quad$ http://www.unlp.edu.ar/institucional

- http://www.unlp.edu.ar/uploads/docs/plan_estrategico_2010_2014_enter o_final....pdf

- http://www.med.unlp.edu.ar/index.php/

- http://www.me.gov.ar/spu/legislacion/Ley_24_521/ley_24_521.html

- http://www.unesco.org/new/es

- http://www.educar.org/articulos/calidadeneducacion.asp

- http://www.uis.unesco.org/Library/Documents/eiguide09-es.pdf

- $\quad$ http://www.eduteka.org/pdfdir/Pisa2009.pdf

- http://www.unesco.org/new/es/santiago/press-

room/newsletters/newsletter-laboratory-for-assessment-of-the-qualityof-education-llece/

- http://www.agenciaeducacion.cl/estudios-e-investigaciones/estudiosinternacionales/icils-estudio-internacional-de-alfabetizacioncomputacional-y-manejo-de-informacion/

- http://www.agenciaeducacion.cl/estudios-e-investigaciones/estudiosinternacionales/timss-estudio-internacional-de-tendencias-enmatematica-y-ciencias/

- http://www.agenciaeducacion.cl/simce/que-es-el-simce/ 


\section{Referencias y Anexos}

\subsection{Encuesta}

Favor de indicar su respuesta para cada pregunta, ya sea marcando una casilla o proporcionando detalles.

\section{1. - Información personal del encuestado}
1.1) Sexo
$1 \square$ hombre $2 \square$ mujer

1.2) Indicar la ciudad donde usted trabaja:

1.3) ¿Cuál es su relación con el graduado?

$1 \square$ empleador $2 \square$ Supervisor $3 \quad \square \quad$ Otros, especificar:....

1.4) ¿Cuánto tiempo hace que está en este puesto?

$1 \square$ hasta 1 año $\quad 2 \square 2$ años $\quad 3 \square 3$ años $\quad 4 \square$ de más de 3 años

\section{2. - Información sobre el graduado}

2.1) Sexo $\quad 1 \square$ hombre $2 \square$ mujer

2.2 a) Año en que el graduado completó sus estudios en

2.2 b) Titulo Obtenido

2.3) Si el graduado trabaja en una ciudad distinta de usted, indicar la ciudad donde trabaja el graduado:

2.4) ¿El graduado continuó con su perfeccionamiento profesional?

$1 \square \mathrm{Si} \quad 2 \square$ No

En caso afirmativo, indicar el tipo de desarrollo profesional que ha emprendido el graduado.

2.5) ¿Cuántos años de experiencia tiene el graduado en el trabajo?

2.6) ¿El graduado ha recibido capacitación en el lugar de trabajo para realizar sus tareas?

$1 \square \mathrm{Si} \quad 2 \square$ No

En caso afirmativo, ¿cuánto tiempo ha durado la capacitación?
$1 \square$ Menos de 24 horas
$2 \square 1-2$ meses
$3 \square 2-4$ meses
$4 \square$ Más de 4 meses

\section{3. - Detalles del trabajo del graduado}

3.1) ¿Cuál es la naturaleza del trabajo que desempeña el graduado?
$1 \square$ Científica
$2 \square$ Técnica
$3 \square$ Otros, especificar: 
3.2) ¿Qué tipo de comunicación es más necesaria para el trabajo?

$1 \square$ Oral $\quad 2 \square$ Escrita $3 \square$ Mediante Informes $4 \square$ Otra, especificar.

\section{4. - Atributos existentes del graduado}

Las siguientes afirmaciones están destinadas a intentar identificar los atributos existentes del graduado objeto de esta encuesta. Por favor marque con una cruz el número de la respuesta que usted crea que representa sus creencias acerca de la afirmación.

\begin{tabular}{|c|c|c|c|c|}
\hline $\begin{array}{c}1=\text { Totalmente } \\
\text { en desacuerdo }\end{array}$ & $\begin{array}{c}2=\text { En } \\
\text { desacuerdo }\end{array}$ & $\begin{array}{c}3=\text { No está } \\
\text { seguro }\end{array}$ & $4=$ De acuerdo & $\begin{array}{c}5=\text { Muy de } \\
\text { acuerdo }\end{array}$ \\
\hline
\end{tabular}

\section{1.-Evaluación de conocimientos}

\begin{tabular}{|l|l|l|l|l|l|}
\hline \multicolumn{1}{|c|}{ Creo que el graduado: } & 1 & 2 & 3 & 4 & 5 \\
\hline $\begin{array}{l}\text { 4.1.1) Entiende los principios básicos y conceptos relacionados } \\
\text { con la licenciatura en enfermería / enfermería /fonoaudiología } \\
\text { /Medicina/ Obstetricia }\end{array}$ & & & & & \\
\hline $\begin{array}{l}\text { 4.1.2) Entiende los fundamentos económicos de licenciatura en } \\
\text { Enfermería/enfermería /Fonoaudiología/Medicina/Obstetricia }\end{array}$ & & & & & \\
\hline $\begin{array}{l}\text { 4.1.3) Entiende en profundidad los procedimientos técnicos en al } \\
\text { menos una disciplina de ciencias de la salud? }\end{array}$ & & & & \\
\hline $\begin{array}{l}\text { 4.1.4) Entiende la identificación de problemas, su formulación y } \\
\text { el desarrollo de soluciones asociadas a ciencias de la salud }\end{array}$ & & & & & \\
\hline $\begin{array}{l}\text { 4.1.5) Entiende las leyes, reglamentos y normas relacionadas } \\
\text { con la ...................................... }\end{array}$ & & & & & \\
\hline $\begin{array}{l}\text { 4.1.6) Entiende los principios de gestión y negocios relacionados } \\
\text { con la ......................................... }\end{array}$ & & & & & \\
\hline $\begin{array}{l}4.1 .7) \text { Comprende otras disciplinas relacionadas con ciencias de } \\
\text { la salud, es decir, psicológicas ,humanas y sociales }\end{array}$ & & & & & \\
\hline $\begin{array}{l}\text { 4.1.8) comprende las implicancias y consecuencias económicas } \\
\text { asociadas a las actividades que desarrolla en su trabajo }\end{array}$ & & & & & \\
\hline $\begin{array}{l}\text { 4.1.9) Entiende el principio de utilización eficiente de los } \\
\text { recursos }\end{array}$ & & & & & \\
\hline
\end{tabular}

\section{2.-Evaluación de habilidades}

\begin{tabular}{|c|c|c|c|c|c|}
\hline \multirow{2}{*}{\begin{tabular}{|l} 
Creo que el egresado es capaz de: \\
4.2.1) Aplicar perfectamente los conocimientos \\
técnicos en al menos una disciplina de
\end{tabular}} & 1 & 2 & 3 & 4 & 5 \\
\hline & & & & & \\
\hline \multicolumn{6}{|l|}{$\begin{array}{l}\text { 4.2.2) Usar apropiadamente las tecnologías } \\
\text { disponibles }\end{array}$} \\
\hline \multicolumn{6}{|l|}{ 4.2.3) Acceder, evaluar y sintetizar información } \\
\hline \multicolumn{6}{|l|}{ 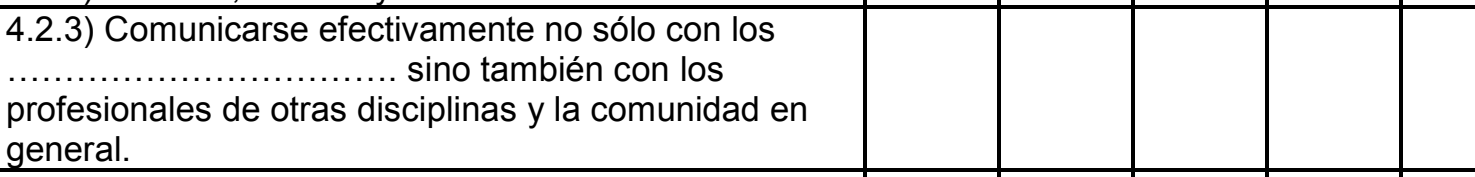 } \\
\hline \multicolumn{6}{|l|}{ 4.2.4) Funcionar eficazmente como un individuo } \\
\hline \multicolumn{6}{|l|}{$\begin{array}{l}\text { 4.2.5) Funcionar eficazmente en equipos } \\
\text { multidisciplinarios o multiculturales }\end{array}$} \\
\hline $\begin{array}{l}\text { 4.2.6) Funcionar eficazmente en equipos con } \\
\text { capacidad de ser miembro }\end{array}$ & & & & & \\
\hline
\end{tabular}




\begin{tabular}{|l|l|l|l|l|l|}
\hline $\begin{array}{l}\text { 4.2.7) Funcionar eficazmente en equipos con la } \\
\text { capacidad de ser un director }\end{array}$ & & & & & \\
\hline $\begin{array}{l}\text { 4.2.8) Funcionar eficazmente en equipos con la } \\
\text { capacidad para ser un líder }\end{array}$ & & & & & \\
\hline
\end{tabular}

\section{3.-Evaluación sobre actitudes}

\begin{tabular}{|l|l|l|l|l|l|}
\hline \multicolumn{1}{|c|}{ Creo que el egresado es capaz de: } & 1 & 2 & 3 & 4 & 5 \\
\hline $\begin{array}{l}\text { 4.3.1) Pensar crítica, creativa y reflexivamente en } \\
\text { su trabajo }\end{array}$ & & & & & \\
\hline $\begin{array}{l}\text { 4.3.2) Comprometerse al aprendizaje permanente } \\
\text { 4.3.3) Comprometerse a cumplir con las } \\
\text { responsabilidades éticas en su trabajo }\end{array}$ & & & & & \\
\hline $\begin{array}{l}\text { 4.3.4) Comprometerse a cumplir responsabilidades } \\
\text { ambientales en su trabajo }\end{array}$ & & & & & \\
\hline $\begin{array}{l}\text { 4.3.5) Trabajar con perspectivas internacionales y } \\
\text { mundiales adecuándose a las mismas. }\end{array}$ & & & & & \\
\hline $\begin{array}{l}\text { 4.3.6) Comprometerse a desarrollar aún más sus } \\
\text { habilidades profesionales }\end{array}$ & & & & & \\
\hline $\begin{array}{l}\text { 4.3.7) Comprometerse a trabajar efectivamente } \\
\text { con diferentes grupos culturales }\end{array}$ & & & & & \\
\hline $\begin{array}{l}\text { 4.3.8) Comprometerse para utilizar habilidades } \\
\text { grupales en su lugar de trabajo }\end{array}$ & & & & & \\
\hline $\begin{array}{l}\text { 4.3.9) Comprometerse para desarrollar habilidades } \\
\text { interpersonales efectivas en su lugar de trabajo }\end{array}$ & & & & & \\
\hline
\end{tabular}

\section{5. - Desempeño en el trabajo}

Las siguientes preguntas están asociadas con el desempeño del trabajo o proyecto emprendido por el graduado. Por favor marque con un círculo el número de la respuesta que exprese su apreciación sobre el graduado.

\section{1.-Evaluación sobre el desempeño de cualquier trabajo}

5.1.1. ¿Cuál es la duración real de los trabajos realizados por el graduado?

\begin{tabular}{|c|c|c|c|c|}
\hline $\begin{array}{c}1=\text { Mucho más } \\
\text { que lo } \\
\text { planificado }\end{array}$ & $\begin{array}{c}2=\text { Más que lo } \\
\text { planificado }\end{array}$ & $\begin{array}{c}3=\text { lgual que lo } \\
\text { planificado }\end{array}$ & $\begin{array}{c}4=\text { Menos que } \\
\text { lo planificado }\end{array}$ & $\begin{array}{c}5=\text { Mucho } \\
\text { menos que lo } \\
\text { planificado }\end{array}$ \\
\hline
\end{tabular}

5.1.2. ¿Cuál es la calidad de los trabajos realizados por el graduado?

\begin{tabular}{|c|c|c|c|c|}
\hline $\begin{array}{c}1=\text { Mucho } \\
\text { menos que lo } \\
\text { planificado }\end{array}$ & $\begin{array}{c}2=\text { Menos que } \\
\text { lo planificado }\end{array}$ & $\begin{array}{c}3=\text { lgual que lo } \\
\text { planificado }\end{array}$ & $\begin{array}{c}4=\text { Más que lo } \\
\text { planificado }\end{array}$ & $\begin{array}{c}5=\text { Mucho más } \\
\text { que lo } \\
\text { planificado }\end{array}$ \\
\hline
\end{tabular}

\section{6. - Satisfacción}

La siguiente pregunta está asociada a su satisfacción con los resultados del trabajo o proyecto realizado por el graduado. Por favor marque con un círculo el número de la respuesta que expresa su apreciación sobre el graduado.

\section{1.-Satisfacción con los resultados del trabajo, tarea o proyectos}

Por favor marque con un círculo el número de la respuesta que exprese su apreciación sobre el graduado. 
6.1.1. ¿Qué tan satisfecho está usted con el resultado de los trabajos realizados por el graduado?

\begin{tabular}{|c|c|c|c|c|}
\hline $\begin{array}{c}1=\text { Muy } \\
\text { insatisfecho }\end{array}$ & $2=$ Insatisfecho & $\begin{array}{c}3=\text { No podría } \\
\text { precisarlo }\end{array}$ & $4=$ Satisfecho & $\begin{array}{c}5=\text { Muy } \\
\text { satisfecho }\end{array}$ \\
\hline
\end{tabular}

\section{7. - Expectativa}

Por favor, otorgue un orden jerárquico de 1 a 9 los atributos sobre el conocimiento que usted espera que el graduado demuestre cuando realiza su trabajo. El número 1 indica que usted asigna como altamente significativo al atributo conocimiento.

\section{1.-Conocimiento}

\begin{tabular}{|c|c|}
\hline El graduado debe: & Rango \\
\hline 7.1.1) entender los principios y conceptos relacionados con ...... & \\
\hline $\begin{array}{lllllll}\text { 7.1.2) } & \text { entender la } & \text { ciencia } & \text { básica } & \text { y } & \text { principios } & \text { fundamentales }\end{array}$ & \\
\hline $\begin{array}{l}\text { 7.1.3) comprender en profundidad el proceso técnico en al menos una disciplina de } \\
\text { ciencias medicas }\end{array}$ & \\
\hline $\begin{array}{l}\text { 7.1.4) lograr identificación de problemas, formulación y desarrollo de la solución } \\
\text { asociado a .................... }\end{array}$ & \\
\hline 7.1.5) entender las leyes, reglamentos y normas relacionadas con ciencias de la salud & \\
\hline $\begin{array}{l}\text { 7.1.6) entender los principios de gestión y negocios relacionados con ciencias } \\
\text { medicas }\end{array}$ & \\
\hline 7.1.7) comprender otras disciplinas relacionadas con $\ldots \ldots \ldots \ldots \ldots \ldots \ldots \ldots$, es decir, & \\
\hline $\begin{array}{l}\text { 7.1.8) comprender las implicancias y consecuencias econ } \\
\text { actividades que desarrolla en su trabajo }\end{array}$ & \\
\hline
\end{tabular}

Por favor, otorgue un orden jerárquico de 1 a 9 los siguientes atributos de habilidad, que usted espera que los graduados demuestren cuando realizan su trabajo. El número 1 indica que usted asigna como altamente significativo al atributo habilidad.

\section{2.-Habilidades}

\begin{tabular}{|l|l|}
\hline \multicolumn{1}{|c|}{ El graduado debería ser capaz de: } & Rango \\
\hline $\begin{array}{l}\text { 7.2.1) aplicar conocimientos técnicos en profundidad en al menos una disciplina de } \\
\text { ciencias médicas }\end{array}$ & \\
\hline 7.2 .2$)$ usar las tecnologías apropiadamente & \\
\hline 7.2 .3$)$ acceder, evaluar y sintetizar información & \\
\hline $\begin{array}{l}\text { 7.2.4) comunicar efectivamente no sólo con los profesionales de ciencias médicas } \\
\text { sino también con la comunidad en general }\end{array}$ & \\
\hline $\begin{array}{l}\text { 7.2.5) funcionar eficazmente como un individuo. (Se entiende por Eficacia: la } \\
\text { capacidad de alcanzar el efecto que espera o se desea tras la realización de una } \\
\text { acción) }\end{array}$ & \\
\hline 7.2 .6$)$ funcionar eficazmente en equipos multidisciplinarios o multiculturales & \\
\hline 7.2 .7$)$ funcionar eficazmente en equipos con capacidad de ser miembro más & \\
\hline 7.2 .8$)$ funcionar eficazmente en equipos con capacidad de ser un director & \\
\hline 7.2 .9$)$ funcionar eficazmente en equipos con la capacidad de ser un líder & \\
\hline 7.2 .10$)$ Capacitado para utilizar eficientemente los recursos & \\
\hline
\end{tabular}

Por favor, otorgue un orden jerárquico de 1 a 9 los siguientes atributos de actitud, que usted espera que los graduados demuestren cuando realizan su trabajo. El número 1 indica que usted asigna como altamente significativo al atributo actitud.

\section{3.-Actitudes}

El graduado debería estar : 
7.3.1) Capacitado para pensar críticamente, creativamente, reflexivamente en su trabajo

7.3.2) comprometido para llevar a cabo el aprendizaje permanente

7.3.3) comprometido con las responsabilidades éticas en su trabajo

7.3.4) comprometido a cumplir responsabilidades ambientales en su trabajo

7.3.5) Capacitado para trabajar con perspectivas internacionales y mundiales, adecuándose a las mismas

7.3.6) comprometido a desarrollar aún más sus habilidades profesionales

7.3.7) comprometido a trabajar efectivamente con diferentes grupos culturales

7.3.8) comprometido para utilizar habilidades grupales en su lugar de trabajo

7.3.9) comprometido para desarrollar habilidades interpersonales efectivas en su lugar de trabajo

7.3.10) comprometido a desarrollar acciones tendientes a reducir los riesgos legales para la organización.

\section{8) Realice comentarios adicionales, si lo desea.}

Por favor, indique su dirección de correo electrónico si le interesaría que la información agregada resultante del procesamiento de este cuestionario se le haga llegar a usted: 